A Manual of Methods and Procedures for the Regional Waterway Management System's
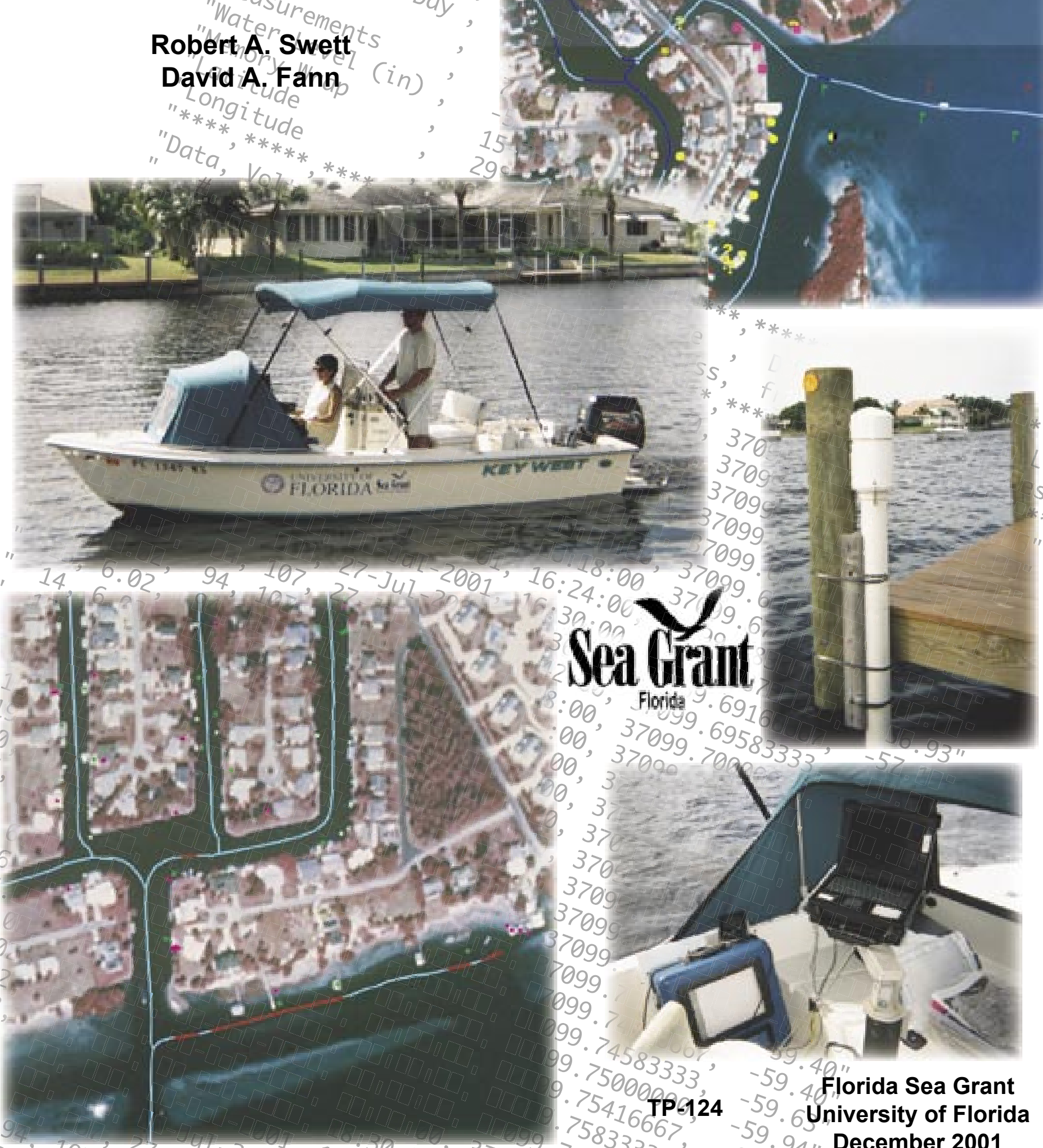

Florida Sea Grant

TP\& 24

University of Florida December 2001

60.78 

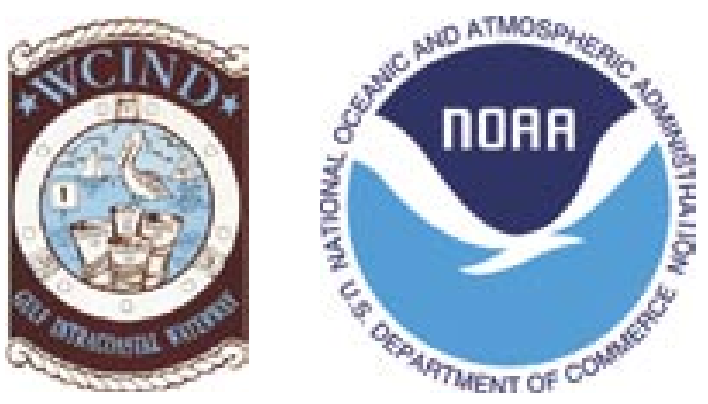

seatirant

Florida
(19. UNIVERSITY OF FLORIDA

Institute of Food and $\mathbf{A}_{\text {pricultural }} \mathbf{S}_{\text {ciences }}$ 


\section{A Manual of Methods and Procedures for the Regional Waterway Management System}

\section{By}

Robert A. Swett

David A. Fann

Florida Sea Grant

University of Florida

December 2001

Reviewed March 2008 


\section{Table of Contents}

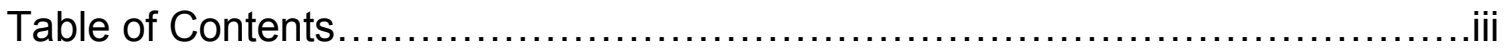

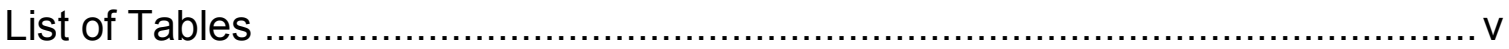

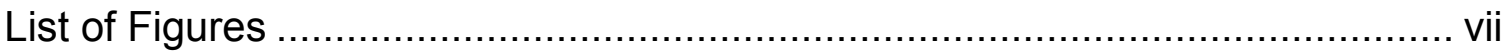

Abbreviations and Acronyms ………..................................................... ix

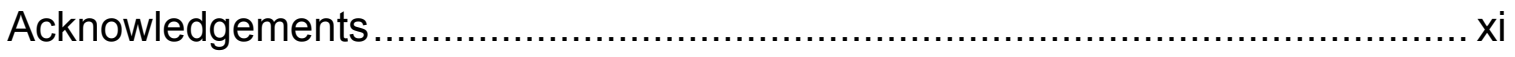

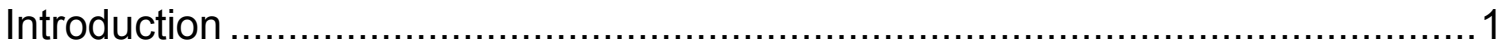

The Regional Waterway Management System ....................................... 1

Waterway Management System Methods ............................................... 2

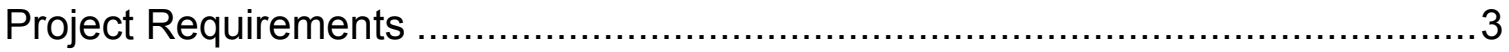

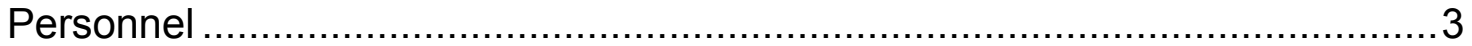

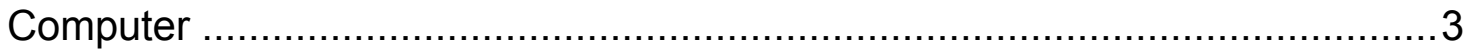

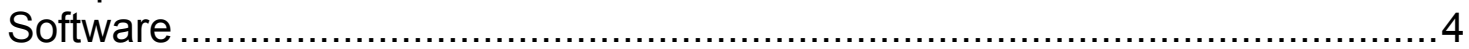

Differential Global Positioning System ................................................. 4

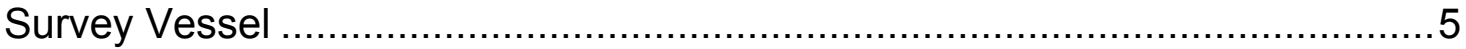

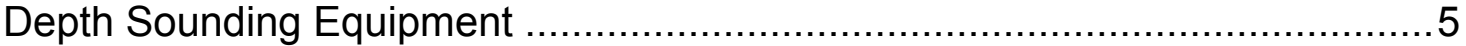

Tide Level Recorders and Stilling Wells ...............................................

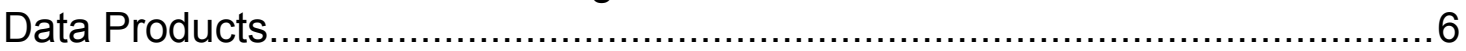

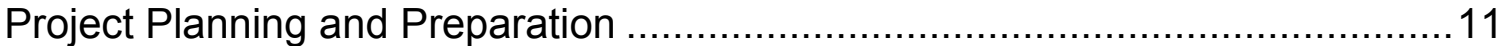

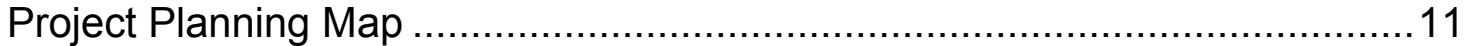

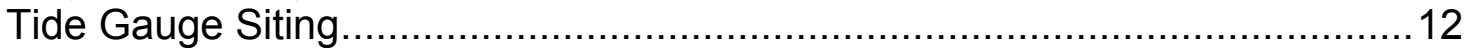

Survey Vessel Outfitting ................................................................... 12

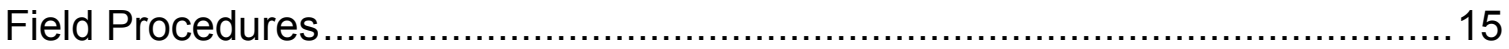

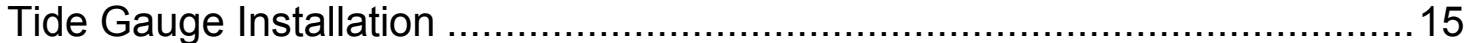

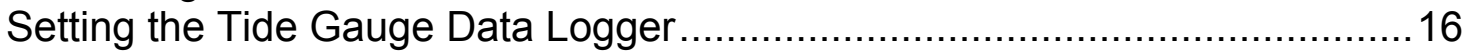

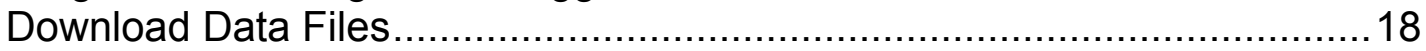

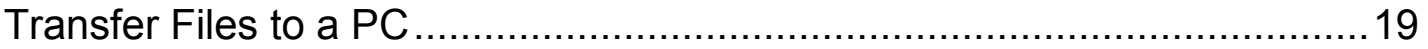

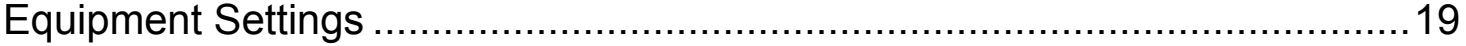

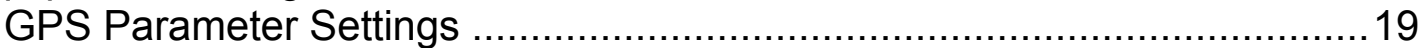

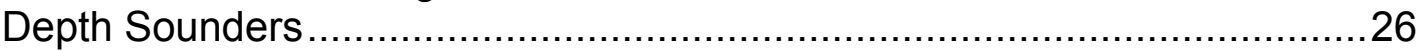

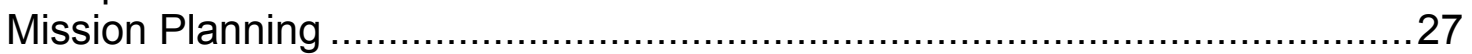

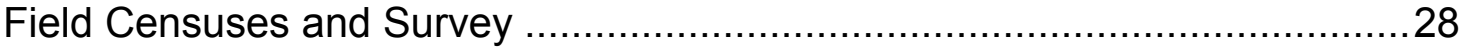

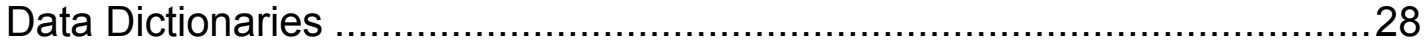

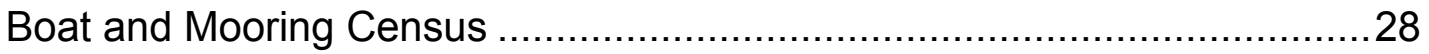

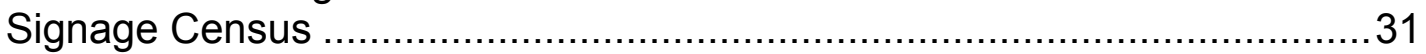

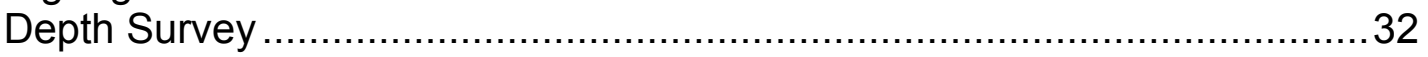




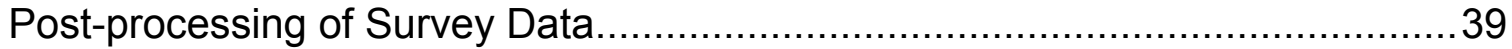

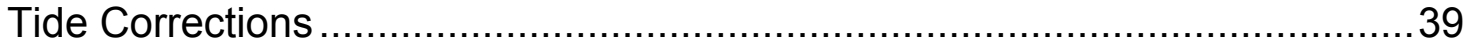

Assigning Parcel Identification Numbers to Boats and Moorings .................. 44

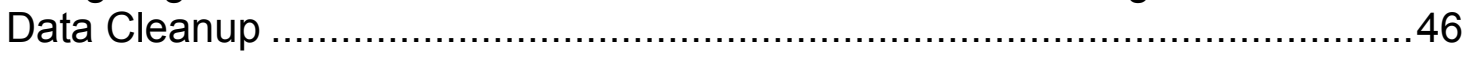

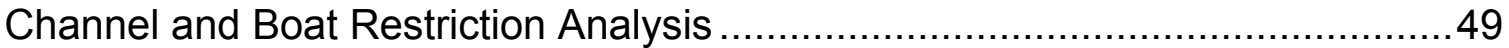

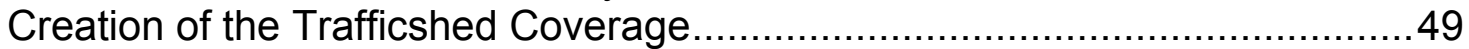

Preparation of the Channel Centerline Coverage ........................................51

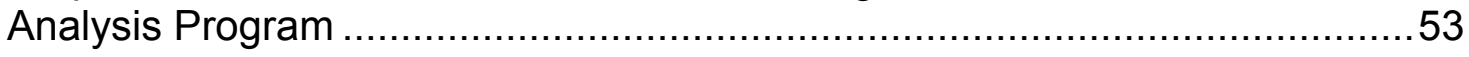

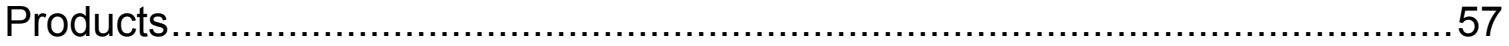

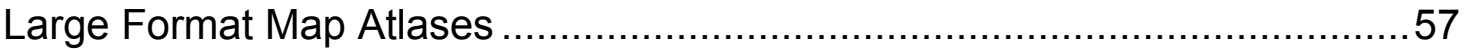

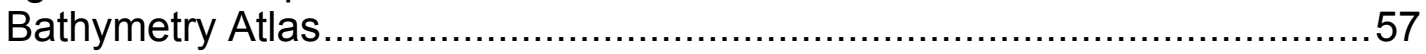

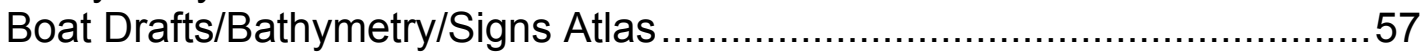

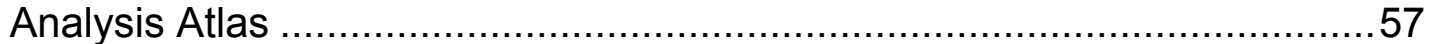

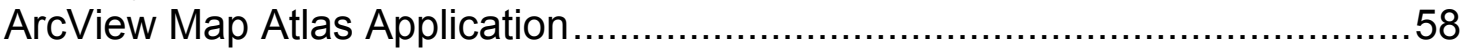

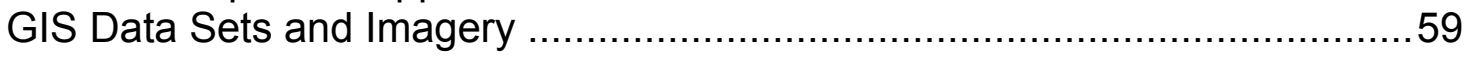

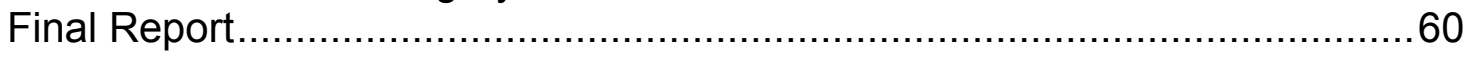

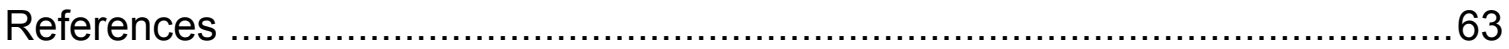

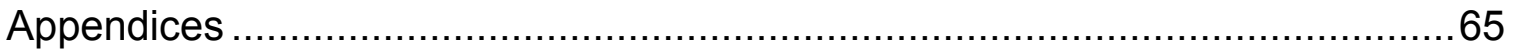

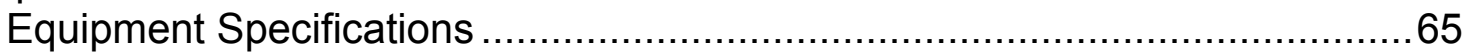

Bathy-500MF Multi-Frequency Survey Echo Sounder ..............................65

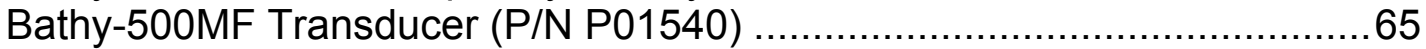

Horizon DS150 Single-beam Echo Sounder........................................66

Infinities USA Model 220 ultrasonic water level loggers ..........................66

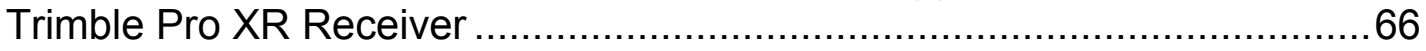

Trimble DSM212H Integrated GPS/MSK Receiver ...............................67

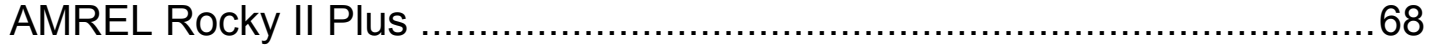

Dell Dimension XPS T750MHz Pentium III ..........................................68

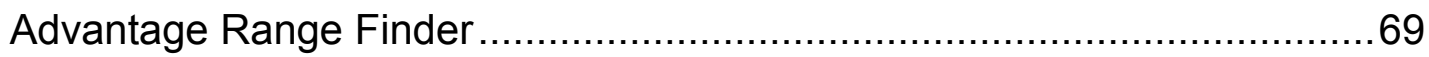

Survey Tide Correction Program ......................................................... 


\section{List of Tables}

Table 1. Survey vessel parameters........................................................

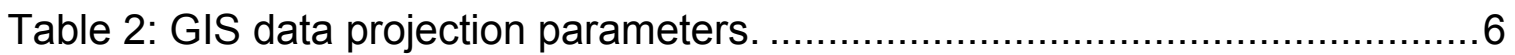

Table 3. HYPACK geodetic parameters....................................................34 


\section{List of Figures}

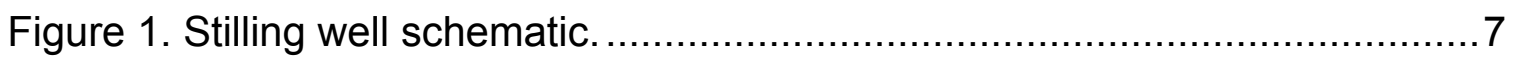

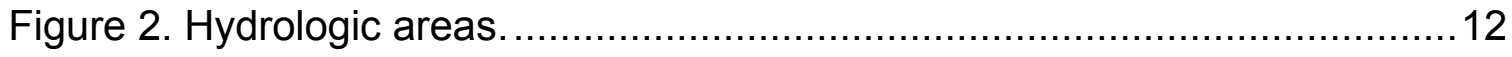

Figure 3. Bathymetric survey equipment.................................................... 14

Figure 4. Bathy-500MF echo sounder front panel......................................26

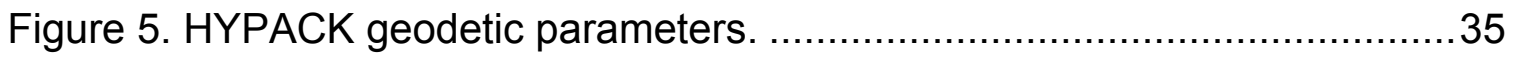

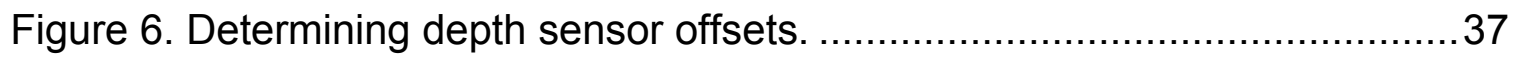

Figure 7. Flow diagram of tide correction procedures. ..................................40

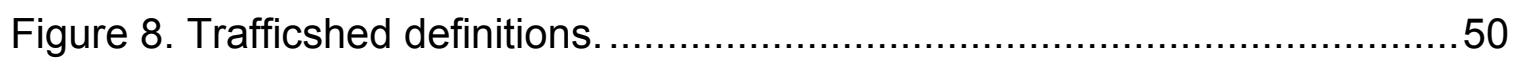

Figure 9. Example travel routes in Estero Bay, Lee County, Florida..................54 


\section{Abbreviations and Acronyms}

$\begin{array}{ll}\text { AAT } & \text { Arc Attribute Table } \\ \text { AML } & \text { Arc Macro Language } \\ \text { CIR } & \text { Color Infrared } \\ \text { DGPS } & \text { Differential Global Positioning System } \\ \text { DOQQ } & \text { Digital Orthophoto Quarter Quadrangle } \\ \text { ESRI } & \text { Environmental Systems Research Institute } \\ \text { FDEP } & \text { Florida Department of Environmental Protection } \\ \text { FLUCCS } & \text { Florida Land Use and Cover Classification System } \\ \text { FMP } & \text { Florida Marine Patrol } \\ \text { FSG } & \text { Florida Sea Grant } \\ \text { FTP } & \text { File Transfer Protocol } \\ \text { GICW } & \text { Gulf Intracoastal Waterway } \\ \text { GIS } & \text { Geographic Information System } \\ \text { GPS } & \text { Global Positioning System } \\ \text { HDOP } & \text { Horizontal Dilution of Precision } \\ \text { JPEG } & \text { Joint Photographic Experts Group } \\ \text { LABINS } & \text { Land Boundary Information System } \\ \text { MHHW } & \text { Mean Higher High Water } \\ \text { MHW } & \text { Mean High Water } \\ \text { MLW } & \text { Mean Low Water } \\ \text { MLLW } & \text { Mean Lower Low Water } \\ \text { MSK } & \text { Minimum Shift Keying } \\ \text { MTL } & \text { Mean Tide Level } \\ \text { NAVD88 } & \text { North American Vertical Datum of 1988 } \\ \text { NGS } & \text { National Geodetic Survey } \\ \text { NGVD29 } & \text { National Geodetic Vertical Datum of 1929 } \\ \text { NMEA } & \text { National Marine Electronics Association } \\ \text { NOS } & \text { National Ocean Service } \\ \text { PAT } & \text { Polygon or Point Attribute Table } \\ \text { PDOP } & \text { Positional Dilution of Precision } \\ \text { PID } & \text { Parcel Identification Number } \\ \text { RTCM } & \text { Radio Technical Commission for Maritime Services } \\ \text { RTL } & \text { Raster Transfer Language } \\ \text { SNR } & \text { Signal-to-Noise Ratio } \\ \text { SSF } & \text { Standard Storage Format (Trimble Navigation, Inc.) } \\ \text { SWFWMD } & \text { Southwest Florida Waterway Management District } \\ \text { TSIP } & \text { Trimble Standard Interface Protocol } \\ \text { WCIND } & \text { West Coast Inland Navigation District } \\ \text { UF } & \text { University of Florida } \\ \text { USACE } & \text { U.S. Army Corps of Engineers } \\ \text { USCG } & \text { U.S. Coast Guard } \\ \text { USGS } & \text { U.S. Geological Survey } \\ \text { UTC } & \text { Coordinated Universal Time } \\ & \\ & \end{array}$




\section{Acknowledgements}

Many people have contributed to the philosophy and methods of the Regional Waterway Management System that is embodied within this manual. We would be remiss not to mention their contributions.

First and foremost, the combined vision and determination of Dr. Gustavo A. Antonini, Sea Grant Professor Emeritus, and Charles Listowski, Executive Director of the West Coast Inland Navigation District, led to the concept and subsequent creation of the Regional Waterway Management System. The evolution of their innovative ideas over the past 10 years has led to application of the System in over 1000 miles of waterways in southwest Florida. Their contributions to Coastal Management in Florida are recognized throughout the state both by their colleagues and by state, regional, and local legislators and coastal managers.

The counties of Sarasota, Manatee, and Lee had the foresight to apply the Regional Waterway Management System to their coastal waters. Specific county commissioners championed the implementation of the System within their respective counties and provided advice: Commissioner Jack O'Neil in Sarasota County, Commissioner Joe McClash in Manatee County, and Commissioner Ray Judah in Lee County. Program administrators for each county were Gary Comp, Sarasota County Natural Resources Department; Jim Englehardt, Manatee County Human Services Division; and Steve Boutelle, Lee County Division of Natural Resources.

The methods contained in the manual have been polished and honed by field staff over the years. Lana Carlin-Alexander served as field crew chief for over 3 years and provided many innovative ideas and enhancements. Field technicians who also have contributed include Patricia Knoll, Bob Williams, Ann Brock, Jerry Gibbs, Chuck West, Jerry Wilson, Brad Stephens, Jim Givens, John Henry, and Sharon Schulte,

Enhancements to specific methodological techniques and field survey procedures have been provided by Cindy Fowler, NOAA Coastal Services Center; Jack Wallace, Senior Hydrographer, National Ocean Service; Dr. Donald Sheppard, Bill Miller, and Sydney Schofield of the University of Florida Coastal and Oceanographic Engineering Program; Evan Brown, previously of the West Coast Inland Navigation District; and Wanda Wooten and Bob Wasno (currently with Florida Sea Grant) of the Lee County Division of Natural Resources. 


\section{Introduction}

This manual details the procedures that are necessary to complete a Regional Waterway Management System for Florida's coastal canals and waterways. The purpose of the Regional Waterway Management System is to provide the West Coast Inland Navigation District (WCIND) and coastal counties with a scientific approach that allows for boat channel maintenance while protecting resources. The Regional Waterway Management System provides a planning tool that permits managers and policymakers to prioritize channel maintenance needs on a regional basis.

\section{The Regional Waterway Management System}

The methodology and objectives of the Regional Waterway Management System stem from a pilot study (Antonini and Box 1996) conducted by Florida Sea Grant (FSG) and the West Coast Inland Navigation District (WCIND) in Sarasota Bay. The pilot study, designed for southwest Florida waterways, was a test application of a management system consistent with municipal, county, Florida Department of Environmental Protection (FDEP), and WCIND goals of facilitating safe boating and reducing boating impacts on natural resources. The design criteria of the Regional Waterway Management System are: (a) fit channel maintenance to boat draft needs; (b) minimize impacts on bay habitats; (c) prioritize and evaluate management alternatives on a regional scale; and (d) identify information products, for boaters and shore residents, which encourage environmental awareness by users of neighborhood waterways and boat access channels.

Results from the pilot study led to follow-up studies in south Sarasota, Manatee, and Lee Counties (Antonini, Swett, Schulte, Fann 1998; Swett, Antonini, Schulte 1999; Swett, Fann, Antonini, Carlin Alexander 2000, 2001). Waterway Management System results provide Florida counties with a rationale and method for implementing a Regional Waterway Management System containing the following elements: (a) documentation of existing depths; (b) establishment of maintenance dredging requirements according to user draft specifications; (c) placement of signs to conform with boat density and traffic patterns; (d) management of boat traffic based on detailed knowledge of boat distributions and travel routes; (e) siting of habitat restoration to protect waterways; (f) regional scale permitting to accommodate water-dependent uses and to minimize environmental impacts; and (g) educating the public, using waterway maps and guide materials, to instill stewardship and best boating practices.

A Memorandum of Agreement (MOA), signed by the FDEP, FSG, and the WCIND (September 26, 1997), provides the required, state-approved framework for a Regional Waterway Management System that is needed to implement the study results. 


\section{Waterway Management System Methods}

The implementation of a Regional Waterway Management System consists of five broad work phases, which include: 1) preparation, 2) field surveys, 3) postprocessing, 4) data analysis, and 5) development of the final products.

The preparatory phase includes such components as gathering necessary data and map materials, hiring and training new personnel, acquiring and configuring equipment, and determining the location and extent of waterways to be included in a waterway management project. Boat channels are identified by interpretation of section aerials, by field reconnaissance, and by tapping local knowledge of the study area's boaters; wherever present, permitted and non-permitted channel markers are used to guide channel identification.

Two field censuses and one field survey are conducted along salt-water accessible canals and waterways using a Differential Global Positioning System (DGPS) to map features of interest. Geographic locations and attributes are logged for boats; boat locations ("moorings"), whether occupied or vacant; derelict vessels; boat-related signs; and channel centerline depths.

Post-processing includes cleaning the boat/mooring and sign census data, cleaning the depth survey data, correcting survey depths to a standard datum, such as the Mean Lower Low Water (MLLW) tidal datum, and transferring property information to each boat and mooring feature.

Data analysis consists of correcting depths to MLLW using tide gauges installed at appropriate locations throughout the project area. An Arclnfo "Arc Macro Language" (AML) application determines channel restrictions and boat accessibility levels from the field data.

Final products include three sets of large-scale (1:2400) map atlases, an ArcView Map Atlas application, a CD containing primary and secondary Geographic Information System (GIS) data layers provided in an ArcView application, and a final report that includes a prioritization of maintenance alternatives. 


\section{Project Requirements}

\section{Personnel}

The application of the Waterway Management System involves a wide variety of tasks and functions. Different software packages and specialized equipment are used during each project phase, and they require personnel with a high level of expertise. Furthermore, during each implementation of a Regional Waterway Management System, unique situations arise that require project personnel to devise innovative solutions.

Fieldwork includes a bathymetric survey, a boat and mooring census, and a sign census. All three require a vessel operator with good seamanship, navigation, and safety skills. Field personnel should have detailed local knowledge of the waterways within the project area. In particular, the person who conducts the bathymetric survey should (a) be very familiar with preferred travel routes, shoal locations, and local boating patterns and behaviors and (b) be prepared to observe and consult boaters encountered during the survey to identify waterways actually used. The person who conducts the boat census should have good boat identification skills, including the ability to identify vessel types and determine their characteristics: such as make/model, draft, and length.

Field personnel, excluding the boat operator, should have good computer skills, or they will need to be trained. Skills required include familiarity with the computer systems and the various software packages discussed below. Furthermore, field personnel should have Internet familiarity, including the ability to use e-mail and FTP in order to communicate with other project personnel. The persons who conduct the fieldwork should have an understanding of the basic principles of DGPS, including knowledge of the various parameters and settings that are necessary to assure survey accuracy and quality. These will be discussed in a subsequent section. Formal instruction in the use of DGPS, such as the course needed to obtain Trimble DGPS operator certification, is desirable.

\section{Computers}

The number of computers required to accomplish project tasks will depend on the scope of each particular waterway management project that is undertaken. In general, computers will be needed for field and office personnel responsible for processing project data. Computer related tasks associated with past waterway management projects have been performed on desktop and laptop computers running several versions of the Microsoft Windows operating system, including 98, NT, and 2000. The Arc Macro Language (AML) program that determines boat accessibility levels and channel restrictions is designed to run on a Sun Solaris system with UNIX ArcInfo. Specifications are given below for the computer equipment used by FSG to implement waterway management projects at publication time. In general, higher end systems should be used to implement future projects. 
Field operations, particularly the bathymetric survey, are accomplished using a Rocky II+ ruggedized notebook from AMREL Systems, Inc. This notebook is designed for field and in-vehicle applications. The laptop is certified to the MILSTD $810 C$ and $E^{1}$ standard and is rain, temperature, shock, vibration, salt fog, and humidity resistant. Computers used for office related tasks include two systems: 1) a Dell Dimension XPS T750r $750 \mathrm{MHz}$ Pentium III with an 18GB SCSI hard drive, and 2) a Sun Ultra II system running Solaris 2.5. Complete specifications for project equipment are contained in the Appendix.

\section{Software}

The software programs listed below are used during various project phases.

1. ESRI Arclnfo 8.x for Workstation

2. ESRI Arclnfo 7.2 for Solaris

3. ESRI ArcPress for Solaris

4. ESRI ArcView 3.x

5. SURVCORR and BASELINE2-tide correction programs (supplied on accompanying CD-ROM)

6. Microsoft Excel

7. Microsoft Access

8. Microsoft Word

9. Adaptec Easy CD Creator

10. Trimble Pathfinder Office 2.51

11. Trimble Asset Survey Software

12. Trimble TSIP TALKER (version 2.0)

13. E-mail and FTP software

14. Compression software (e.g., WinZip)

\section{Differential Global Positioning System}

The Regional Waterway Management System, as designed, is intended as a planning tool. However, the bathymetric survey procedures and methods meet Class 1 standards as described in the U.S. Army Corps of Engineers (USACE) Hydrographic Survey Manual (U.S. Army Corps of Engineers 2001) and hydrographic survey specifications of the National Ocean Service (National Ocean Service 1999).

Two code phase DGPS units are used to record horizontal positions: 1) a Trimble Pro XR DGPS with a TSC1 data logger and a radiobeacon receiver is used for the boat and signage censuses, and 2) a Trimble DSM212H GPS receiver with an integrated MSK dual-channel receiver with Everest ${ }^{\mathrm{TM}}$ technology $^{2}$ is used for

\footnotetext{
${ }^{1}$ Rated for shock, vibration, temperature (operating $-0^{\circ} \mathrm{C}$ to $50^{\circ} \mathrm{C}$; storage $-20^{\circ} \mathrm{C}$ to $60^{\circ} \mathrm{C}$ ), humidity ( $85-95 \% \mathrm{RH})$, rain (4 in./hr/ 0.5-4.5 mm/drop $30 \mathrm{~min}$. period), salt fog ( $35^{\circ} \mathrm{C} 5 \% 48$ hour period), and altitude.

${ }^{2}$ Everest technology improves results in high multipath environments and locations where other radio frequencies could jam the GPS signals.
} 
the bathymetric survey. Under optimum conditions, the horizontal accuracy (RMS) for both GPS units, using the RTCM radiobeacon transmissions, is $50 \mathrm{~cm}$ $+1 \mathrm{ppm}$ on a second-by-second basis, which, for the 4-county area of the WCIND, is better than 1 meter (Trimble Navigation Ltd. 1998b). Under normal operating conditions the horizontal accuracy for 95 percent of feature positions is expected to be 2 meters or less, which conforms with USACE and National Ocean Service (NOS) accuracy standards. An Advantage Range Finder from Laser Atlanta measures feature offsets during the boat and sign censuses.

\section{Survey Vessel}

In order to provide background on suitable vessel types needed to complete fieldwork, a description of vessels used during recent projects follows. The first vessel, a Key West model 1720, is an open fisherman with a shallow $V$ fiberglass hull and a center console. The Key West has a 70hp, 4-stroke, Evinrude outboard and a fuel capacity of 31 gallons. The second vessel, a Boston Whaler 130 Sport, is an open sport with a side console and a tri-V fiberglass hull. The Whaler has a $25 \mathrm{hp}, 4$-stroke, Mercury outboard and a fuel capacity of 6.6 gallons. The physical characteristics of each vessel are found in Table 1 below.

Table 1. Survey vessel parameters.

\begin{tabular}{|l|c|c|}
\hline & Key West & Boston Whaler \\
\hline Length & $17^{\prime} 2^{\prime \prime}$ & $13^{\prime} 3^{\prime \prime}$ \\
\hline Beam & $6^{\prime} 10^{\prime \prime}$ & $5^{\prime} 11^{\prime \prime}$ \\
\hline Weight (Ib) & 1050 & 600 \\
\hline Draft & $8^{\prime \prime}$ & $7^{\prime \prime}$ \\
\hline
\end{tabular}

\section{Depth Sounding Equipment}

Sounding equipment consists of a Bathy-500MF multi-frequency, single-beam echo sounder (Ocean Data Equipment Corporation); a Standard Horizon DS150 single-beam echo sounder (Standard Communications); and a fiberglass sounding pole, calibrated and marked at 0.01-foot intervals (see Appendix for equipment specifications).

Soundings from the Bathy-500MF and the DS150 are passed to HYPACK Max hydrographic survey software (Coastal Oceanographics, Inc.) loaded on the AMREL Rocky II+ notebook computer. The sounding pole is used to verify any suspect echo sounder readings and to check depths in shallow areas (below 3 feet). Calibration of the depth sounders is accomplished using a bar, which consists of a $1.25 \mathrm{ft}$. X $2.9 \mathrm{ft}$. lead-weighted aluminum plate. The bar is lowered below the transducer with a 25 -foot long, $1 / 8$-inch diameter twisted stainless steel wire cable marked at 5 -foot intervals, from 5 feet to 20 feet.

\section{Tide Level Recorders and Stilling Wells}

Tide observations are necessary to correct soundings to chart datum (MLLW). Tide level recorders consist of Model 220 solid-state, ultrasonic fluid level sensors manufactured by Infinities USA, Inc. (see Appendix for equipment 
specifications). Each Model 220 data logger stores 3,906 records, which allows for 16 days of tide data at a logging interval of 6 minutes. Data files can be downloaded, in the field, to a laptop computer or an HP-48GX calculator and examined for integrity.

Each gauge is mounted on a stilling well, the dimensions of which are shown in Figure 1. All sections of the stilling well are cemented together except for the cap, which is secured to the closet flange using two padlocks to protect the tide level recorder. The stilling well is secured to a piling using wooden I-beam mounts and stainless steel worm gear clamps.

\section{Data Products}

Several GIS data themes need to be obtained or created during the preparatory phases of the waterway management project. These data sets must meet project currency requirements and they must cover the geographic extent of the project area. Required data include background imagery, existing USACE bathymetric surveys, seagrass and mangrove coverages, salt-water accessible parcel boundaries and attribute information (parcel identification number, owner, and address), and vertical benchmark locations and attributes. Each data set is described below.

The Albers equal-area ${ }^{3}$ projection is the recommended projection system for the waterway management project. At present, most third-party data sets necessary to complete the project are distributed in this format. Table 2 lists the projection parameters.

Table 2: GIS data projection parameters.

\begin{tabular}{|l|c|}
\hline \multicolumn{2}{|c|}{ Projection Parameters } \\
\hline \hline Projection & Albers \\
\hline Units & Meters \\
\hline \hline Datum & HPGN (or NAD83) \\
\hline \hline 1st standard parallel & $24^{0} 00^{\prime} 00^{\prime}$ \\
\hline \hline 2nd standard parallel & $31^{0} 30^{\prime} 00^{\prime \prime}$ \\
\hline \hline Central Meridian & $-84^{0} 00^{\prime} 00^{\prime \prime}$ \\
\hline \hline Latitude of projection's origin & $24^{0} 00^{\prime} 00^{\prime \prime}$ \\
\hline \hline False easting (meters) & 400000.0 \\
\hline \hline False northing (meters) & 0.0 \\
\hline
\end{tabular}

\footnotetext{
${ }^{3}$ Equal-area means that a spatial unit of set size, when placed on different parts of a map, will cover exactly an equal area of the actual earth, no matter where on the map the unit is placed. Although neither shape nor linear scale is truly correct, the distortion of these properties is minimized in the region between the standard parallels.
} 


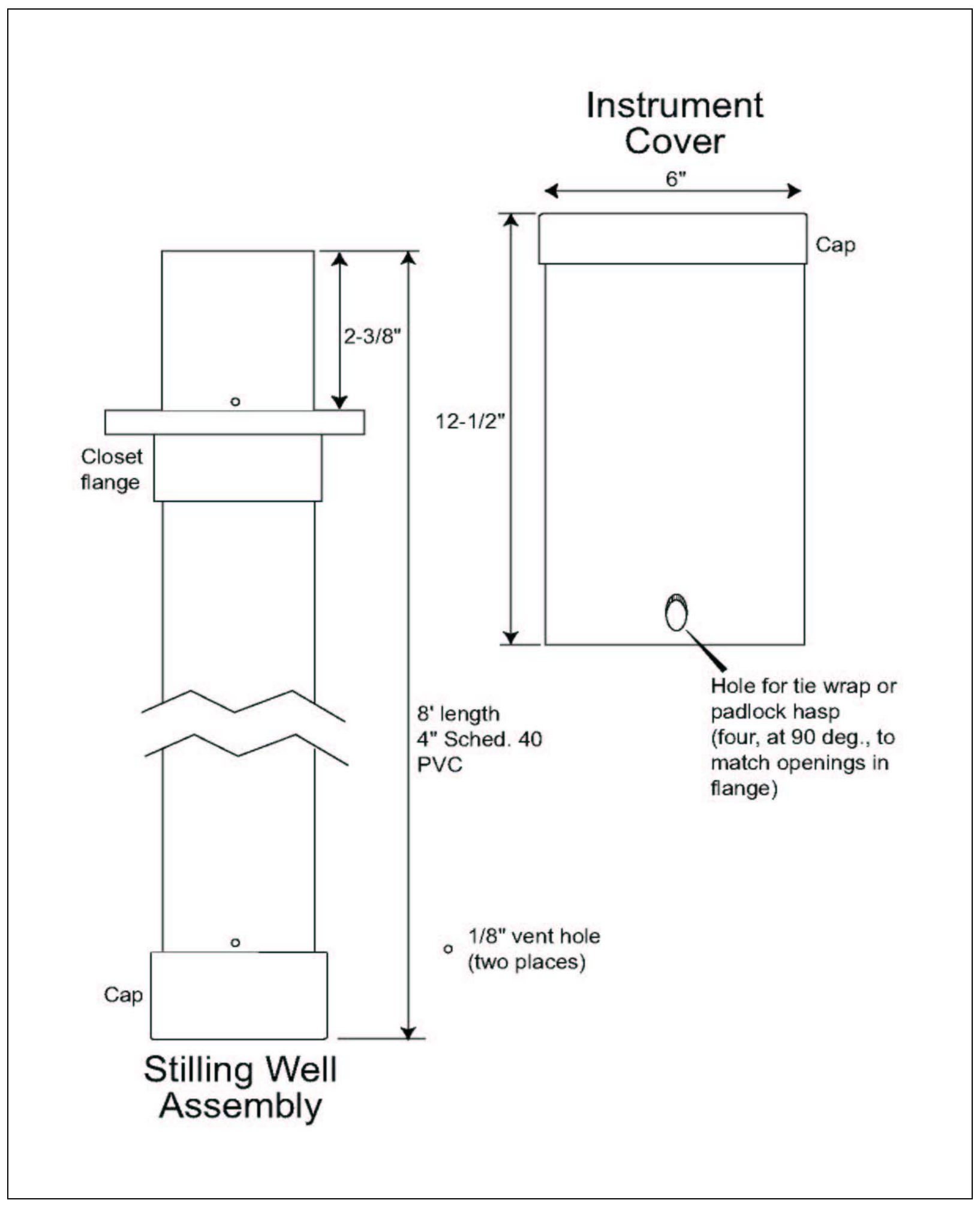

Figure 1. Stilling well schematic. 
U.S. Geological Survey (USGS) Digital Orthophoto Quarter Quadrangles (DOQQs) are recommended for use as background imagery during all project phases. This imagery is readily available for all areas of Florida and can be obtained in JPEG image compression format, at resolutions of 1, 2, and 3-meter, from the web site maintained by the Land Boundary Information System (www.labins.org).

DOQQs combine the image characteristics of a photograph with the geometric qualities of a map. Image displacements caused by camera tilt and terrain relief are removed, so that ground features are displayed in their true ground position. This allows for the direct measurement of distance, areas, angles, and positions. Furthermore, a DOQQ displays features that may be omitted or generalized on maps. The DOQQs used for past waterway management projects in southwest Florida are based on 1994-95, 1:40,000-scale Color Infrared ${ }^{4}$ (CIR) photography.

USACE bathymetric surveys have been used during past projects to complement data collected by FSG or to provide data for areas not surveyed by FSG, such as the Gulf Intracoastal Waterway (GICW). A point of contact, to determine the availability and characteristics of USACE survey data, is the ConstructionOperations Division of the Operations and Maintenance Technical Support Section of the USACE (904-232-1132; P.O. Box 4970, Jacksonville, FL 322320019).

Seagrass, mangroves, and land use/land cover normally are extracted from databases obtained from third parties, such as Florida's Water Management Districts. For example, the Southwest Florida Waterway Management District (SWFWMD) has ArcView shapefiles of seagrass for the years 1982, '88, '90, '92, ' 94 , ' 96 , and ' 99 . The seagrass beds were interpreted from 1:24,000 natural color aerial photography. The spatial extent of the SWFWMD seagrass GIS databases varies from year to year, but generally extends from Tampa Bay to Charlotte Harbor.

Mangroves normally are extracted from a land use/land cover GIS database that is categorized according to the Florida Land Use and Cover Classification System (FLUCCS) (Florida Bureau of Comprehensive Planning, 1976) and whose features were photo-interpreted from 1:12,000 USGS CIR DOQQs. SWFWMD GIS databases are available for download from: www.swfwmd.state.fl.us

Parcel boundaries and property appraiser data may be obtained from the appropriate local or regional agency. Ideally, parcel boundaries are available as ArcView polygon shapefiles in the Albers projection. If not, they will need to be converted to a shapefile and re-projected. The parcel boundary GIS file should contain the parcel identification number (PID) in the theme attribute table. The

\footnotetext{
${ }^{4}$ Color infrared photography differs from conventional color film because its emulsion layers are sensitive to green, red, and near-infrared radiation ( 0.5 micrometers to 0.9 micrometers).
} 
PID enables linkage of the parcel boundary file to information contained in the property appraiser database. Property appraiser data should be obtained for the parcels within the study area and fields should include parcel owner name and address.

Vertical benchmark information is obtained from several sources, starting with local offices of city and county surveyors. A number of web sites maintained by state and federal agencies contain detailed benchmark information. The LABINS web site (www.labins.org) contains databases with information on horizontal and vertical benchmarks, including the National Geodetic Survey (NGS) database and USGS $3^{\text {rd }}$ order vertical data. The National Ocean Service (NOS) (www.ngs.noaa.gov/datasheet.html) allows retrieval of NGS data and NOS tidal benchmark information via interactive map, permanent identifier, radial or rectangular search, station name, project identifier, or USGS quad name. USGS tide gauges and associated benchmarks are situated in a number of locations throughout the state and their location and status is recorded in the USGS Water Year reports. Contact the USGS to determine their availability and suitability for project requirements. 


\section{Project Planning and Preparation}

\section{Project Planning Map}

The field crew requires a map of the study area that delineates the salt-wateraccessible canals, channels, and other waterways where boats, moorings, derelict vessels, and signs are to be tallied and where depths are to be surveyed. A copy of the map should be made for each field census and survey to help plan and monitor fieldwork progress. For past waterway projects USGS 1-meter DOQQs were used as the map base. Map production is best accomplished in GIS software, such as ArcView. A permanent ArcView Project file should be created so that future modifications or additions can be readily incorporated.

The planning map includes several GIS themes, most importantly the location and extent of channel centerlines throughout the study area. The overview provided by the planning map will help to plan the work schedule, monitor field progress, and annotate areas as they are completed. As each segment of fieldwork is completed, the resulting data should be mapped in the GIS to ensure that no data gaps exist.

The planned waterway centerlines are best drawn by persons with knowledge of travel routes actually used by boaters. The county or regional agency that is charged with waterway management within the project area should oversee this procedure. For example, during project implementation in Lee County, personnel from the Marine Services Program, a section of the Division of Natural Resources, determined the extent and location of channels to be included. The resultant map is deemed preliminary, as the field crew will update it during the surveys. Field personnel should, as necessary, consult knowledgeable shore residents and observe actual boat travel routes.

Other themes included on the planning map are the locations and characteristics of signs, vertical benchmarks, hydrologic areas, tide gauges, locks, boat lifts, etc. Depending on project circumstances, additional map themes may be helpful. The sign census is conducted first and the resulting GIS theme included on the planning map for the depth survey. Vertical benchmarks can be categorized by their source, such as marks from the city or county, LABINS, NOS, or USACE. Hydrologic areas are delineations drawn by project personnel to guide the placement of tide gauges and the scheduling of depth survey work. Their inclusion on the planning map is important in complex areas, as exemplified by the City of Cape Coral (Figure 2). In less complex situations, hydrologic areas may be unnecessary. The map should include planned tide gauge sites (see Tide Gauge Siting) and gauges that are maintained by other agencies, such as the USGS. 


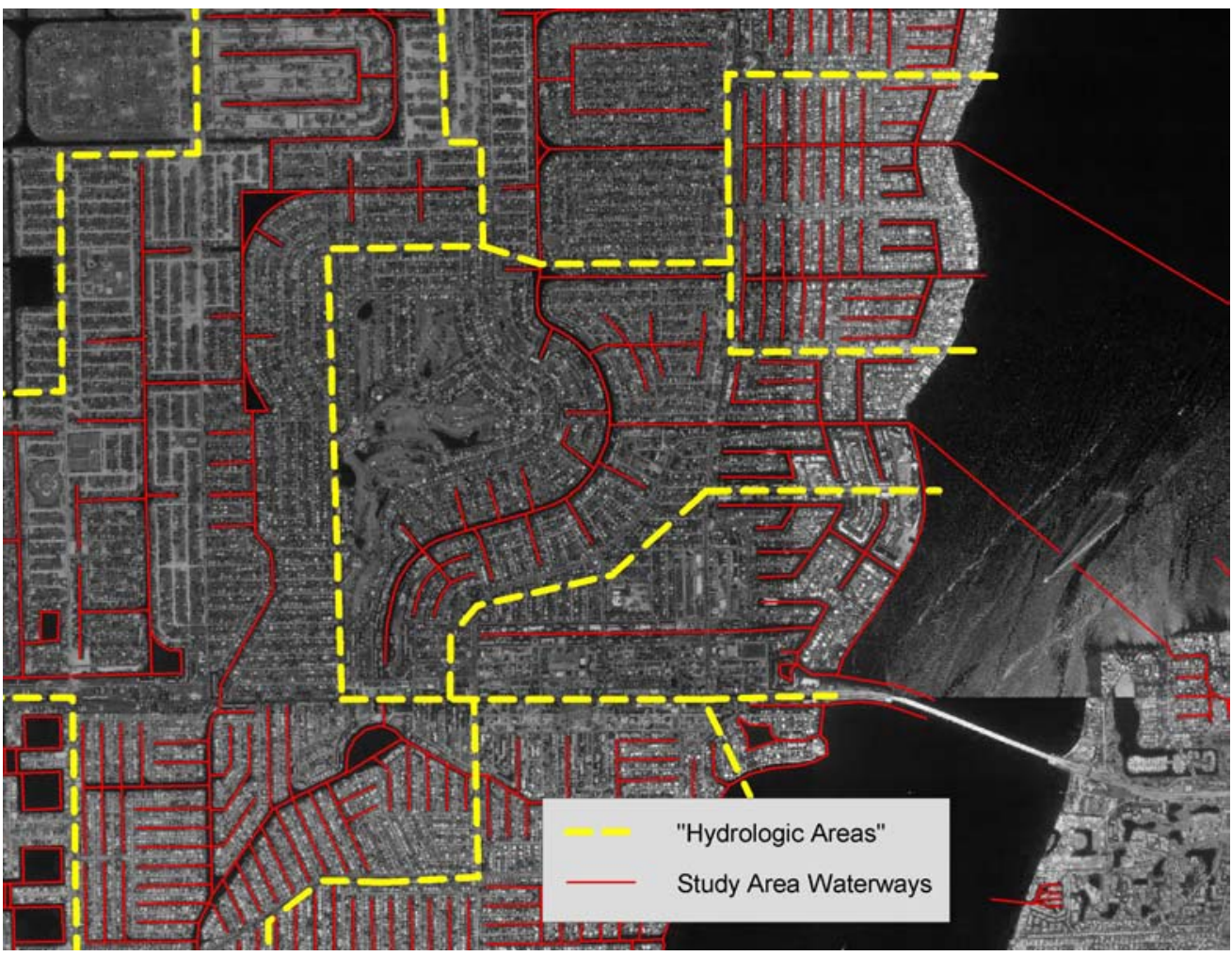

Figure 2. Hydrologic areas.

\section{Tide Gauge Siting}

During collection of bathymetric data, the water surface elevation relative to mean lower low water (MLLW) will vary with local tides, freshwater flows, and environmental effects (e.g., wind). To correct for these effects, all bathymetric data are collected near a gauge or between pairs of gauges. Gauge sites are selected in accordance with NOS and USACE standards required for tidal correction of bathymetric data (National Ocean Service 1999; U.S. Army Corps of Engineers 2001). The spatial distribution of project tide gauges is determined in consultation with qualified personnel $\left.\right|^{5}$ using the mapped hydrologic areas to guide gauge siting. Additional factors considered for gauge locations include safe, secure sites, and the availability of nearby monuments of known elevation, to which gauges can be referenced.

\section{Survey Vessel Outfitting}

Survey equipment needs to be securely mounted on the vessel before initiating fieldwork (Figure 3). The exact location that equipment is mounted will depend on the particular vessel used for the survey and on the positioning of personnel during the survey. Though the survey equipment, which was described previously, is designed for foul weather conditions, precautions should be taken to protect the equipment from inclement weather and salt spray.

\footnotetext{
${ }^{5}$ Dr. D. Max Sheppard, Professor in the University of Florida Coastal and Oceanographic Engineering Program, provided guidance on tide gauge siting in several study areas.
} 
Currently, a 17-foot Key West is used for the bathymetric survey (Figure 3G). An explanation follows on how the equipment was mounted on the Key West, in order to guide the placement of sounding equipment on other vessels. A special side mount for the Bathy-500MF transducer fits in a rod holder on either the port or starboard side (Figure 3A). The DGPS antenna is attached directly above the transducer mount and, thus, directly over the Bathy-500MF transducer (Figure $3 \mathrm{~A}$ and $\mathrm{C}$ ). A bulkhead mount holds the Bathy-500MF instrument on the inside, forward, port side (Figure 3D); a custom fabric cover protects the Bathy-500MF from spray. The DSM212H DGPS is mounted on the inside back cover of the Bathy-500MF. The Horizon DS150 transducer is transom mounted and the DS150 display unit is placed on the console, visible to the boat operator. A fighting chair for the equipment operator, forward of the console, replaces the original passenger seat cushion (Figure 3E). A swivel mount, adapted from a commercial monitor stand, holds the AMREL laptop forward of the chair (Figure 3B). This mount is bolted to the aft bulkhead of the foredeck. A custom canvas dodger, with a roll-up clear plastic forward window, protects the entire work area from spray and rain and provides shade that improves the laptop computer display visibility (Figure 3G).

Two custom $12 \mathrm{~V}$ outlets, in addition to the cigar lighter on the console, provide power for the survey equipment. A dual-battery system, with a second battery added in parallel with the original boat battery, has proven a reliable source of clean instrument power.

The Trimble Pro XR DGPS, the TSC1 data logger, a radiobeacon receiver, and the Laser Atlanta rangefinder are used for the boat/mooring and sign censuses. The census taker sits in the captain's chair, adjacent to the DGPS antenna, which is mounted in a rod holder.

A maintenance schedule needs to be established and followed for each of the survey vessels. Each day the vessel should be secured and all survey equipment removed. During the bathymetric survey, it is important that fuel be kept within a certain range to insure that the load conditions do not vary from one extreme to another, thus affecting the static draft.

In order to minimize travel time, suitable locations to overnight the boat should be found. This will require locating willing local residents. Likewise local residents with appropriate facilities should be found for mounting tide gauges on docks. (A productive way to find such volunteer participants is through organizations such as boating clubs.) Key site criteria include security for the boat and tide gauges, as well as accessibility by the field personnel. Prior permission must be obtained to access the tide gauge or use the dock when no one is home. 


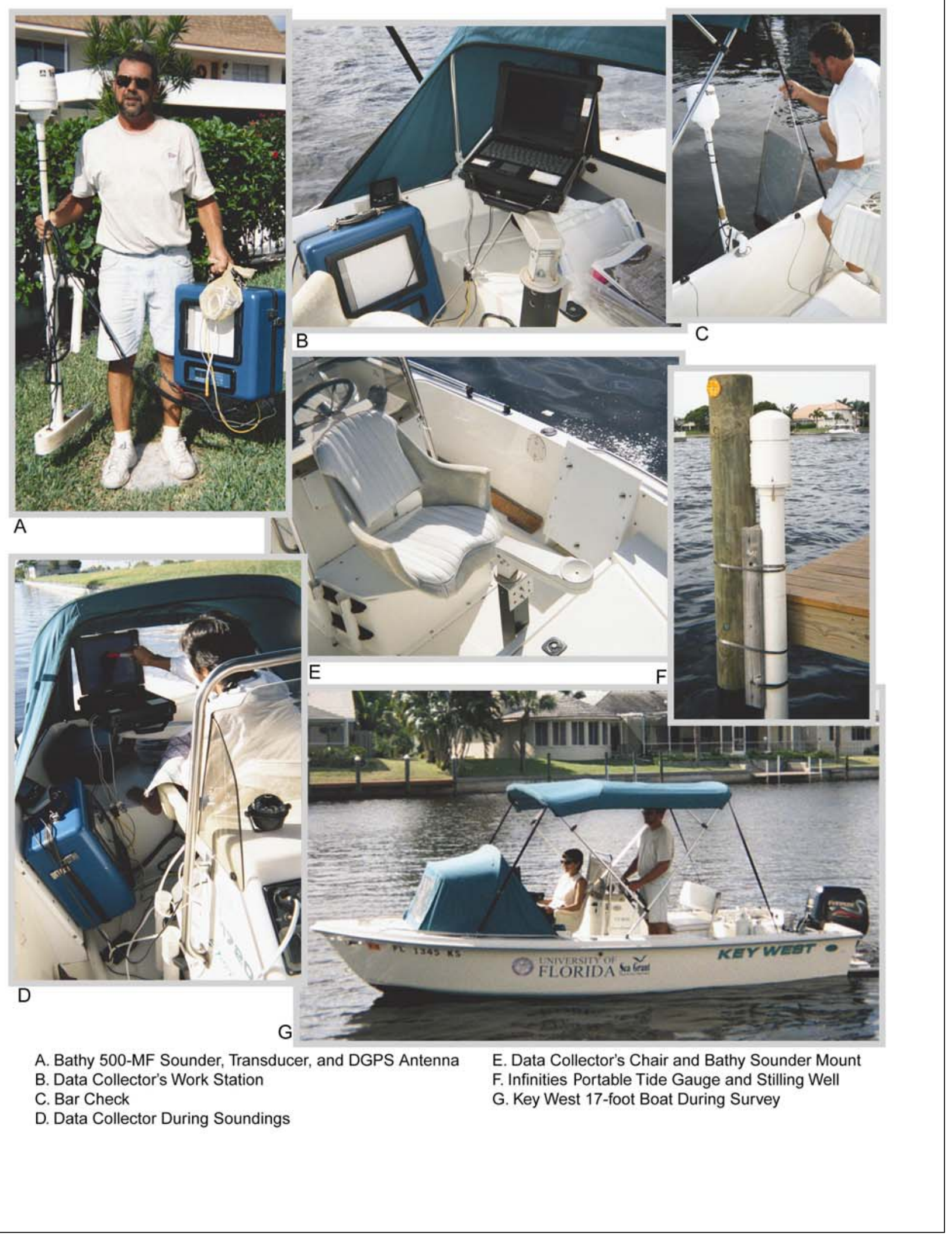

Figure 3. Bathymetric survey equipment. 


\section{Field Procedures}

\section{Tide Gauge Installation}

Once appropriate tide gauge sites are established (see Tide Gauge Siting), secure facilities need be found where gauges can be installed. Experience has shown that the best location is a dock at a private residence, as it provides greater security. Each proposed gauge site should be visited to confirm the presence of vertical benchmarks and their suitability to determine tide gauge elevation. Ideally, benchmarks are located within sight of the tide gauge installation, such as on a seawall or on an adjacent road or structure. If no suitable benchmarks are found in the vicinity of the gauge site, then a licensed surveyor must establish benchmark (at least $3^{\text {rd }}$ order), or another gauge site needs to be selected.

Naturally, property owners must give permission to install gauges on their docks. Tide gauge stilling wells must be securely fastened to a protected piling or other suitable mounting location (Figure 3F). Stainless steel straps, similar to automotive hose clamps, but available in lengths of 4 feet or longer, have proven a satisfactory means. Straps with thread slots over most of their length, rather than just near the tip, are preferable, as they accommodate a wide variety of dock piling diameters. An I-beam of $2 \times 4$ lumber, securely screwed together and placed between the stilling well and piling, provides a stable mount with a suitable standoff distance. The field crew must carefully monitor the gauge's elevation relative to the piling to check for vertical slippage or other problems.

The elevation of installed gauges, relative to NGVD29 or NAVD88, can be determined by differential leveling conducted by project personnel. If the benchmark is located on a seawall, then simultaneous measurements to the water surface from both the gauge and benchmark are used to establish gauge elevation. The average of three or more measurements, made under calm conditions, is used to establish the gauge elevation. From other benchmarks, not located on seawalls, the gauge elevation can be established via differential leveling. The MLLW tidal datum is determined in reference to historical NOS tidal benchmarks located in the vicinity of the gauge. The NOS tidal benchmark sheets, in many cases, provide elevations of tidal and geodetic datums referenced to MLLW (feet). The following example is for a historical NOS tide gauge that was located on the Peace River: 
HIGHEST OBSERVED WATER LEVEL

$=3.85$

MEAN HIGHER HIGH WATER (MHHW)

$=2.24$

MEAN HIGH WATER (MHW)

$=1.93$

MEAN TIDE LEVEL (MTL)

$=1.17$

* NATIONAL GEODETIC VERTICAL DATUM-1929 (NGVD) $\quad=0.56$

MEAN LOW WATER (MLW)

$=0.41$

MEAN LOWER LOW WATER (MLLW)

$=0.00$

LOWEST OBSERVED WATER LEVEL (01/16/1972)

$=-2.72$

Tidal benchmark sheets may be obtained from the following NOAA web site: http://co-ops.nos.noaa.gov/bench.html. Supplemental water level data may be obtained from USGS water-stage recorders when located within project areas.

During installation of the tide gauge, record all critical parameters on the 'Gauge Installation Form', which can be found on the accompanying CD-ROM (/FieldProcedures/TideGaugelnstallationForm.doc). Information recorded on this sheet includes benchmark characteristics and a record of the procedures and measurements obtained during tide gauge calibration and leveling procedures. This information is of vital importance when correcting depth measurements to the MLLW tidal datum.

Tide corrections are performed by means of a computer program, Survey Tide Correction (SURVCORR.exe), developed by the University of Florida (UF) Coastal and Oceanographic Engineering program. SURVCORR was developed to correct depths within a winding canal or river system. The program, with inputs of spatially referenced soundings and tide gauge readings, determines and applies depth corrections based on time and relative location. Tide data are interpolated to each centerline, or user-constructed baseline point, by assuming a linear variation of the tide through the system. Weighting the interpolation by the distance from a gauge provides correction for non-linear effects, such as viscous dissipation. A more detailed description of the program can be found in the Appendix (see Survey Tide Correction Program).

\section{Setting the Tide Gauge Data Logger}

After the tide gauge stilling well is secured in its operating position and nearby benchmarks identified to serve as elevation references, set (program) the data logger, in accordance with the Infinities user manual (Infinities USA, Inc. 1999). The logger can be set using either a laptop computer or a Hewlett-Packard HP48GX calculator. A laptop PC is faster, and its software is considerably more user-friendly. However, the HP48GX is much handier in the field and is usually the interface device of choice. The following paragraphs summarize the procedure for setting a data logger with the hand-held calculator. 
Before beginning fieldwork, load the Infinities software into the HP48GX. The Infinities user manual explains this rather complicated process in detail. For step-by-step help, call Infinities USA at 1-888-808-5488. (Important: A special version of the Infinities data logger software, included on the accompanying $C D$, allows use of the "Offset" field to tag a site-specific numeric identifier code to each data record. If the standard Infinities software is used instead, the numeric value of the code entered will be added to each record! The site code will stay the same until the logger is reset at a different site.) Set the calculator's internal clock. (Experience has shown it advisable to set all system clocks to UTC.)

Before installing the special version of the Infinities data logger, decompress the three disk images on the CD-ROM to 3-1/2 inch floppies

(/FieldProcedures/InfinityGauge/Disk1.zip, Disk2.zip, and Disk3.zip).

Setting the data logger and downloading data are done via the HP serial cable purchased with the calculator. First, turn on the HP48GX and then insert the cable into the calculator's top 4-pin socket. Be careful; the socket pins are easily bent. Connect the 9-pin connector on the other end of the cable to the data logger.

Navigating the HP48GX's keyboard is best done at first with the Infinities manual on hand, as each key has multiple functions. To set the data logger, select Set Datalogger from the Datalogger Start Menu and then choose Reset Auto Set. Enter a three-digit identifier code number for the station and press the OK "soft key" (the key below the desired choice in the calculator's display). It is best to enter the station codes for a study area with large numbers, such as 100,101, etc., rather than 001. Then, if an HP48GX with the standard Infinities software is inadvertently used, and the code is added to the depth readings as an "offset," the large resulting error will be immediately obvious.

The Time to Begin display will appear. Enter the number of days (zero), hours, minutes, and seconds (zero) from 12AM to the desired first sounding time. For a 6 -minute logging interval, choose to start at $0,6,12,18 \ldots$ or 54 minutes after the hour. (The software uses a 24-hour clock system.) As an example, if the present time is 3:08PM, enter zero days, 15 hours, 12 minutes, and zero seconds to start the logger at 3:12PM (1512 in the 24-hour system), the next appropriate logging time for a 6-minute interval. Press OK when the setting is correct, and enter the Time Interval Between Readings in hours (zero), minutes (6), and seconds (zero). Press OK to return to the Datalogger Start Menu.

Make several data logger readings and nearly simultaneous staff gauge or tape measure determinations of drop to the water surface from the stilling well rim (which corresponds to the logger's transducer height). This can be done by waiting for the logger to make its scheduled readings every six minutes. A more efficient method is to select Current Status from the Datalogger Start Menu, which will cause the logger to immediately take and display a reading. (This special reading is not stored in the logger memory, so it will not appear in downloaded data files.) Record and compare the readings. If the logger sounding 
error exceeds the specified limit (1 percent of reading), calibrate the logger, using the logger's built-in calibration routine, and then repeat the measurements. To calibrate the logger, select Calibrate Logger from the Datalogger Start Menu and enter a depth reading and its corresponding manual measurement. Then take a couple of additional test readings to verify the calibration reduced the error to within the specification.

Scroll down to Name \& Message on the Datalogger Start Menu to enter a name for the station (8 characters maximum) and, if desired, additional text (up to 31 characters). This information will appear in the headers of downloaded data files, but-unlike the three-digit numeric station code entered earlier-it is not tagged to each data record.

When the data logger is correctly programmed, wait for a least one scheduled reading to be taken, and download it as described in the next section. If the reading is on time and appears reasonable, the logger is running and collecting water level data. Screw the data logger's cap on snugly and install the protective housing on the stilling well assembly.

Be sure to record the drop from the chosen benchmark to the water simultaneously with some of the readings taken after the gauge is calibrated and known to be taking accurate readings. That information will later be used in adjusting the data logger's water level readings to a tidal datum (such as mean lower low water).

\section{Download Data Files}

Each tide station data logger should be downloaded at least weekly, preferably more often, in order to ensure data are not lost due to "wrapping," which occurs when the logger's memory is full and each new record causes deletion of the oldest record in storage. Also, frequent visits to a tide station will reveal problems (malfunctions, stilling well movement, theft, vandalism, etc.) before many days of soundings are taken that can not be corrected for tides.

Connect the HP48GX to the data logger as described above. From the Datalogger Start Menu, choose a data dump mode. Dump Since Set, which downloads all data collected since the logger was last set, is the usual choice. (An Entire Memory Dump downloads all data in the logger. If there is any doubt about whether data have been downloaded and backed up, the Entire Memory Dump will collect all possible readings. Then the station-unique ID number will allow sorting out which records came from which site.) When a mode is selected and OK pressed, the data will be transferred from the logger to the HP48GX.

Examining a plot of the data allows a quick data quality check. From the Datalogger Start Menu, select View Plots, and then scroll to select a file to view. The newest file will be at the top of the list. If the data are good, the plot will clearly show the rise and fall of the tide. The small screen shows a limited subset ("page") of the data at a time. Pressing the Cancel soft key will display the next pages until the file has been completely viewed. Press the $(X, Y)$ soft key to show cursor coordinates, then move the cursor via the arrow keys to some data points 
near the top and bottom of the plot. This allows verifying the displayed tide range is reasonable. Units are inches. (If the stilling well bottom aperture is partially blocked or the pressure relief hole is completely obstructed, the water level in the well may rise and fall with the tide, but with amplitude less than the actual tidal variation.) Press Cancel to exit View Plots and then Enter to return to the Datalogger Start Menu. When the data dump is complete, the logger will continue to collect depth readings.

Transfer Files to a PC

Back in the office, connect the HP48GX calculator to a serial port on a Windows computer, using the same HP serial cable used with the data loggers. Start the Infinities PC Transfer 9598 NT program and select Handheld Retrieval Device. Choose the serial port to which the HP calculator is connected and then click Receive Files. Status bars show the progress of the download. The HP48GX shuts itself off when it is finished sending all of its files.

The downloaded files can be immediately inspected in a text or word processor or opened as delimited text files in a spreadsheet, for graphing or preparation of files for tidal correction of soundings.

\section{Equipment Settings}

The following sections cover the principal settings for project equipment. Before using any piece of equipment, carefully read its accompanying user/operational manual.

\section{GPS Parameter Settings}

The Trimble Pro XR, TSC1 data logger, and the MSK beacon receiver are used for the boat/mooring and sign censuses; the Trimble DSM212H is used for the depth survey. Feature positional accuracy obtained during data collection depends on several factors including the number of satellites, multipath, distance between base station and the rover, Positional Dilution of Precision (PDOP), Signal-to-Noise Ratio (SNR), and satellite elevation (Trimble Navigation Ltd. 1995). These factors may be controlled or monitored via software and hardware settings. The following discussion describes parameter settings for field data collection during the waterway management project. A more detailed discussion of each parameter may be found in the Trimble manuals that accompany the GPS equipment (Trimble Navigation Limited 1998a, 1998b, 1998c).

The Asset Surveyor software on the TSC1 data logger is used to set critical and non-critical parameters for data collection (Trimble Navigation Limited 1998a). As fieldwork progresses all settings should be confirmed daily, as they have been known to occasionally reset to their default values. Parameter settings are accessed from the 'Configuration' menu, which is one of eight selections found on the Asset Surveyor main menu. The following paragraphs discuss appropriate settings for each relevant parameter, which are displayed in bold italics in the tables that accompany the discussion. 
'Logging options' is the first group of configuration parameters found under 'GPS Rover Options'.

\begin{tabular}{|r|r|}
\hline \multicolumn{2}{|c|}{ LOGGING OPTIONS } \\
\hline Logging intervals & \\
\hline Point Feature: & $\mathbf{5 s}$ \\
\hline Line/area: & $6 \mathrm{~s}$ \\
\hline Not in feature: & None \\
\hline Velocity: & None \\
\hline Minimum positions: & $\mathbf{1}$ \\
\hline Carrier phase & \\
\hline Carrier mode: & Off \\
\hline Minimum time: & 10 mins \\
\hline Dynamics code: & Land \\
\hline
\end{tabular}

Logging intervals specify the elapsed time between GPS positions that are logged, or recorded, by the TSC1. Point features (boat, moorings, derelicts, or signs) are the only feature type collected during the boat/mooring and sign censuses. The Point Feature logging interval should be set to 5 seconds, rather than the default 1 second, to help the operator avoid logging multiple positions. During fieldwork only one position should be logged for each point feature; logging is paused after one position is recorded and, then, feature attributes are entered into the data logger. Since only one position is to be collected for each feature, Minimum positions should be set to a value of one. If more than one position is accidentally collected for a feature, then during the editing process (explained later), the first position should be retained and all others discarded. The Dynamics code should be left at the default land setting, which is the mode for operating in areas where obstacles (e.g., condominiums or trees) may obscure satellite signals and when data collection takes place at a relatively low boat speed.

Once 'Logging options' have been set, return to the 'GPS Rover Options' menu by pressing Escape. 'Position filters' settings control the computation and application of GPS positions.

\begin{tabular}{|l|r|}
\hline \multicolumn{2}{|c|}{ POSITION FILTERS } \\
\hline Position mode: & Manual 3D \\
\hline Elevation mask: & $15^{\circ}$ \\
\hline SNR mask: & 6.0 \\
\hline PDOP mask: & 6.0 \\
\hline PDOP switch: & 8.0 \\
\hline Apply real-time: & Yes \\
\hline RTK mode: & Off \\
\hline
\end{tabular}


The Position mode is a critical setting, since it affects the operation of the Trimble Pro XR GPS receiver. This parameter should be set to Manual 3D, which assures that the receiver uses four or more satellites to compute positions. This setting usually will yield the most accurate GPS positions and allows for greater flexibility during fieldwork. The Elevation mask is set so that only satellites that are 15 degrees above the horizon are used to calculate positions. This is to assure that the same satellites used by the U.S. Coast Guard (USCG) radiobeacon ${ }^{6}$ station are those used during fieldwork. Also, this setting helps to avoid the greater ionospheric noise that is associated with low horizon satellites. The Signal-to-Noise Ratio (SNR) mask compares the information content and the noise ${ }^{7}$ that are carried by a satellite signal. Increasing values indicate that the signal carries a relatively greater amount of information than noise; a value of 6.0 is the appropriate SNR setting. PDOP mask determines the maximum Positional Dilution of Precision allowed to compute GPS positions. PDOP is a measure of the quality of the spatial arrangement of the constellation of satellites that have been acquired by the DGPS receiver. The accuracy of GPS positions increases as the PDOP value decreases. A PDOP of 6.0 provides for sub-meter accuracy when using a Trimble Pro XR receiver. Use the Pathfinder Office Quick Plan utility to determine when acceptable PDOP will be available during a particular survey day (see Mission Planning). The Apply Real-time switch should be set to yes, since all GPS positions are to be corrected using the RTCM signal.

The next parameters to check are the 'Communications options' located under the 'Configuration' menu.

\begin{tabular}{|c|c|}
\hline \multicolumn{2}{|c|}{ REAL-TIME INPUT OPTIONS } \\
\hline Radio type: & Custom \\
\hline Baud rate: & 9600 \\
\hline Data bits: & 8 \\
\hline Stop bits: & 1 \\
\hline Parity: & None \\
\hline RTCM options & \\
\hline Station: & Any \\
\hline Age limit: & $20 \mathrm{~s}$ \\
\hline
\end{tabular}

\footnotetext{
${ }^{6}$ The U.S. Coast Guard established a network of radio-broadcast DGPS stations that cover the Pacific, Atlantic and Gulf coastlines of the U.S. plus some inland waterways. These sites broadcast RTCM-104 v. 2 format corrections utilizing Minimum Shift Keying (MSK) modulation of existing radio beacon signals. Each station has a broadcast range of generally 100 to 150 miles and their data can be utilized by any MSK beacon receiver, such as the Trimble Pro XR receiver, which has a with built-in MSK receiver. Real-time DGPS correction accuracy is specified by the Coast Guard to be better than 10 meters. Actual field accuracies have been found to be as good as 1 meter with a system such as Trimble's Pro XR.

${ }^{7}$ Choose a location for the antenna with a minimal amount of ambient noise. Some common sources of electrical and magnetic noise are gasoline engines, television and PC monitors, alternators and generators, electric motors, propeller shafts, equipment with DC-to-AC converters, florescent lights, power lines, and switching power supplies.
} 
Real-time corrections are obtained from the radiobeacon component of the Pro $\mathrm{XR}$ and, thus, the parameters should be left as listed in the table above. The RTCM Station option is set to 'Any', which allows the receiver to acquire the best signal from available USCG radio-broadcast DGPS stations. USCG DGPS stations in Florida are located at Cape Canaveral, Key West, MacDill Air Force Base (Tampa), and Miami. The operational parameters and current status of all USCG radio-broadcast DGPS stations can be obtained at the following web site: http://www.navcen.uscg.gov/ADO/DgpsSelectStatus.asp

Since the Pro XR integrated DGPS is used to apply real-time corrections, press the F1 soft-key on the TSCl keypad in order to check the parameter settings.

\begin{tabular}{|l|r|}
\hline \multicolumn{2}{|c|}{ INTEGRATED DGPS } \\
\hline Source: & Beacon \\
\hline Mode: & Auto range \\
\hline Frequency: & N/A \\
\hline
\end{tabular}

The Source for real-time position corrections is RTCM messages broadcast from one of the USGS MSK radiobeacon stations listed above. Mode is set to Auto range, which allows the Pro XR to track available stations and select the best one in terms of proximity and signal strength. Frequency is not applicable since the Pro XR is set to switch between available stations.

Return to the 'Configuration menu' by pressing the Escape key. The settings under 'Coordinate system' and 'Units and display' can be left at their default values as listed in the TSC1 Asset Surveyor Software User Guide (Trimble Navigation Ltd. 1998a). The 'Time and date' settings are for TSC1 display and file naming purposes only. GPS data is recorded in GPS time, which is essentially the same as Universal Time Code (UTC). Thus, there will be no effect on GPS data records if you reconfigure the receiver and/or data logger when there is a change in the local time.

Next, from the 'Configuration menu', select 'External sensors' and highlight the selection for Laser and press the setup soft key.

\begin{tabular}{|l|r|}
\hline \multicolumn{2}{|c|}{ LASER RANGEFINDER } \\
\hline Type: & Atlanta Advantage \\
\hline Auto connect: & Yes \\
\hline Serial port: & Top \\
\hline
\end{tabular}

The laser Type should be set to Atlanta Advantage and Auto connect set to 'Yes', since the range finder is used throughout both censuses. The rangefinder is connected to the top Serial port on the TSC1. 
The last available selection from the 'Configuration menu', 'Hardware (TSC1)', contains useful information and settings.

\begin{tabular}{|l|r|}
\hline \multicolumn{2}{|c|}{ HARDWARE (TSC1) } \\
\hline LCD contrast: & $\mathbf{3 0 \%}$ \\
\hline Backlight: & Off \\
\hline Auto shutoff: & $\mathbf{2 0}$ \\
\hline Beep volume: & High \\
\hline Free space: & $\mathbf{1 6 4 8 k B}$ \\
\hline PC card free space: & $\mathrm{N} / \mathrm{A}$ \\
\hline Battery source: & External \\
\hline Internal battery: & $100 \%$ \\
\hline External battery: & Unknown \\
\hline Software version: & 4.01 \\
\hline
\end{tabular}

Lighting conditions change throughout the day and LCD contrast allows the TSC1 display screen to be adjusted accordingly. In general, with brighter lighting a higher value is required. It is best to leave the Backlight Off, as it places a relatively large drain on battery power. Auto shutoff powers down the TSC1 when no key has been pressed during the allotted time. Choose a setting between 1 to 60 minutes that best meets the data entry habits of field personnel. Beep volume set to 'High' will alert the user when certain data logger functions have been performed (e.g., position recorded). The remaining fields cannot be set, but offer important information to the user. Free space indicates how much TSC1 storage space is left for data (rover) files. Battery source indicates whether the TSC1 is running on its own internal batteries or from an external power source, such as the GPS receiver battery. Internal battery indicates the level of charge remaining in the TSC1's main internal batteries. When the TSC1 is hooked up to an external source the External battery field shows the power level, if available. The Software version of the Asset Surveyor software is also displayed. This concludes the discussion of settings for the Trimble Pro XR GPS.

The Trimble DSM212H and its integrated dual-channel MSK beacon receiver are configured using Trimble Standard Interface Protocol (TSIP) TALKER software installed on a PC (e.g., the AMREL laptop, which is used during the depth survey). The TSIP TALKER software is used to configure key GPS operating parameters: DGPS input and output, and NMEA-0183 output messages; as well as to monitor the current status of receiver processes. The DSM212H is connected to a PC serial port via Port B on the DGPS. The communication parameters are set using the TSIP TALKER software.

Once communication is established between the TSIP TALKER software and the DSM212H, DGPS receiver parameters are accessed from the drop-down menu. 


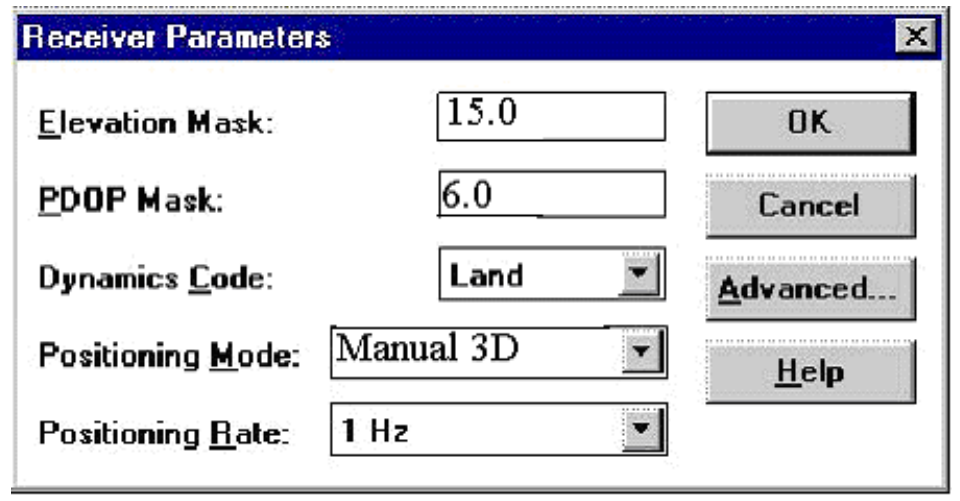

The settings are the same as for the Trimble Pro XR. The Elevation Mask is set to 15 degrees, PDOP Mask to 6.0, Dynamics Code to land, and the Positioning Mode to Manual 3D. The Positioning Rate, which is set to $1 \mathrm{Hertz}$ $(\mathrm{Hz})$, determines the rate at which the DSM212H outputs position reports to the HYPACK hydrographic software.

The DGPS menu includes options for configuring the DGPS source and radiobeacon data acquisition channels, viewing radiobeacon information, and monitoring the health status of radiobeacons. The first set of parameters is located under 'Source'.

Radio-broadcast USCG DGPS stations serve as the DGPS Source for position corrections. Beacon Mode is set to automatic, which allows the receiver to acquire the best signal from available USCG DGPS stations. Two settings are available for beacon mode: auto range or auto power. Generally, auto range provides a more accurate position, as the receiver uses the signal from the closest station. When beacon mode is set to auto power, the strongest signal is used, which provides greater signal reliability. The Satellite Settings are irrelevant, as satellites are not used for DGPS corrections during the bathymetric survey. 


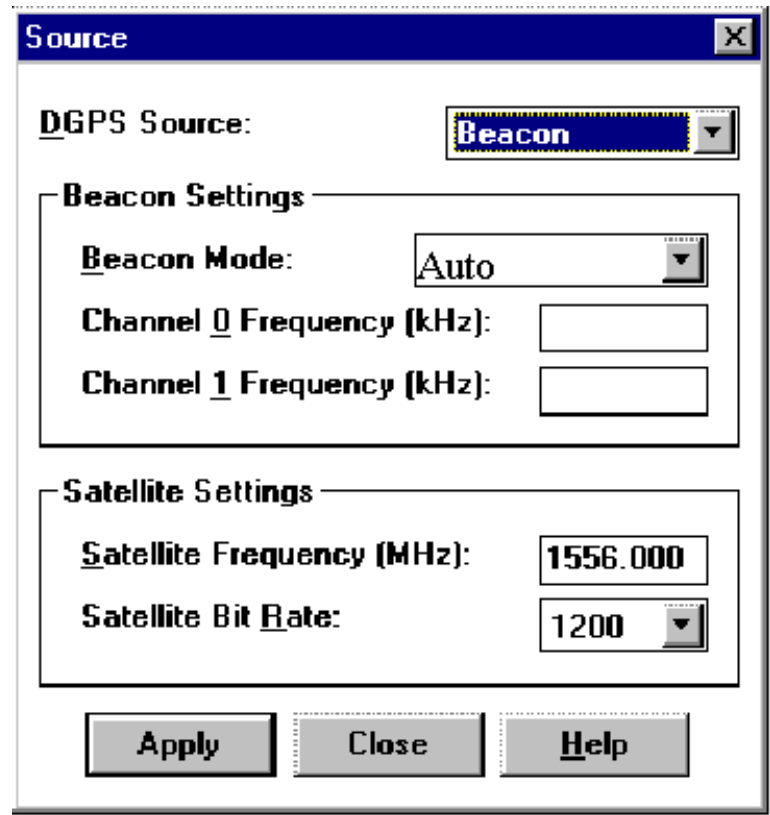

The next set of parameters located under the DGPS menu 'Configuration' set the DGPS acquisition mode, the maximum pseudorange correction (PRC) age, and the source of DGPS corrections.

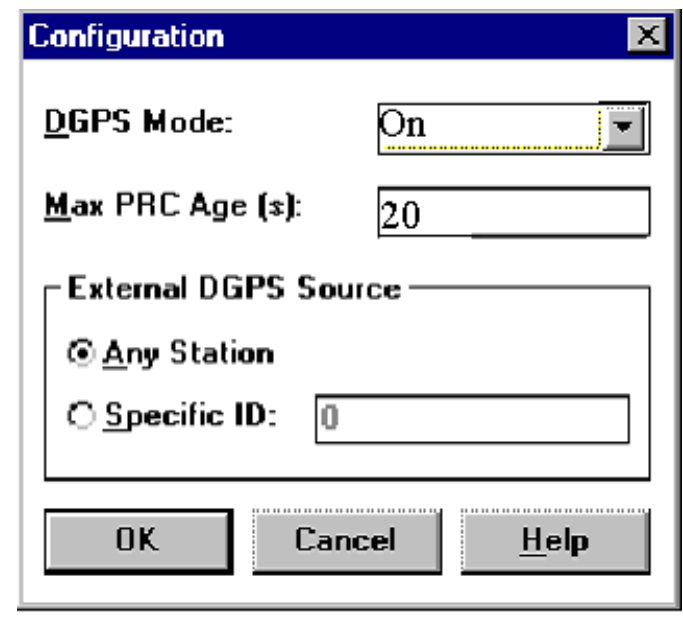

DGPS Mode determines receiver behavior when DGPS corrections are received from a radiobeacon station. Set the mode to 'On' to assure that the receiver computes positions only when DGPS corrections are available. Set Max PRC Age to 20 seconds to eliminate older PRCs from position calculations, since they quickly age and lose accuracy. Set the External DGPS Source to 'Any Station' to automatically acquire DGPS corrections from any radiobeacon in the area.

The 'Beacon List' and 'Beacon Health' selections available from the 'DGPS' menu provide information on the available radiobeacon stations, including their status. The 'View' menu lets you display windows containing status information 
collected from the receiver. These are useful for viewing receiver configuration and monitoring receiver processes during the bathymetric survey.

\section{Depth Sounders}

Bathy-500MF-the Bathy-500MF echo sounder is controlled using the 16 keys that are located on the front panel (Figure 4). The settings described below are those that have been found appropriate during a hydrographic survey conducted for the WCIND along the Caloosahatchee River and adjoining canals and waterways. The settings for other locations may be different. Only digital depth output has been used during WCIND surveys; not the paper chart capabilities of the sounder. Refer to the user manual for a complete description of Bathy-500MF functions and parameter settings (Coastal Oceanographics, Inc. n.d.).

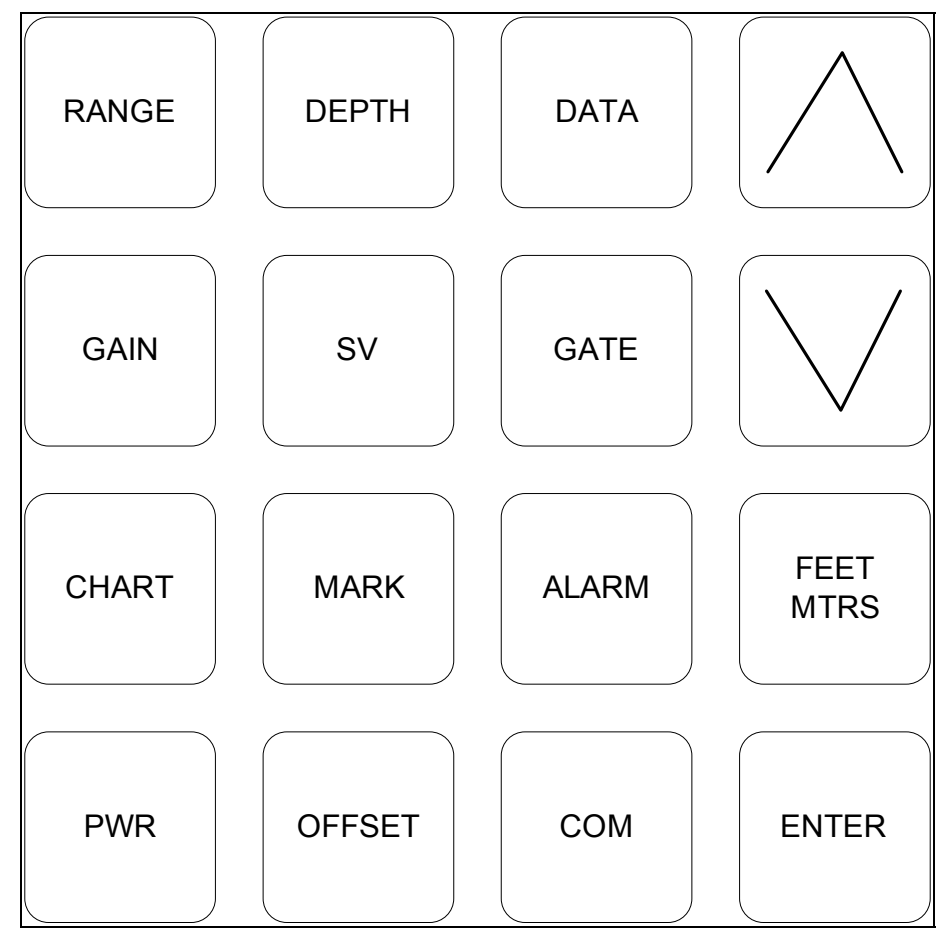

Figure 4. Bathy-500MF echo sounder front panel.

To power up the Bathy-500MF, simultaneously depress the PWR and ENTER keys. During the startup, view the LCD display to determine if the unit is set to the proper transducer frequency (currently using a $200 \mathrm{kHz}$ transducer). If the transducer frequency is not properly set, then quickly press the COM key and select the proper transducer frequency (e.g. $200 \mathrm{kHz}$ ) from the 'SET FREQ' menu.

The RANGE setting will depend on the range of depths encountered during a particular survey. A setting of either $0-30 \mathrm{ft}$ (or $0-60 \mathrm{ft}$ ) is normal for surveys conducted for the WCIND. The PHASE setting is $0-120 \mathrm{ft}$, the GAIN is set to 'Auto', and TVG set to 100 . The daily bar check is used to determine if any 
corrections are needed due to variations in sound velocity. If there is a difference between the sounder depth reading and the bar depth, sound velocity (SV) is adjusted until the two depths match. Field notes should be kept to record observations from each daily bar check and any adjustments to SV that are made. The data output I/O format for transmitting depths to the HYPACK software is selected by repeatedly depressing the COM key. The NMEA dbs output format is recommended. The depth of the transducer below the waterline is determined under normal load conditions and the measurement is entered into the Bathy-500MF using the OFFSET key. ALARMs can be set to notify the operator when sounder readings are above or below specified limits. Alarms can be useful to notify the operator when the sounder gives false readings. Potential causes of false readings can include turbulence, temperature gradients, density variations, and biological layers.

Horizon DS150 - the procedures for entering settings into the Horizon echo sounder are described in the user manual (Standard Communications 2001). The keel offset (depth of the transducer below the waterline) is determined under normal load conditions (equipment and personnel) and the measurement is entered into the HYPACK Hardware driver settings for the Horizon.

The setting for Display Damping is to control for rough water conditions, schools of fish, and thermal layers, all of which can cause erratic depth readings. Display damping controls the rate that the displayed depth can change and will help remove these variations. There are three levels of damping, with $\mathrm{d} 1$ having the least effect and d3 having the greatest effect. When operating in shallow or at high speeds it is best to use a low level of damping. During past WCIND surveys, the Horizon DS150 setting for damping was set to D1.

The Turbulence Setting provides three settings of turbulence rejection: $t 1, t 2$, and $t 3$. A setting of $t 2$ should be used unless a problem occurs while underway. A setting of $\mathrm{t} 1$ enables the instrument to work in water as shallow as 3 feet at an increased susceptibility to water turbulence and surface noise. A setting of $t 3$ provides maximum immunity to water turbulence and surface noise at the expense of shallow water (less than 4 feet) performance.

\section{Mission Planning}

The boat/mooring and sign censuses and the depth survey require the use of DGPS to log features. Thus, mission planning is critical to project efficiency. To ensure adequate positional accuracy, the "constellation" of satellites must be satisfactory. Enough satellites must be visible, they must be spread over a large area of the sky, and they must be sufficiently high above the horizon. These factors all contribute to accuracy or lack thereof. Combined, they result in a number called Positional Dilution of Precision, or PDOP. There is no point in trying to collect data when the PDOP is too high, as the TSC1 is set to not collect data when PDOP exceeds 6 . When this occurs, a "PDOP too high" message appears, and the data logger will not record a position. With a PDOP limit of 6 , 
field personnel can work most of the time. The $\mathrm{TSCl}$ also is configured to require four or more satellites and an elevation mask of $15^{\circ}$ in order to compute positions.

To work efficiently, it is best to use the Pathfinder Office Quick Plan utility (Utilities $\rightarrow$ Quick Plan) to forecast possible downtimes. But first, it is necessary to tell Pathfinder Office where the satellites will be in the future. This is done by downloading an "almanac" file from the TSC1. A new almanac should be downloaded from the data logger every month or so. (The TSC1 records the latest almanac whenever it is used.) It is just another data file to be downloaded from the data logger, using the same procedure as for rover files. Select Almanac as the Data Type, rather than Data. Quick Plan will automatically reference the latest almanac file if you always save new ones to the same directory.

Start a Quick Plan session. If necessary, define a location. (Don't forget our longitude is West; the default is East). Select a day of interest. Look at the PDOP graph to see how it varies throughout each day. If below 6 all day, data may be collected any time. If there are times when PDOP exceeds 6 , it may be possible to plan lunch, refueling, or some other activity for those periods.

\section{Field Censuses and Survey}

\section{Data Dictionaries}

The boat and mooring ${ }^{8}$ census, the sign census, and the depth survey are accomplished using data dictionaries created in Pathfinder Office and uploaded to the TSC1 data logger. Copies of the most recent data dictionaries and a printout (PDF) of each are contained on the CD-ROM that accompanies this manual (/FieldProcedures/Data Dictionary). Sometimes it is necessary to modify a data dictionary to reflect changing circumstances that may arise during a new project (e.g., a new mooring type). Modifications are accomplished with the Data Dictionary Editor in Pathfinder Office (Utilities $\rightarrow$ Data Dictionary Editor) and then uploaded to the Trimble data logger using the Data Transfer utility (Utilities $\rightarrow$ Data Transfer).

\section{Boat and Mooring Census}

The purpose of the boat/mooring census is to determine the location and characteristics of all boats and moorings within the study area. This census is conducted during the peak boating season-December through April-using the Trimble Pro XR, the TSC1 data logger, and the Laser Atlanta Advantage laser rangefinder. The data logger must contain the boat/mooring data dictionary (Boat2001.ddf), which has two point features: one for boats/moorings

\footnotetext{
${ }^{8}$ Moorings are defined as boat locations that are either occupied or vacant. Mooring types include anchorage, beached or blocked, boat lift, davits, dry stack, float/ramp (usually for personal watercraft), hoist, mooring, ramp, seawall, trailer, and wet slip.
} 
(BOATMOOR) and the other for derelict vessels (DERELICT). The BOATMOOR characteristics (fields) collected during the census are:

1) BEGIN-whether the feature is a boat (and its associate mooring) or an empty mooring.

2) FACILITY - land use classification to which the boat and mooring are associated.

3) BOAT TYPE— use characteristic of the boat.

4) MOORING-manner in which the boat is secured.

5) LARGO-length class to which the boat belongs (feet).

6) AGE-decade in which the boat was manufactured.

7) MAKE/MODEL - manufacturer make and model of the vessel.

8) VARIABLE DRAFT - whether the boat has variable draft capabilities.

9) DRAFT—boat draft to the nearest $1 / 2$ foot.

10) AERIAL—corresponding aerial photo identification number.

11)STATE REG—bow number; used if field identification not possible.

12) VIN — manufacturer hull identification number; should be on transom; used if field identification not possible.

13) $\mathrm{PHOTO}$ - photograph associated with feature; used if field identification not possible.

14)COMMENT-user notes.

15) DATE-date when the boat was surveyed; automatically generated.

16)TIME-time when the boat was surveyed; automatically generated.

A spreadsheet of reference numbers that correspond to boat manufacturer makes and models is maintained for the boat census. During the census, a printout of the spreadsheet table, sorted by make/model, is used to enter a reference number into the MAKE/MODEL field for each logged vessel.

Make/models that are encountered during the census, but not found on the printout, are added to the table printout and assigned the next available reference number (numbers ascend numerically). At the next available opportunity, the spreadsheet is updated with the new make/models and their corresponding reference numbers and re-sorted by make/model. A copy of the most recent make/model table is contained on the CD-ROM (/FieldProcedures/MakeModel.xls).

Most important for waterway management system analyses is determination of vessel draft. If identification of boat make/model and other data do not reveal the draft, the field personnel should take other measures, including asking the boat owner or a knowledgeable neighbor.

The DERELICT point feature in the boat/mooring data dictionary contains all of the above fields (except BEGIN) and, in addition, the following:

1) FMPMark — whether the vessel has a Florida Marine Patrol (FMP) mark. 
2) DCOND—derelict condition.

3) DBEACH-whether the derelict is beached.

4) DAFLOAT-indicates if the derelict is afloat.

5) DSUBMERGE-submersion percent of the derelict vessel.

The data fields for boat/mooring and derelict features are further described in the sample metadata files contained on the CD-ROM

(/FieldProcedures/Metadata/boats.htm and derelicts.htm).

The boat/mooring census is conducted for all boats (whether they are located in the water or on land) and moorings on salt-water accessible canals and waterways. Facilities that are surveyed may be commercial, governmental, or residential. Examples include single and multi-family residences, anchorages, clubs, dry stacks, hotels/motels, marinas, restaurants, shops, and boat yards. Dealer inventory stock at commercial facilities, such as boat yards and marinas, is not included in the boat census.

The TSC1 data logger is set to log DGPS positions at a five-second interval and only one position is logged for each feature. Position logging is paused after the first position is recorded, feature characteristics are recorded, and the feature then is saved. In addition to using DGPS equipment to log boat, mooring, and derelict vessel information, each feature should be marked on large-scale $(1: 2400$ to $1: 12,000)$ orthophoto maps, or aerials, as the survey progresses. The location of some features may need to be adjusted during the post-survey editing process, at which time the field annotated photomaps will prove invaluable. Onemeter USGS DOQQs normally are used to produce the photomaps; however, the availability of higher resolution imagery from city or county sources should be ascertained. If possible, parcel boundary (lines) should be added to the photomaps to guide placement of feature marks. Each feature mark should be color-coded according to feature type: e.g., boat (red) or mooring (blue).

At the end of each field day a number of tasks should be completed. First, all rovers collected using the TSC1 data logger should be downloaded onto a computer using the Pathfinder Office data transfer utility (Utility $\rightarrow$ Data Transfer). Once downloaded, the rovers should be viewed in Pathfinder Office, over background imagery, to insure that the data is in the correct geographic location, covers all areas that were to be to be surveyed that day, and that no data gaps exist. Backup copies of original and edited rover files should be maintained on separate media in a secure location. If possible, copies should be sent electronically to personnel located at another site.

Boat/mooring census data should be cleaned and edited as soon after field collection as possible, since the recollection of field personnel diminishes with time. Preferably, editing sessions will occur at least weekly. The first editing step is to check the data using the SSF Record Editor, which can be accessed from Pathfinder Office (Utilities $\rightarrow$ Other $\rightarrow$ SSF Record Editor). Each feature (boat, 
mooring, or derelict vessel) is checked to assure that only one position was recorded by the DGPS. The survey vessel usually is in motion during the census and the average of multiple positions results in a less accurate location determination for each feature. Therefore, only the first position is maintained if multiple positions have been recorded.

The following technique greatly facilitates this editing process: Once the rover is loaded into the SSF record editor, select View $\rightarrow$ Records by Type. Click "Hide All." Then turn on (check) "Feature Block Start - FON," Feature Block Off - FOF, and "Position Records - POS". This hides everything except for the start and end of each feature's records and one line for each position logged. It is then easy to spot multiple positions for a feature and to delete all but the first one. Be sure to Save after completing the edits. Note: Records "deleted" are not removed from the rover file, but are simply flagged to be disregarded. They may be undeleted at any time.

Upon completion of the boat/mooring census the data needs to be cleaned and edited. These procedures are best accomplished within a data base manager, such as Microsoft Access. This involves summarizing each attribute by unique value and checking for correct spelling and logical consistency. Some examples include checking boat draft versus boat length or make/model; and checking the facility value obtained from the field census versus that contained in the property appraiser database.

\section{Signage Census}

The purpose of the signage census is to determine the location and characteristics of all boat-related signs within the study area. This census is best conducted before the depth survey, so that a set of aerials containing sign locations and characteristics can be produced to guide the depth survey. The signage census is carried out using the Trimble Pro XR DGPS, TSC1 data logger, and the laser rangefinder. The data logger must contain the signage data dictionary (Sign2000.ddf), which has two point features: one for signs (SIGN) and the other for hazards (HAZARD). The sign characteristics (fields) collected during the census are:

1) SITE-where the sign is located (e.g., bridge).

2) TYPE-structural characteristic of the sign (e.g., buoy).

3) MESSAGE-message that the sign conveys (used in conjunction with the comment field; e.g., channel mark).

4) LABEL - categorization of the sign into 6 general classes.

5) STATUS - status of the sign (e.g., permitted or non-permitted).

6) CONDITION-physical condition of sign.

7) COMMENT—observation of field personnel (use in conjunction with message field).

8) DATE-date on which the field observation was made; automatically generated. 
9) TIME - time at which the field observation was made; automatically generated.

The hazard (HAZARD) point feature, while not included in the waterway management scope of work, was created to map existing navigation hazards, such as submerged pilings or branches. The hazard characteristics collected during the census are COMMENT, DATE, and TIME. The sign fields are further described in the sample signage metadata file contained on the CD-ROM (Metadata/signs.htm).

The same daily and weekly editing procedures followed during the boat/mooring census should be observed during the sign census.

\section{Depth Survey}

The purpose of the depth survey is to obtain channel centerline soundings for all salt-water accessible canals and waterways within the study area. The timing of the depth survey is not as critical as that of the boat/mooring census. The depth survey is carried out using the DSM212H DGPS, AMREL laptop, and the Bathy500MF and Horizon DS150 echo sounders.

\section{Survey Procedures}

Prior to conducting the depth survey, tide gauges should be installed and checked to make sure they are working properly. There are a number of corrections that need to be applied to the raw soundings to account for error sources attributable to systematic and system-specific instrument errors, static and dynamic variations in boat draft, environmental conditions, and tidal variations (National Ocean Service 1999; U.S. Army Corps of Engineers 2001).

Instrument Error and Sound Velocity Corrections-to determine corrections for sound velocity and instrument error, bar checks are performed within the survey area. A minimum of two bar checks is conducted during each survey day to verify the depth reading from the Bathy-500MF and DS150 transducers.

Bar checks should take place at the start and end of each survey day. The bar consists of a metal plate that is lowered to set distances, at 5-foot intervals, below each transducer. The sounder depth reading, at each 5 -foot interval, is compared to the bar depth and, if necessary, the appropriate correction factor is entered into the DS150 instrument as one component of the keel offset, along with the static draft correction (see below). To apply the correction to the Bathy$500 \mathrm{MF}$, the velocity setting is adjusted until the depth reading equals the bar depth. If more than one correction factor results for either sounder, the corrections are cataloged and applied to the soundings during post-processing. At the end of each day, the two daily bar checks are compared and if they agree by 0.3 feet or less the survey data are accepted. Otherwise, the data are rejected and the area resurveyed. Daily bar checks are recorded in a field notebook. 
Static draft corrections - the static draft correction accounts for the depth of the transducer face below the waterline. The measurement is made at least to the nearest 0.1 -foot as determined under normal load conditions with boat personnel in their survey positions. A person standing on a dock next to the survey vessel is best situated to make the measurement. The correction is entered into the Bathy$500 \mathrm{MF}$ as a component of the offset, along with any necessary sound velocity correction (see Instrument Error and Sound Velocity Corrections). The correction is entered into the DS150 as a "Keel Offset".

Squat and Settlement-differential leveling conducted, under normal load conditions (including personnel, fuel, and equipment) determines squat/settlement corrections to the nearest 0.1 -foot for the range of survey operating speeds. The range of operating speeds may be determined from a survey of posted speed limits within the study area.

Squat/settlement corrections should be determined in non-tidal waters, under calm conditions, in depths that equal the average expected for the study area. To determine squat/settlement corrections a level is set-up on a dock and the boat run parallel to the shoreline in front of the level, at various speeds. A rod is held over the transducer and a series of observations taken with the vessel standing still, and at the range of survey operating speeds. The squat/settlement correction factor for each operating speed should be based on the average of a minimum of three runs at each speed. Squat/settlement corrections are automatically applied during the depth survey by installing the Draft Table Driver within the HYPACK hydrographic survey software. The Draft Table is a listing of correction values with their corresponding vessel speeds. The average boat velocity, as determined from the DGPS, is recorded for each RPM level.

Motion Corrections - for depth surveys conducted in protected, near shore waters under calm sea conditions, correction for heave, the only motion correction applicable for a single-beam survey (National Ocean Service 1999), is considered unnecessary. During bathymetry data collection in the residential canal systems, the primary weather considerations are crew safety (especially with regards to lightning), collision avoidance (when maneuvering near other vessels in heavy sustained or gusty winds), and efficient operation of instrumentation (particularly in heavy rain). On workdays when conditions are suitable in those regards, the weather does not significantly affect boat dynamics in the canals, and data quality remains high. The crew should plan to work only sheltered waters, such as canal systems, on windy days that are otherwise safe for operations.

\section{HYPACK Software Settings}

There are a number of HYPACK software settings that are necessary to conduct the depth survey. Detailed information on these settings is contained in the HYPACK user manual (Coastal Oceanographics, Inc. n.d.). 
The GEODETIC PARAMETERS settings depend on the projection parameters and the coordinate system of the background imagery used for a project. If USGS DOQQs in Albers Equal Area projection are used, then the parameters are set as shown in Table 3 and represented in Figure 5.

Table 3. HYPACK geodetic parameters.

\begin{tabular}{|l|c|}
\hline \multicolumn{2}{|c|}{ Geodetic Parameters } \\
\hline Predefined Grids & none \\
\hline Distance unit & Meter \\
\hline Depth unit & same as horizontal \\
\hline Ellipsoid & WGS-84 \\
\hline Orthometric Height Correction & 0.00 \\
\hline Projection & Albers Equal Area \\
\hline Central Meridian & $84^{\circ} 00^{\prime} 00.0000^{\prime \prime} \mathrm{W}$ \\
\hline Reference Latitude & $24^{\circ} 00^{\prime} 00.0000^{\prime \prime} \mathrm{N}$ \\
\hline North Parallel & $31^{\circ} 30^{\prime} 00.0000^{\prime \prime} \mathrm{N}$ \\
\hline South Parallel & $24^{\circ} 00^{\prime} 00.0000^{\prime \prime} \mathrm{N}$ \\
\hline False Easting (X) & 400000.0000 \\
\hline False Northing (Y) & 0.0000 \\
\hline
\end{tabular}

\section{Hardware Setup}

Four device drivers need to be installed for the depth survey equipment to communicate properly with the HYPACK software. These include the two echo sounders: the Bathy-500MF and the DS150; and the DSM212H DGPS. A fourth device consists of a table to quantify the relationship between boat speed and squat/settlement. The table is used to apply real-time squat/settlement corrections to raw depths during the survey.

The relative location of each sensor that provides input to the HYPACK software must be determined. Select a point on the survey boat to serve as the "boat origin." Each sensor is then referenced based on its location relative to the origin: "to starboard"(X-direction) and "forward" (Y-direction). The offset units must be the same as those used to record depths (e.g., meters).

Figure 6 illustrates the Key West survey vessel as configured during the Lee County Phase 3 depth survey, with two echo sounders and one DGPS antenna. The boat origin was positioned directly over the Bathy-500MF transducer, above which was mounted the DGPS antenna. All offsets forward and starboard of the 


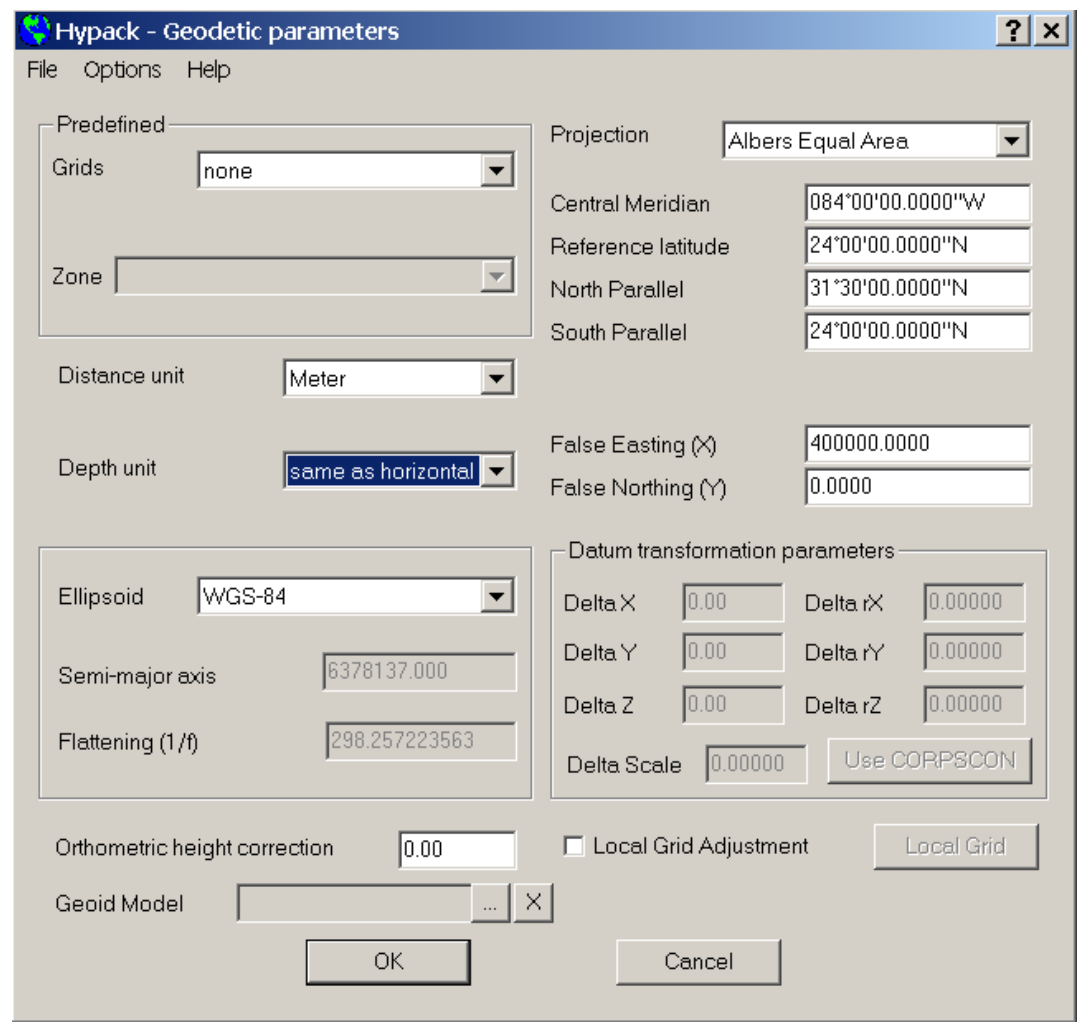

Figure 5. HYPACK geodetic parameters.

boat origin have a positive value. The DS150 Horizon transducer was located aft of (negative offset) and to the port (negative offset) of the boat origin.

Once the preliminary tasks are completed, initiate the device driver installation process by following the HYPACK manual instructions that pertain to 'Hardware Setup'. The specific settings for each survey device are detailed below.

Bathy-500MF: From the 'Select device type' dialog choose the 'NMEA-0183' driver (NMEA.dll) and give the device an appropriate Name, such as 'BathyNMEA'. The Update frequency controls the rate (ms) at which HYPACK requests a depth reading from the echo sounder. This value will depend on the speed of the survey vessel. To control data density during Phase 3 of the Lee County project, which took place at no wake speeds, the setting was set to 500 ms. The device Type is 'Echosounder' and the selected Options should be 'Record raw data' and 'Record quality data'. Depress the Record button and activate the 'Always' option; Depress the Connect button and set the port (usually serial) and the port parameters: Baud rate-9600, Parity-none, Data bits-8, Stop bits-1, and Flow control-None. Depress the Offsets button and enter starboard and forward offsets as necessary. Depress the Setup button and select the following NMEA sentences: DBS, DPT, and DBT and the sentence output as GLL. 
DS150 Horizon: From the 'Select device type' dialog choose the 'NMEA-0183' driver (NMEA.dll) and give the device an appropriate Name, such as 'Horizon'. The Update frequency controls the rate (ms) at which HYPACK requests a depth reading from the echo sounder. The horizon outputs depths at a slower rate than does the Bathy-500MF; this setting can be left at $50 \mathrm{~ms}$. Device Type is 'Echosounder' and the selected Options should be 'Record raw data' and 'Record quality data'. Depress the Record button and activate the 'Always' option; Depress the Connect button and set the port (usually serial) and the port parameters: Baud rate-4800, Parity-none, Data bits-8, Stop bits-1, and Flow control-None. Depress the Offsets button and enter the starboard, forward, and height offsets as previously determined. Depress the Setup button and select the following NMEA sentences: DPT and DBT, and set the sentence output to GLL.

DSM212H: From the 'Select device type' dialog choose the 'NMEA-0183' driver (NMEA.dll) and give the device an appropriate Name, such as 'DSM212H'. Leave the Update frequency at $50 \mathrm{~ms}$. Device Type is 'Position', 'Heading', and 'Speed' and the selected Options should be 'Record raw data' and 'Record quality data'. Depress the Record button and activate the 'Always' option; Depress the Connect button and set the port (usually serial) and the port parameters: Baud rate-9600, Parity-none, Data bits-8, Stop bits-1, and Flow control-None. Depress the Offsets button and enter the latency, which was determined in consultation with Coastal Oceanographics, Inc. to be -0.3 for the DSM212H; enter starboard and forward offsets if necessary. Depress the Setup button and select the following NMEA sentences: GGA and VTG, select the options: 'send alarm when non-differential' and 'suspend logging when nondifferential'. Set the HDOP limit to 2.50 and choose the option to generate a GLL NMEA sentence.

Squat/Settlement Corrections: From the 'Select device type' dialog choose the 'Coastal Oceanographics Draft Table' driver (DraftTable.dll) and give the device an appropriate Name, such as 'KWSquatSettlement'. Leave the Update frequency at $50 \mathrm{~ms}$. Device Type is 'Draft' and the selected Options should be 'Record raw data' and 'Record quality data'. Depress the Record button and activate the 'Always' option; Depress the Connect button and set the port (usually serial) and the port parameters: Baud rate-9600, Parity-none, Data bits-8, Stop bits-1, and Flow control-None. There are no Offsets. Depress the Setup button enter the speed (knots) and squat/settlement relationships in the table, as determined during the squat/settlement calibration tests described previously. Remember that the units need to be the same as those set for depth when entering the Geodetic Parameters (meters, for the Albers projection). 


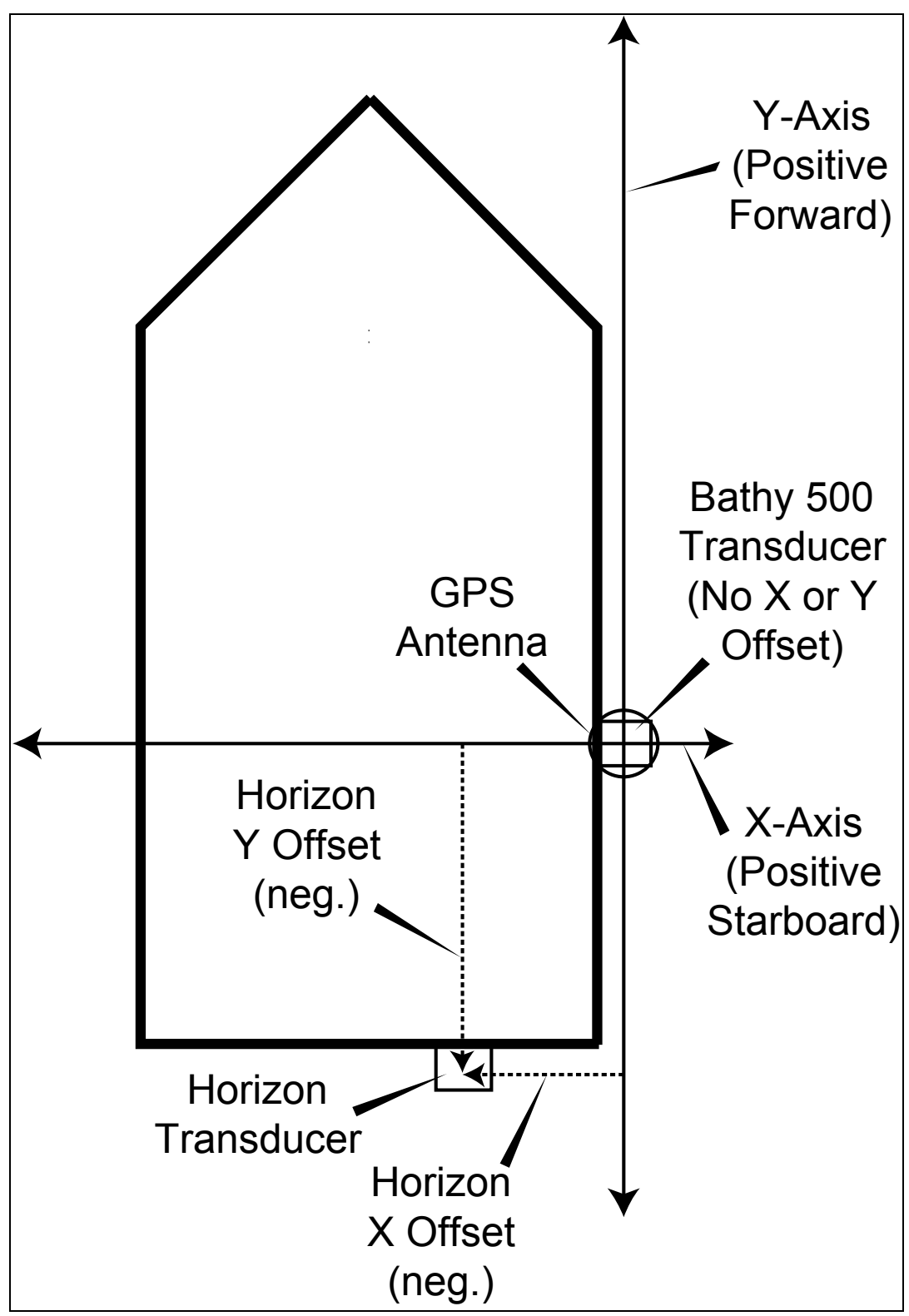

Figure 6. Determining depth sensor offsets.

In the HYPACK Max Matrix Editor (Preparation $\rightarrow$ Editors $\rightarrow$ Matrix Editor) construct a "matrix" file for the study area. As soundings are collected, the Survey program will fill in the matrix cells with pre-selected sounding colors, allowing continual monitoring of data goodness and enabling the crew to see a track generated over the background imagery as the boat moves. It is preferable to make one large matrix for each work area. This need be done only once for each area, as Survey retains the matrix file in the project. A cell size of 3 meters gives good results.

After performing the initial bar check for each sounder, begin the survey. The boat should follow a planned course, to sound centerlines and each side of 
waterways. Three parallel lines are surveyed at 25,50 , and 75 percent of the canal width. The data collector monitors progress and directs the boat operator as required. The boat should stop when soundings are missed due to absence of DGPS positions or other causes. Audible and visible alarms alert the crew to data dropouts. The data collector should pause logging when the boat stops or maneuvers off the planned course to avoid traffic or other hazards. Separate windows provide continuous, real-time monitoring of Sounder and GPS data streams.

When the water is too shallow for sounder operation, the data collector or boat operator should man the staff gauge. Manual soundings should be noted on the aerial photomap, along with the date and time. If soundings cannot be logged automatically due to excessive PDOP or loss of the beacon under bridges, near large buildings, etc., record sounder readings on the map, again with the date and time.

At the end of the day, conduct the second bar check and return the boat to its berth. With the AMREL PC back in the office, back up the day's raw files to other media, such as Zip disks, either by simply copying the files in Windows Explorer or by compressing the HYPACK project onto the backup media (File $\rightarrow$ Compress Project). Be sure to DESELECT background image files when compressing the project! 


\section{Post-processing of Survey Data}

\section{Tide Corrections}

A specialized computer program, Survey Tide Correction (SURVCORR.exe), created by the University of Florida Coastal and Oceanographic Engineering Program, corrects soundings for the local state of the tides at the time each depth was recorded. The complete SURVCORR operator's manual, found in the Appendix, details the functionality of the program and specifies the required content and formatting for each input file. The SURVCORR program is found on the CD-ROM.

Each SURVCORR session requires three ASCII-text-formatted input files: (1) uncorrected soundings (Survey Data File); (2) a "baseline" of georeferenced points, along which time and tide interpolation algorithms operate (Baseline Location File); and (3) tide gauge readings with interpolated time and location tags (Baseline Tide Data File). The program can correct soundings taken near a single tide gauge in the "one-gauge case" (with interpolation based only on time) or between pairs of gauges in the "two-gauge case" (interpolating over both time and distance).

SURVCORR output is a text file containing the raw depth, corrected depth, date/time, and $X Y$ coordinates for each sounding. This file can be used to generate an ArcView event theme and/or Arclnfo coverage of corrected depths.

Note: The two required header rows for each SURVCORR input file are not used in calculations and may be left blank; they are available to make the files "self documenting."

Figure 7 is a diagram of data flow from the tide gauge and sounder outputs through generation of tide-corrected ArcView GIS shapefiles.

\section{Survey Data File}

The following steps for generating the Survey Data File result in a sounding distribution that is useful for data display, map atlas printing, and channel construction for restriction analyses. These steps apply to files from one depth sounder.

1. Open each raw file for one sounder in the HYPACK Single Beam Editor, then save into a catalog in the Edited Data Files folder. (Do not use "presorting" to thin the data.)

2. With the HYPACK Sort utility (Processing $\rightarrow$ Sounding Selection $\rightarrow$ Sort), "sort" (thin) all the soundings from the desired sounder for an area, selecting an appropriate radius, such as 6 meters. (The utility can sort an entire catalog of edited files at once.) Save the output "XYZ" file with an appropriate name, then change the file name extension to ".txt." Open this file in a word processor, 
Tide Data

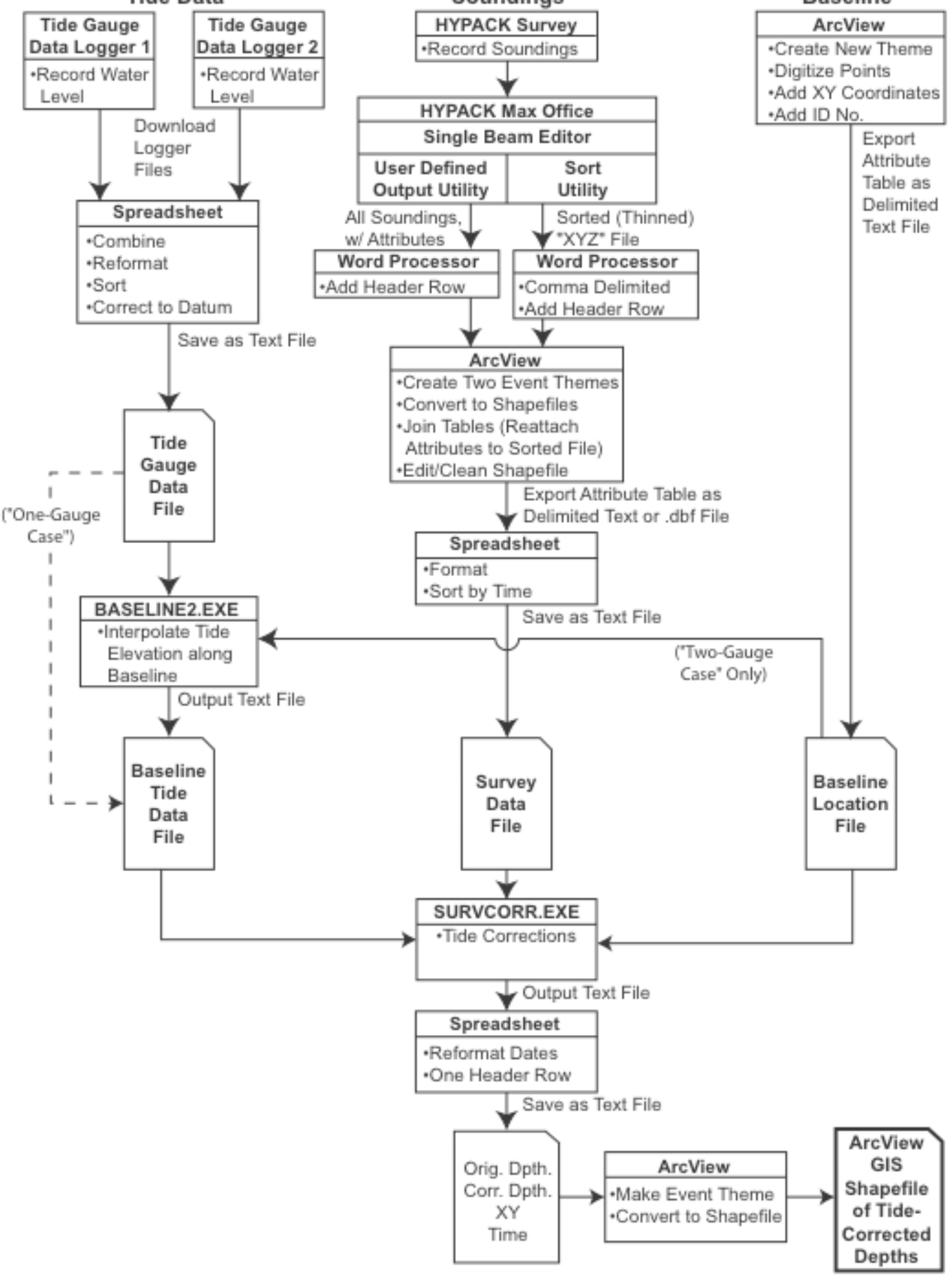

Figure 7. Flow diagram of tide correction procedures. 
replace the space delimiters with commas, and add headers: $\mathrm{X}, \mathrm{Y}$, and Corr Depth.

3. With the HYPACK User Defined Output utility (Utilities $\rightarrow$ File Work $\rightarrow$ User Defined Output), export the full set of soundings, with desired attributes (including, at least, X, Y, Raw Depth1, Corr Depth1, date, and time). Be sure to select a comma-delimited output format. Append the extension ".txt" onto the file name. In a word processor, add headers for the attributes, separated by commas. (This file may be $25 \mathrm{MB}$ or larger, but MS Word will be able open it for editing; WordPad may not suffice, and NotePad almost certainly will not.)

4. Import the two new .txt files into ArcView.

5. In a View, use View $\rightarrow$ Add Event Theme to create a new theme from the $\mathrm{XYZ}$ table. The table still can not be edited (not being a .dbf file), so use Theme $\rightarrow$ Convert to Shapefile. Once the data are in a shapefile, the table will be editable.

6. Create two new numeric fields (XPlus and YPlus). The default field width of 16 characters is satisfactory. Calculate XPlus $=X^{\star} 100$ and YPlus $=Y^{\star} 100$. (ArcView rounds floating-point numbers to integers when converting them to strings. However, it is necessary to retain two decimal places in the XY coordinates to avoid ambiguity in the table join process, step 8, below. When ArcView rounds XPlus and YPlus to integers, the significant digits are retained.)

7. Create a new string field called JoinXY. Make it wide, say 32 characters. Using the Field Calculator, calculate it equal to XPlus(asString) + YPlus(asString).

8. Similarly, make an event theme from the large table containing the desired attributes and convert it to a shapefile. Create and populate XPlus, YPlus, and JoinXY fields in this table, as described in step 6 and 7 above.

9. Join (Table:Join) the large attribute shapefile's table to the sorted XYZ shapefile's table, using Join $X Y$ as the Join Item. The larger attribute table is the "source" table, and the smaller XYZ table is the "destination" table. (ArcView Help explains the Join process very well.) Now, each sounding in the sorted shapefile's table has the appropriate attributes (plus a lot of extra stuff) attached to it. Sanity check a few records.

10. Important: Immediately convert the sorted sounding shapefile, with its joined table attributes, to a new shapefile, in order to preserve the join and make the table editable. Attempting to edit the newly-joined table, especially deleting fields, before converting to a new shapefile will cause ArcView-and often, Windows-to crash.

11. Create a new string field (UT) in the new shapefile's table, 24 characters wide. Populate it by adding the Date field to the Time field with the Field 
Calculator. Use the ++ operator, which will insert a space between date and time.

12. Delete surplus fields. For instance, there will be two $X$ and two $Y$ fields, the XPlus and YPlus fields, the JoinXY field, and an extra depth field, which are no longer needed. (Do not delete fields that will be of subsequent use, such as Raw Depth1. Use Table $\rightarrow$ Properties to hide, by unchecking, such fields. They will no longer be visible, and they will not be included when exporting the table as a text file. They will be again available when checked in Table Properties.)

13. Create a new numeric field called Depth_ft. Calculate it equal to Corr Depth * 3.28083989501 , to convert meters to feet.

14. Inspect and edit the shapefile. If all is $O K$, it is now safe to delete the $X Y Z$ and attribute text tables, to save disk space and unclutter the ArcView project.

In a spreadsheet application, reformat the table as required for the SURVCORR Survey Data File. Reformat the UT field into the days-from-1900 numeric format and sort in chronological order. There should be two header rows and four data columns, in the following order: time, $\mathrm{X}, \mathrm{Y}$, depth (i.e., UT, X, Y, Depth_ft). At this point, the Survey Data File is ready for inputting into SURVCORR.

\section{Baseline Location File}

In the "two-gauge case," an auxiliary program, BASELINE2.exe, generates the Baseline Tide Data File for SURVCORR.exe. As BASELINE2.exe and SURVCORR.exe each require the Baseline Location File for input, it is logical to create it next. (For the "one-gauge case", the BASELINE2 program is not used; the Baseline Tide Data File is generated by simply making a one-gauge data file and then adding a third column, identical to the second.)

Make careful note of which is the starting and the ending tide gauge station. (In a given study area, baselines should be consistently constructed in the same direction-from, say, north to south or east to west-if possible.) A simple way to construct this file is to create a new point theme in ArcView and mouse-click along the baseline over a background map, beginning at the starting gauge location and stopping at the ending gauge. A baseline point should be added at each significant turn or intersection along the waterway. Either run the ArcView Avenue script "addxycoo.ave" or use the ArcView extension Addxycoord.avx (on the accompanying $C D$ ) to add attribute table columns for the $X Y$ coordinates of each point. Add a column of ID numbers $(1,2 \ldots n)$. Then, export the attribute table as a text file, with columns in this order: ID, X, Y.

In the "one-gauge case," the Baseline Location File has only two rows: ID numbers 1 and 2 populate the first column, and the same $X Y$ coordinates are used in both rows. The coordinates are not used for interpolation, so need not be identical with those of the gauge location. 


\section{Tide Gauge Data File}

To prepare the Tide Gauge Data File for BASELINE2, using data downloaded from Infinities tide data loggers (see Setting the Tide Gauge Data Logger), it is necessary to (a) delete all header rows but two and (b) delete all data columns but the last two, which contain time (in days from 1900) and water level (in inches of drop from the gauge transducer to the water's surface). If tide files from more than one dump from a data logger site are required, they should be concatenated into one file. Convert the drop in negative inches to positive feet, and subtract from the elevation of the gauge (in feet, relative to the chosen datum, usually local mean lower low water) to yield the water surface elevation relative to MLLW. The time column should be in the numeric days-from-1900 format. For the "two-gauge case," combine files from two tide gauges into one, with a single time column followed by two water level columns. Be sure the first level column is from the first station on the baseline and the second level column is from the file for the last station on the baseline. Verify that all records in both water level columns are in the correct rows for the times they were recorded. Also, be certain the final data file is sorted by time before saving.)

Run BASELINE2. The output is a new text file, the Baseline Tide Data File. It is correctly formatted for input into SURVCORR.

\section{$\underline{\text { SURVCORR Output File }}$}

With the Survey Data File, Baseline Location File, and Baseline Tide Data File as inputs, run SURVCORR.exe to generate a file of soundings, relative to MLLW and corrected for tides. Caution: SURVCORR is intolerant of missing data, nonnumeric data, and times that are not sorted in chronological order. The program has few error messages; the usual results of data errors are (1) the program stops and its window vanishes or (2) output data are incorrect, not necessarily in obvious ways. If the time span of the tide data does not encompass the times at which soundings were taken, an appropriate error message will result; however, this message may also appear if input data are just incorrectly sorted by time. The program has no way of knowing if the start and end stations of a baseline are transposed. It is imperative to be careful and methodical in preparing data files for input into SURVCORR and then to inspect the output for reasonableness.

In a spreadsheet, convert the days-from-1900 times to the desired date/time format. Delete the empty first column and one of the two header rows, leaving a row with the column headers Time, X, Y, Orig Depth, and Corr Depth. As the output file includes $X Y$ coordinates, a straightforward way to get it into a GIS file is to import it into an ArcView project as a table. Then use the table to add an "event theme" to a view (View $\rightarrow$ Add Event Theme). If an event theme's attribute table is not a .dbf file, it can not be edited, so the new theme should immediately be converted into a shapefile (Theme $\rightarrow$ Convert to Shapefile), which can be 
inspected and edited. For use in Regional Waterway Management System analyses, the Arclnfo SHAPEARC command will convert the shapefile to a coverage.

\section{Assigning Parcel Identification Numbers to Boats and Moorings}

Regional Waterway Management System guidelines require the association of each boat and mooring feature with the county Parcel Identification (PID) number of the parcel with which the feature is associated. Using the PID as a Join item, the name and address of the parcel owner can be attached to each feature.

The county property appraiser office can supply GIS-format maps of parcels for the study area. These maps are very large files. Only parcels near waterways accessible by boats from saltwater are of interest to the project; therefore, a preliminary step should be to delete all parcels more than approximately three away from such waterways. The time for this editing is quickly regained in the resulting speedup of computer processes, such as screen re-draws. It may be similarly helpful to divide a large study area into several small parcel maps.

An efficient way to associate each boat and mooring with the appropriate PID is to use a freeware ArcView extension called Nearest Features. (The data CD contains a copy of the extension.) Note: The versions of Nearest Features available from the ESRI Web site and other online sources do not accommodate numeric fields as wide as PID numbers. Be sure to use the version provided on the $C D$.

Important: This PID assignment work should be done before separate boat and mooring themes are extracted from the "boatmoor" theme. Add an ID field (UFReference) to the boatmoor theme attribute table and populate it with a unique number for each feature. (This may be done easily by running the ArcView sample script "addid.ave." Be sure the boatmoor theme attribute table is the active window before running the script.) Then, (a) PID assignments will have to be done only once, and (b) each occupied mooring will retain the same PID and UF-Reference number as its boat. After this point in the analysis process, do not change the existing UF-Reference numbers. If features are added, simply assign them new UF-Reference numbers greater than the largest one already used.

Nearest Features automatically finds features nearest to each other in two different ArcView themes. It offers a variety of ways to use and display parameters associated with the feature pairs it identifies, so many options are available when it runs. Most of these may be ignored for our purposes.

First, copy the file nearfeat.avx into your ArcView extensions directory (C:IESRIIAV_GIS30VARCVIEWIEXT32) and turn on the Nearest Features 3.4 extension in your project. A new button will appear above the view. 
1. Nearest Features works on the assumption that each boat and mooring is closest to the correct parcel. However, parcel maps are not made with GPS accuracy and will likely require adjustments. Examine the parcels in an area of interest (for instance, a residential canal system) for proper alignment with the base imagery. If boats and moorings are nearer incorrect parcels than correct ones, start editing the parcel theme (make it active and select Theme $\rightarrow$ Start Editing), select the parcels in the area of interest, and slide them into place over the base map. (It is almost certainly best NOT to save the edits to the parcel theme at this time, and it is OK to leave the parcel theme in editable mode during the subsequent steps.)

2. Make both the boatmoor and parcel themes active. Select their desired features, using the Select Feature tool; Shift-select to add features to those already selected. Remember, with two themes active (boatmoor and parcels), the Select Features tool simultaneously selects features of both themes. (If no features are selected, the Nearest Feature extension acts on all features of both themes.)

3. Click the Nearest Features button above the View.

4. For the Input theme, choose the boatmoor theme. For the ID field, choose UF-Reference. Click OK.

5. For the Comparison theme, choose the parcel theme. For the ID field, choose PID. Click Add and then OK.

6. In the next dialog, make sure Number of Closest Comparison Features per Input Feature is set to 1. Also, make sure the RESULTS Data Table for Nearest Features has Comparison Feature ID checked. Make sure the Join Tables item is unchecked. (These are the defaults.) Click OK.

7. In the next dialog, highlight Nearness Number 1. Choose Connect Centroids under Line Connection. Choose a line style and color. Then click Add to List. Click OK.

8. In the next dialog, tell the program where to write the output data table and assign it a meaningful name. Click OK.

9. After the program runs, examine the output table and the new lines in the view. If necessary, refer to the boatmoor and parcel theme tables and edit the output table for any cases where the tie line goes to the wrong parcel (Table $\rightarrow$ Start Editing).

10. When all is OK, delete the lines (they are only graphics). Use Edit $\rightarrow$ Select All Graphics and then hit the Delete key. 
NOTE: You probably don't want to save the parcel theme's spatial edits at this point, especially if you have moved only a subset of parcels. Select Theme $\rightarrow$ Stop Editing, and click No when asked if changes should be saved.

Each invocation of Nearest Features results in a new output .dbf table, which contains two columns: PID and UF-Reference. Combine (concatenate) these tables in a spreadsheet or database manager. Then, in ArcView, join the boatmoor theme's attribute table with the new, combined table, using UFreference as the Join Item. This will attach the correct PID to each boatmoor feature. Immediately use Theme $\rightarrow$ Convert to Shapefile to make a new shapefile, preserving the Join.

\section{Data Cleanup}

"Sanity checking" and editing soundings, signage, boat, and mooring positions and attributes are best done when the fieldwork is fresh in the crew's memory. A look at the feature positions over the background imagery (in HYPACK for soundings and in PathFinder Office and/or ArcView for signs, boats, and moorings) should be the final part of each day's work, except for file backups.

[Very rarely, Pathfinder Office will be unable to open or process a DGPS rover file, reporting it corrupt. If the Check SSF Files utility can not fix the problem, try downloading the file again. If that fails, Trimble Tech Support may be able to recover the file. Consult the Trimble manuals for contact information and send the SSF file to them as an E-mail attachment.]

\section{Soundings Cleanup}

Processing soundings using the procedures described above will result in a distribution of data points suitable for display and for constructing channels to be used in the restriction analyses; that is, data clumps around overpasses, shoals, or other places where the boat moved slowly will have been appropriately thinned. However, very rarely the DGPS will make obvious errors, manifested by soundings that are displayed in the wrong place, perhaps on land. These errors are not subtle, but readily apparent. The data collector should look carefully at the location of soundings over the entire study area. If such anomalies are observed, do not try to correct the situation by editing the sounding positions in a GIS. Rather, the affected part of the study area must be surveyed again. Note: Soundings collected in new canal systems or near inlets where storm events have caused shoreline changes since the background imagery was created may appear to be on land. Verify, as required. Remember, editing sounding positions is not acceptable.

Several error sources can affect depths measured by echo sounders. Common are excessively deep soundings caused by multiple bounces of the transducer signal from the bottom, back to the boat hull, and off the bottom again. This results in doubling (or even quadrupling) the true depth. If the sounder fails to 
record a depth for a position, it may send a zero reading to the survey software. Raw soundings (before boat squat/settlement corrections) of exactly zero are always bogus, because sounders have minimum operating depths greater than zero.

An initial step in cleaning up sounding data-after creating the shapefile with thinned data point and all attributes, but before creating text files for tide corrections-should be to select and delete all data points with a "Raw Depth 1" value of zero. In an ArcView view, make the sounding theme editable (make it active and choose Theme $\rightarrow$ Start Editing). Use the Query Builder tool to select the zero depths. Query: ( [Raw depth 1] = 0 ). Delete them by use of the Delete key.

Construct appropriate queries and look closely at soundings with raw depths of less than approximately three feet. Delete if questionable, based on field notes and knowledge of actual minimum depths in a study area and the characteristics of the sounder(s) being used.

Estimate the maximum depth reasonably expected in an area, and build a query to select all depths deeper than that value. Examine the selected (highlighted) soundings and delete them if appropriate. This will eliminate many, perhaps most, of the doubled or quadrupled readings.

Apply a color-coded legend to the depths that makes changes in depth categories visually obvious. (For example, the file depths_ft.avl, on the accompanying CD, provides a useful legend. Note that the appropriate Values Field for it is Depth_ft, which is in units of feet.) Then carefully examine the depths for sporadic, unlikely values. Simultaneously displaying depths from two different sounders can be very useful. Overall, the colors displayed from the sounders should be very similar. A series of points with differing colors from the two sounders should be investigated. Often, only one of the two sounders will "double," and the difference will be obvious.

With reference to field notes and aerial photo annotations, digitize soundings to fill in gaps caused by shoals or loss of DGPS positions around buildings or under trees and bridges. Make the theme editable, and then use the Draw Point tool to create points at the appropriate locations. In the theme's attribute table, enter the depth and the time of each sounding.

Display the soundings along with a line shapefile of the waterways planned for surveying to ensure no areas have been missed.

\section{Signage Cleanup}

Most signage features are mapped using a laser rangefinder with the DGPS data logger. It is possible to miss a sign with the rangefinder and grab the position of a 
background object. Such misses should be readily seen when the signs are displayed over the background imagery. In most cases, field personnel can locate the correct position on the imagery. If so, simply make the theme editable, select the errant sign, and, using the Pointer tool (solid black arrow cursor), slide it into place.

Deliverable signage maps will require a meaningful legend, showing the different sign messages by symbology. Such a legend is also helpful in cleaning up the signage shapefile. Signs.avl (on the CD) applies specifically to signage mapped in Lee County, but it can be modified to suit actual signs in other areas.

The DGPS has occasionally mapped all the signs of a rover file in the wrong place, a mile or more from the correct positions. The array of signs was the correct size and shape, just in the wrong place. Selecting them all and carefully sliding them "cross country" to the right place has sufficed for correction.

\section{Boats and Moorings Cleanup}

Boat and moorings rover files are subject to the same kinds of positional errors mentioned above for soundings and signs. Again, the rangefinder may miss the intended feature, or the DGPS might make gross errors. The correct position of a boat or mooring along a canal or marina pier may often be determined by the logging times. Boats and moorings are large objects, so sliding the features back to the approximate locations on the aerial, within the feature dimensions, is a good solution. 


\section{Channel and Boat Restriction Analysis}

The purpose of the channel and boat restriction analysis is to determine the degree of accessibility for each boat and to determine the location and magnitude of corresponding channel restrictions. The detailed, comparative analysis of water depth and boat draft relations provides a comprehensive overview of channel conditions and the geographic distribution and severity of waterway restrictions. The analysis delineates and quantifies, at a $0.5 \mathrm{ft}$ resolution, levels of boat accessibility to deep, open water ${ }^{1}$, and the location and extent of channel depth restrictions. Boat access refers to the difference between a boat's draft and the depth of the shallowest downstream channel segment, at MLLW, that it must pass to gain access to open water.

The analysis is accomplished using Arc Macro Language scripts (AMLs) programmed to run on UNIX Arclnfo and requiring the PERL language be installed. In most instances the scripts can run on Arclnfo in Windows; however, the analysis.aml has proved to be more robust on UNIX. The scripts are located on the accompanying CD-ROM in the AMLS subdirectory.

This following section contains examples showing how to use commands. The commands themselves and any additional responses typed in by the user appear in bold text:

\section{Arc: build boats points}

Arc: describe boats

\section{Creation of the Trafficshed Coverage}

The term trafficshed is used to define a boat source area that contains a concentration of boats that use a common channel, exclusive to the trafficshed, to gain access to secondary access channels and, ultimately, to deep, open water. The number of trafficsheds that are defined for a particular study will depend on the number of boat source areas that are delineated. Figure 8 shows four defined trafficsheds on Estero Island, Lee County. The boundaries of each trafficshed polygon are drawn (in ArcEdit or ArcView) so that all boats, moorings, depths, and signs that pertain to the trafficshed are included within the boundaries of the trafficshed polygon.

${ }^{1}$ Deep, open water-defined as a function of vessel draft-begins at that location in the transit of a vessel, from its berth, beyond which the vessel is no longer restricted to a channel because of environmental or depth limitations. The location of what is considered deep, open water also can be associated with the aggregated draft characteristics of a trafficshed or a boating region. 


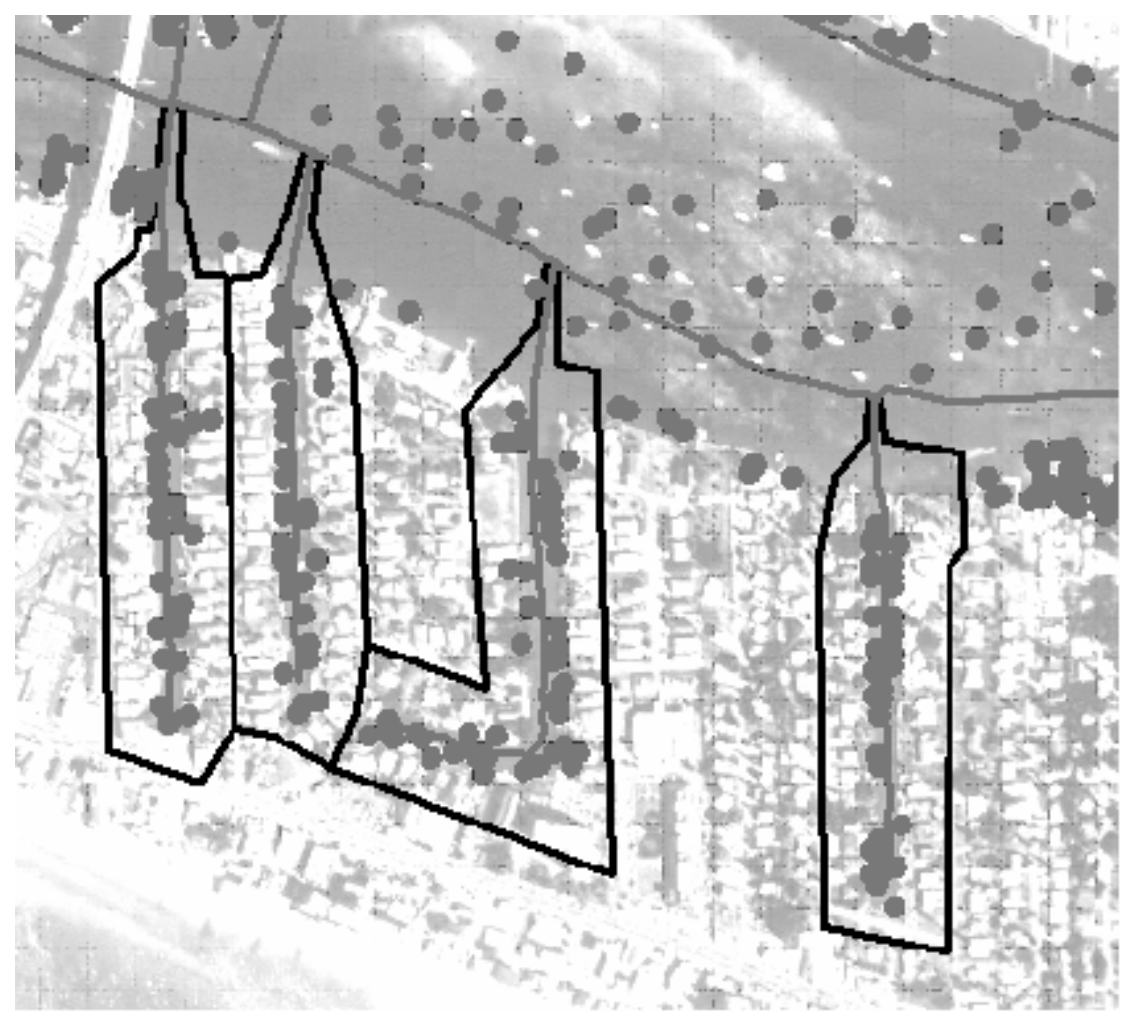

Figure 8. Trafficshed definitions.

The trafficshed polygon coverage will contain the following items:

\begin{tabular}{|l|l|l|l|l|}
\hline NAME & WIDTH & OUTPUT & TYPE & N.DEC \\
\hline AREA & 4 & 12 & F & 3 \\
\hline PERIMETER & 4 & 12 & F & 3 \\
\hline TRAFSHEDS\# & 4 & 5 & $\mathrm{~B}$ & - \\
\hline TRAFSHEDS-ID & 4 & 5 & $\mathrm{~B}$ & - \\
\hline TRAFSHED & 4 & 6 & $\mathrm{~B}$ & - \\
\hline NAME & 50 & 50 & $\mathrm{C}$ & - \\
\hline BOATS & 4 & 4 & $\mathrm{I}$ & - \\
\hline RESTBOATS & 4 & 4 & $\mathrm{~B}$ & - \\
\hline MOORINGS & 4 & 4 & $\mathrm{I}$ & - \\
\hline SIGNS & 4 & 4 & $\mathrm{I}$ & - \\
\hline DERELICTS & 4 & 4 & $\mathrm{I}$ & - \\
\hline NORMDREDGEVOL 8 & 10 & $\mathrm{~F}$ & 2 \\
\hline ADDDREDGEVOL & 8 & 10 & $\mathrm{~F}$ & 2 \\
\hline REGION & 4 & 2 & $\mathrm{~B}$ & - \\
\hline
\end{tabular}

The non-standard Arclnfo Polygon Attribute Table (PAT) items are defined as follows: 
1) TRAFSHED—-trafficshed identification number (user defined).

2) NAME-where available, the name given to a trafficshed (user defined).

3) BOATS - number of berthed boats in a trafficshed at survey time.

4) RESTBOATS - number of restricted boats contained in a trafficshed at survey time.

5) MOORINGS—number of moorings contained in a trafficshed at survey time.

6) SIGNS-number of signs contained in a trafficshed at survey time.

7) DERELICTS—number of derelict vessels contained in a trafficshed at survey time.

8) NORMDREDGEVOL-estimated dredge volume (cubic yards) to achieve normal depth clearance within the trafficshed (MLLW $=0 \mathrm{ft}$ datum).

9) ADDDREDGEVOL the estimated dredge volume (cubic yards) to achieve additional depth clearance within the trafficshed, which requires a one foot clearance between the lowest point of boat and channel bottom.

10)REGION-in some instances, a study area may be divided into different boating regions, based on the primary routes that boats are assumed to travel to reach open, bay waters. Boats are assigned to a primary route to facilitate the analysis of channel and boat restrictions.

The only item that needs to be assigned prior to analysis is TRAFSHED. The remaining items are assigned when the analysis has been completed and checked.

\section{Preparation of the Channel Centerline Coverage}

Create Channel Centerlines-two coverages are required as input for the analysis AML: channels and boats. The channel coverage is an arc coverage that is created from the depth point coverage using LINE.AML (on CD-ROM). Before running LINE.AML to create channel centerlines, a copy of the depth point coverage must be BUILT with the POINT and LINE options. The coverage should be given an obvious name, such as 'Channels'. The following item must be added to the Arc Attribute Table (AAT) of the channels coverage:

\section{ITEM NAME WIDTH OUTPUT TYPE N.DEC $\begin{array}{lllll}M L L W+5 & 8 & 7 & F & 1\end{array}$}

LINE.AML must be run from within ArcEdit with the channel coverage as the EDITCOVERAGE, EDITFEATURE set to points, and DRAWENVIRONMENT set to points and arcs. It is necessary to create the channel centerlines in a "downstream" direction; otherwise the analysis will not perform correctly, as the analysis AML is designed to route boats from trafficshed interiors towards deep, open waters. 
When creating the channel network, it is best to work on one trafficshed at a time. To guide the selection of depth points used in channel creation, the TEXTITEM command should be used to display the MLLW depth.

\section{Arcedit: TEXTITEM label mllw+5}

Start at the upstream limit of the trafficshed and work towards the outlet of the canal system or waterway. The AML processes two depth points at a time to create a channel segment between them. Thus, the AML requires the user to select successive depth points in the downstream direction. Once two points are selected, the AML will create a channel segment between them and calculate the segment depth as the minimum MLLW depth of the two depth points. The $X$ and $Y$ coordinates for the end points (nodes) of each channel segment are derived from the two depths points.

Upon completion, the channel coverage should be checked carefully to assure that channel segments are digitized in a downstream direction. The upstream node of a particular arc segment should be the from-node and the downstream node should be the to-node. Proper arc direction can be checked either on the display or by printing hardcopy maps of the centerline channel system. Draw the channel network with arrows turned on (ArcEdit: DRAWENVIRONMENT ARC ARROWS; ArcPlot: ARCARROWS). Edit as required to flip arrows to the downstream direction (ArcEdit: FLIP). The depths assigned to each channel segment should be checked as well. This can be done by querying channels for depths outside the range of expected values, such as negative or depths with a value of zero and by making plots with color-coded segments.

Make Routes-the next step is to assign the arcs within the channel coverage to route systems. For most study areas only one route system needs to be created. However, there may be situations when it is desirable to create multiple routes. This would occur, for example, when the travel paths leading from separate trafficsheds converge and follow a common centerline to deep, open water. Boats will be assigned to a particular travel route. This assures that each boat follows the appropriate travel route during the analysis process. The analysis AML is designed to ignore any arcs that are not assigned to a route system. This provides a mechanism by which channels can be delineated and, if desired, removed from the routing analysis. Figure 9 shows a portion of Estero Bay, in Lee County, for which three separate route systems were created. Starting from the upper left figure and proceeding clockwise, the first map shows all three routes, followed in succession by isolated views of routes 1,2 , and 3 .

Route systems are created in ArcEdit, making the channel coverage the EDITCOVERAGE and arcs the EDITFEATURE. A subset of arcs that belong to a particular route are selected using an appropriate selection option, such as SELECT PATH. Once the subset is selected, then the MAKEROUTE command 
is used and an appropriate name is chose for the route subclass, such as route.travel.

\section{Arcedit: MAKEROUTE <subclass>}

Assign Boats to Arc and Travel Routes-to perform the routing analysis a link must be established between each boat feature and its entry point into the channel network. Each boat must carry, within its attribute table, a unique, numeric identifier that establishes its connection to a channel segment. This link is created by using the CheckBoat2Channel.AML, which uses the NEAR command:

\section{Arc: \&r CheckBoat2Channel.aml <Point Cover $><$ Line Cover $>$ Search Radius\}}

The boat cover is normally the point cover and the channel cover is usually the line cover. The search radius is the maximum expected distance between a boat and its nearest channel feature. If, for a particular boat, a channel segment is not found within the search radius, the program will give the user the option to abort and reassign a different search radius. The program produces an output coverage named checklines, which consists of a series of arcs that connect each boat to its nearest associated channel segment. Thus, the endpoints for each 'checkline' are the boat with which it is associated and the closest arc segment to the boat.

The checkline coverage is used to visually check that each boat is associated with the correct channel segment. Cases will occur where the closest arc to a boat is not located on the boats proper downstream route. For example, for a beached boat the closest arc may be in a nearby, unrelated canal. Corrections are made within ArcEdit with the checkline coverage as a background coverage. Background imagery, consisting of 1-meter USGS Digital Orthophoto Quarter quadrangles, is used to provide context. The TRANSFER command is most appropriate to assign the proper NEARARC item value to boats.

\section{Analysis Program}

The channel and boat restriction analysis is accomplished within Arclnfo GIS using the Analysis.AML (on CD-ROM), which is designed to run from within ArcEdit on a UNIX system.

\section{Arc: \&r Analysis.aml}




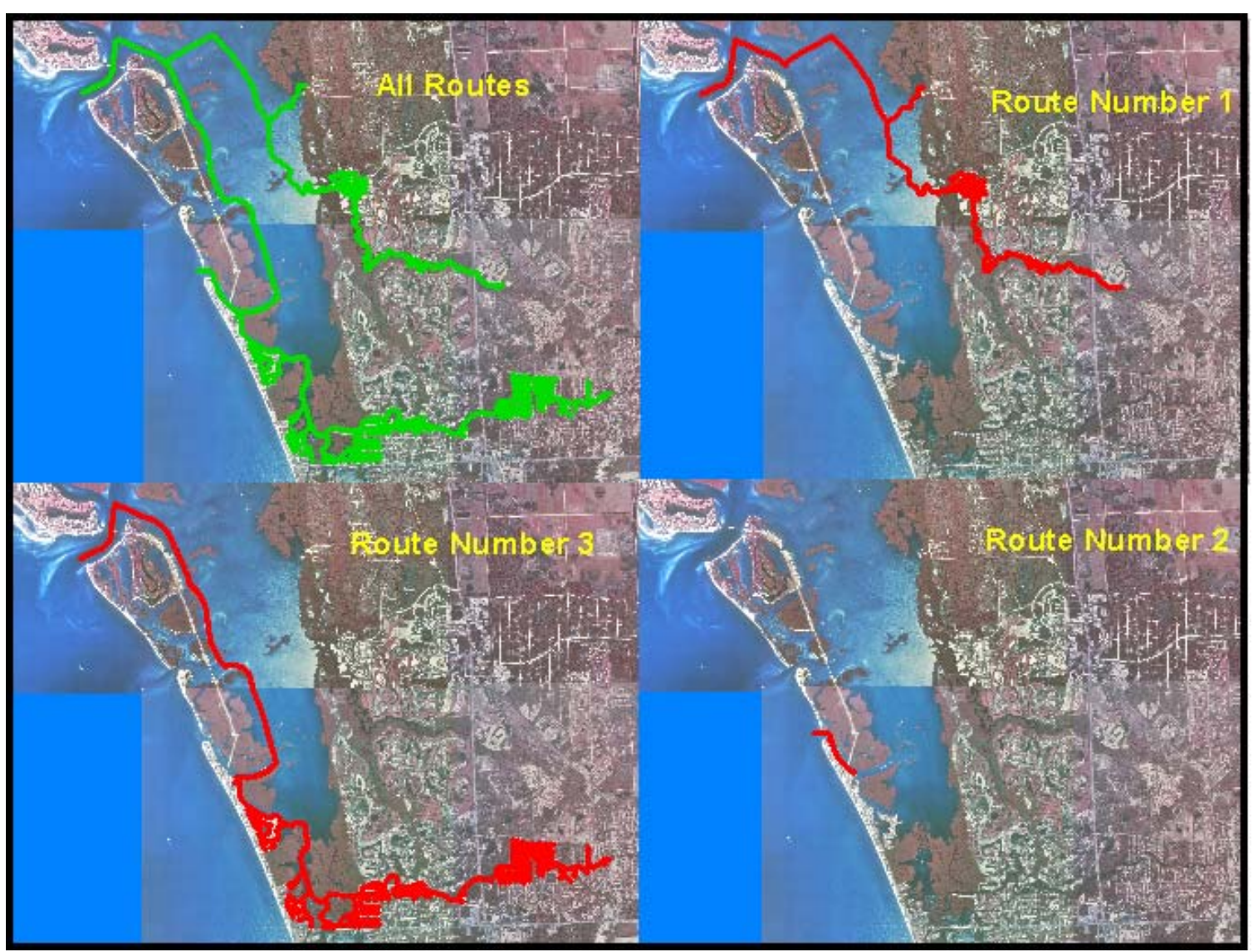

Figure 9. Example travel routes in Estero Bay, Lee County, Florida.

A series of prompts and dialog boxes request that the user:

1) Select the channel cover from a list of arc coverages.

2) Select the boat cover from a list of point coverages.

3) Select the route system.

4) Identify which item contains the boat draft (normally DRAFT).

5) Identify which item contains the trafficshed number (normally TRAFSHED).

6) Whether to reset the analysis items in the boat and channel coverages.

If the channel coverage contains more than one route, the user will be prompted to identify a boat event file. The creation of a boat event file is only necessary when multiple routes have been defined, as shown in Figure 9. The analysis.aml selects each boat in succession following information from the user: the names of two input coverages: the arc coverage that contains the channel segments, and the point coverage that contains the boat features.

Once the analysis AML has completed, the results should be confirmed. This is done by visually checking, within ArcView or Arclnfo, the values that are calculated for the boat PAT and the channel AAT. 
During the analysis, the following items are added to the point attribute table (PAT) for the boat coverage, and the item values are calculated for each boat feature:

1) ALLCONDEPTH - the controlling centerline depth (feet) outside of the trafficshed, reported to the nearest 1/2-foot and MLLW. A value of 99.9 indicates that the boat does not traverse any delineated channel segments located outside of the trafficshed in order to reach open bay water.

2) TSHEDCONDEPTH — the controlling centerline depth (feet) within the trafficshed, reported to the nearest 1/2-foot and MLLW. A value of 99.9 indicates that the boat was not assigned to a trafficshed.

3) TBLOCKAGE-defined as the difference between boat draft and the controlling centerline depth within the trafficshed. For example, if boat draft equals 4.5 feet and the controlling depth is 3.0 feet, then the boat is restricted by 1.5 feet. A negative value indicates that boat is not restricted. A value of 99.9 indicates that the boat was not assigned to a trafficshed.

4) ABLOCKAGE-defined as the difference between boat draft and the controlling centerline depth located outside of the boat's trafficshed. For example, if boat draft equals 4.5 feet and the controlling depth is 3.0 feet, then the boat is restricted by 1.5 feet. A negative value indicates that the boat is not restricted.

5) BLOCKAGE-the maximum depth restriction presented to the boat by channel segments within the trafficshed and outside the trafficshed. The blockage value is the maximum of the ABLOCKAGE and TBLOCKAGE attributes.

During the analysis, the following items are added to the arc attribute table (AAT) for the channel coverage, and the item values are calculated for each channel segment:

1) BIGBOATUPSTRM - the vessel (draft) with the largest draft (feet) located upstream of the channel segment. A value of -1 indicates the arc segment is not part of a principal travel route used in the restriction analysis. A value of -99.9 indicates that no boats are upstream of segment.

2) RESTRBOATCNT-the number of upstream boats that are restricted by the channel segment.

3) DREDGE-Level of Restriction (feet): Defined as the difference between channel segment depth (Item name: MLLW+5) and the maximum draft of vessels located up-channel. For example, a channel segment with a depth of 2.5-feet will restrict a 3.5-foot boat located upstream by 1.0 foot.

Upon completion of the analysis, the results are used to produce the final products as described in the next section. 


\section{Products}

Deliverable products, based on the results of the Regional Waterway Management System include large-scale, large format map atlases; an ArcView application to reproduce the map atlases; a CD-ROM containing project databases; and a final report.

\section{Large Format Map Atlases}

Three multi-page, 1:2400-scale, large format (35" x 35") map atlases portray depths, boat drafts, signs, waterway restrictions, and boat accessibility for saltwater accessible canals and waterways within a project area.

Bathymetry Atlas

The bathymetry atlas contains depth points collected for centerline and adjacent shoals. Depths portrayed on each atlas page are those collected by project personnel, supplemented by depth points obtained from the USACE for Federally maintained waterways. The depth points that are collected according to methods presented in this manual are accurate to $1 / 2$-foot and are corrected to MLLW.

Boat Drafts/Bathymetry/Signs Atlas

This atlas contains depth points accurate to $1 / 2$-foot and corrected to MLLW. The depths are presented in six classes (ft) : $<=1,1.5$ or $2.0,2.5$ or $3.0,3.5$ or 4.0 , 4.5 or $5.0,>5.0$. Depth points collected by project personnel, and portrayed in the bathymetry atlas, are supplemented by any available depths obtained from the USCAE. Boats are presented in six draft classes (ft) : $<=1,1.5$ or 2.0, 2.5 or $3.0,3.5$ or $4.0,4.5$ or $5.0,>5.0$. Signs are presented in eight classes: speed regulation, hazard warning, resource protection, navigation guide, private ownership, government, business, and other.

Analysis Atlas

The analysis atlas contains plots of channel and boat restrictions. Channel restrictions are defined as the difference between a channel segment depth and the maximum draft of vessels located up-channel ("upstream"). For example, a channel segment with a depth of 2.5-feet will restrict a 3.5-foot boat located upstream by 1.0 foot, and is displayed in the atlas by a thick, color-coded line. The degree of channel restriction is portrayed in seven classes: No restriction; 0.0 feet, 0.5 foot, 1.0 foot, 1.5 feet, 2.0 feet, and greater than or equal to 2.5 feet. Boat Restrictions are defined as the difference between boat draft and the controlling centerline depth. For example, if boat draft equals 4.5 feet and the controlling depth is 3.0 feet, then the boat is restricted by 1.5 feet, and is portrayed in the atlas by a color-coded cross. Boat restrictions are portrayed in seven classes: No restriction; 0.0 feet, 0.5 foot, 1.0 foot, 1.5 feet, 2.0 feet, and greater than or equal to 2.5 feet.

Each of the three atlases can be produced using Arclnfo AMLs included on the accompanying CD-ROM (/Products/MapAtlases). The bathymetry atlas is 
produced using 'depths-atlas.aml', the Drafts/Bathymetry/Signs atlas using 'alldata-atlas.aml', and the analysis atlas using the 'analysis-atlas.aml'.

The AMLs are written to run on a UNIX system. Each AML needs to be edited in order to set directory locations for the required Arclnfo coverages and support files, such as credits, images, legends, and legend keys. The necessary support files are included on the CD-ROM. The AMLs require USGS 1-meter DOQQs, and the $D O Q Q$ routine within the AML needs to be modified for each new project area.

An Arclnfo polygon coverage that contains an index of map pages is required to run each AML. The page index coverage is created from a quarter-quad grid index of Florida that was obtained from the FDEP Technical Services Geographic Information Services web site and included on the CD-ROM (/Products/MapAtlases/qquadindex.e00). To create the page index for a project area, the relevant quarter quadrangles that encompass project field data (boats, moorings, depths, signs, and trafficsheds) are extracted from the FDEP coverage and each quarter quadrangle is then partitioned, using Arclnfo (or ArcView), into 16 equal area tiles. Each tile represents $1 / 16$ th of a DOQQ and is labeled with the quadrangle name, the quadrangle quarter (NW, NE, SW, SE), the tile number (1 to 16), the Florida Department of Environmental Protection quadrangle number, and a user assigned page number that corresponds to the mapping extent for the series of 1:2400 thematic atlases. An example of the resultant page index coverage is included on the CD-ROM (/Products/MapAtlases/qquadindexEXAMPLE.e00).

To run any of the map atlas AMLs use the following syntax:

\section{Arc: \&run <Atlas AML $><$ SCREEN|PLOTTER $><$ Pages $>$}

The atlas AML will be one of the three mentioned above: depths-atlas.aml, alldata-atlas.aml, or analysis-atlas.aml. Selection of the SCREEN option versus the PLOTTER option results in each page plotted to the screen. The PLOTTER option sends each page to the UNIX line printer (Ipr) and also produces Raster Transfer Language (RTL) files that are saved at an assigned disk location. The RTL files are packaged with the ArcView Map Atlas Application that is described in the next section. The page numbers to be plotted are listed on the command line separated by a space. The page size of each plot is 35 inches by 35 inches and, thus, requires a large format printer. The color scheme for the atlas RTL files was matched and calibrated to plot on a HP DesignJet 2000CP inkjet plotter.

\section{ArcView Map Atlas Application}

An ArcView Map Atlas application is available that allows users to make copies of individual map atlas pages. An example of the application is included on the CD-ROM. To use the application for future WCIND project areas modifications need to be made to the ArcView project file (/ufatlas/projects/mapatlases.apr). The Arclnfo coverage of the page index, described in the preceding section, 
needs to be converted to a shapefile and placed in the shapfiles directory (/ufatlas/shpfiles) and unrelated page indices from prior projects removed. Name the new page index shapefile according to the county or project area (e.g., lee.shp) where the project is being conducted. Include a field in the index theme attribute table that is named with the first letter of the shapefile filename followed by '_id' (e.g., for lee.shp the fieldname is $L_{-}$id). This field needs to be populated with the index page numbers.

Start the ArcView project and apply the index legend (/ufatlas/shpfiles/index.avl) to the page index theme. Label the theme with page numbers using the special 'Label All' tool, which is made available by setting its invisible property to 'False' from the customize dialog. The label tool allows the user to select the page number field and to set the label font. Once the labels have been finalized, save and exit the project.

Place uncompressed map atlas print files (.rtl) in a subdirectory named for the atlas with which they are associated (i.e. Depths, Boats, or Analysis). This subdirectory is placed under the '/ufatlas/atlases' directory (e.g., /ufatlas/atlases/Boats). Map atlas filenames that begin with ' $a$ ' are associated with the Bathymetry atlas, those that begin with ' $b$ ' with the Bathymetry/Boats/Signs atlas, and those with 'c' with the Analysis atlas.

Edit the project file in a text editor, such as NotePad, and make all references to file locations relative by removing the drive letter. Save the edited project file and set the file permissions to read only. The ArcView Map Atlas application is then installed on a computer by following the instructions contained in the Usernotes.doc (/ufatlas). Project data metadata files (/ufatlas/metadata) will need to be updated for each new project. The metadata files are in html format and describe, in detail, the individual thematic layers from which the atlases were constructed.

\section{GIS Data Sets and Imagery}

At the completion of each project, the background imagery and the GIS data sets created during project implementation are packaged in an ArcView project file (.apr) for delivery. An example of the structure of the data CD is contained on the CD-ROM that accompanies the manual. Each data set is packaged in two formats: 1) Arclnfo export files contained in the ArcExport directory, and 2) ArcView shapefiles contained in the AVShape directory.

The ArcView project (e.g., /ProjectDataCD/leephase1.apr) is created with a view containing all data sets and imagery. The imagery included with the example are JPEG images and, thus, require that the JPEG (JFIF) extension be invoked from the available extensions.

The data sets and imagery that are normally included are described as follows: 
a. DEPTHS-information on depths points recorded for all channel centerlines and approaches to boating facilities and referenced to the navigation datum, MLLW, and reported to the nearest $1 / 2$ foot.

b. CHANNELS - boating access channels, classified according to depth (nearest 1/2-foot; MLLW) and degree of restriction.

c. BOATS—boats berthed in the water or stored on salt-water accessible parcels. Information includes boat type, length, age, make and model, draft, facility, mooring type, the date the boat was surveyed, and the level of restriction.

d. MOORINGS-moorings, including information on facility, mooring type, and the date the mooring was surveyed.

e. DERELICTS-derelicts vessels, including information on condition, whether the vessel is beached or afloat, percent of submersion, and the date the vessel was surveyed.

f. SIGNS-boat-related signs in the water and along the waterfront and visible to boaters. Information includes site, type, message, status, condition, and the date the sign was surveyed. The signs are grouped into the following classes: hazard warning, municipal mooring, navigation guide, private ownership, resource protection, and speed regulation.

g. TRAFFICSHEDS - trafficsheds (navigable waterways that serve as boat source areas). Trafficsheds serve as units of analysis and allow the county to prioritize waterway management efforts. Information provided for each trafficshed includes the numbers of boats, moorings, signs, and derelict vessels that were present in the trafficshed at the time of the field surveys. Trafficsheds range from complex canal systems to short, one-segment channels that provide access from shore to open-bay waters.

h. ATLASINDEX - tiles constructed from a digital map index of USGS quarter quadrangles. Each tile represents $1 / 16$ th of a quarter quadrangle and is labeled with the quadrangle name, the quadrangle quarter (NW, NE, SW, SE), the Florida Department of Environmental Protection quadrangle number, and a page number that corresponds to the project mapping extent.

i. Background imagery derived from USGS 1-meter digital orthophoto quadrangles is included in the directory labeled Images. Each image is provided JPEG formats, and the JPEG images are available in 1, 3, and 6 meter resolutions.

Metadata is provided for all data sets in HTML format (/Products/ProjectDataCD/Metadata).

\section{Final Report}

A final report presents the Regional Waterway Management System Findings. Sections in the report include: Introduction, Background, Information on the data sets collected during the field work, an explanation of the data products, project results, special management considerations for the project area, and conclusions and recommendations. The bibliography that accompanies this manual contains 
citations for past reports, which can be referred to when preparing future reports (Antonini and Box 1996; Antonini, Swett, Schulte, and Fann 1998; Swett,

Antonini, and Schulte 1999; Swett, Fann, Antonini, and Carlin-Alexander 2000, 2001). 


\section{References}

Antonini, G.A., R. Swett, S. Schulte, and D. Fann. 1998. Regional Waterway Management System for South Sarasota County. TD-1. Gainesville, FL: Florida Sea Grant College Program.

Antonini G.A., and P. Box. 1996. A Regional Waterway Systems Management Strategy for Southwest Florida. TP-83. Gainesville, FL: Florida Sea Grant College Program.

Coastal Oceanographics, Inc. n.d. HYPACK User's Manual. Middlefield, CT: Coastal Oceanographics, Inc.

Florida Bureau of Comprehensive Planning. 1976. The Florida Land Use and Cover Classification System: A Technical Report. Tallahassee, FL: State of Florida, Department of Administration, Division of State Planning.

Infinities USA, Inc. 1999. Data Logger User's Manual 2.1. Daytona Beach, Florida: Infinities USA, Inc.

National Ocean Service. 1999. NOS Hydrographic Surveys, Specifications and Deliverables. April 23, 1999. Accessed on-line at http://chartmaker.ncd.noaa.gov/ocs/text/hsd-0.html

Ocean Data Equipment Corporation. 2000. Bathy-500MF Survey Echo Sounder Owner's Manual. Walpole, Massachusetts: Ocean Data Equipment Corporation.

Standard Communications. 2001. Horizon DS150 Digital Depth Sounder Owner's Manual. Los Angeles, CA: Standard Communications.

Swett, R.A., D.A. Fann, G.A. Antonini, and L. Carlin-Alexander. 2001. Regional Waterway Management System for Lee County, Phase 2. TD-4. Gainesville, FL: Florida Sea Grant College Program.

Swett, R.A., D.A. Fann, G.A. Antonini, and L. Carlin-Alexander. 2000. Regional Waterway Management System for Lee County, Phase 1. TD-3. Gainesville, FL: Florida Sea Grant College Program.

Swett, R.A., G.A. Antonini, and S. Schulte. 1999. Regional Waterway Management System for North Manatee County. TD-2. Gainesville, FL: Florida Sea Grant College Program.

Trimble Navigation Limited. 1998a. TSC1 Asset Surveyor: Software User Guide. Revision A. Sunnyvale, CA: Trimble Navigation Limited. 
Trimble Navigation Limited. 1998b. Pro XR/XRS Receiver Manual. Revision A. Sunnyvale, CA: Trimble Navigation Limited.

Trimble Navigation Limited. 1998c. DSM12/212 Operation Manual. Revision A. Sunnyvale, CA: Trimble Navigation Limited.

Trimble Navigation Limited. 1995. Pro XL System Operation Manual. Revision C. Sunnyvale, CA: Trimble Navigation Limited.

U.S. Army Corps of Engineers. 2001. Engineering Manual, EM 1110-2-1003, Hydrographic Surveying. Washington, DC: Department of the Army. 


\section{Appendices}

\section{Equipment Specifications}

Bathy-500MF Multi-Frequency Survey Echo Sounder

- Depth Range: 0-15, 0-30, 0-60, 0-120, 0-240, 0-480, 0-1920 Feet; 0-10, 0,20, $0-40,0-80,0-160,0-640$ Meters

- Phasing: 0-120, 60-180, 120-140, 180-300, 240-360, 300-240, 360-480 Feet, Auto; 0-40, 20-60, 40-80, 60-100, 80-120, 100-140, 120-160 Meters, Auto

- Accuracy rating: \pm 0.5 percent

- Chart Record: 8.5 inch X 90 feet high-contrast thermal paper

- Digital Display: LCD (4 line X 16 characters) 0.25 inch characters; Depth display: 0.75-inch characters; Back-lighting: Electro-luminescent Resolution: 0.01 units for depths less than 100 meters; 0.01 for depths greater than 100 meters; 0.1 feet on all ranges

- Frequency: Any single frequency (user selectable \& changeable via keypad) from these: $33 \mathrm{Khz}, 40 \mathrm{Khz}, 50 \mathrm{Khz}, 200 \mathrm{Khz}$ (Acoustic output=600 watts)

- Depth Alarms: Shallow and deep (selected by keypad)

- Sound Velocity: 4600-5250 feet/second (1393-1590 meters/second); user selected by keypad

- Offset: 0 to +30 feet or meters (allows the user, via keypad, to adjust for the net sum of transducer depth and tide

- Geographic Position: NMEA-0183 GGA or GLL format for GPS/DGPS

- Data I/O Compatibility: COM1 provides bi-directional interface to PC or other peripheral device; this port accepts external annotation from external sources such as hydrographic software. This port also allows remote control of all echo sounder functions using Ocean Data's Windows 95/98/NT based software. Com2 accepts GPS/DGPS inputs and provides additional (from COM1) data outputs.

- Data Outputs: ODEC PMS dt (True Depth \& Status); Atlas DESO-25; Odom Digitrace; Odom Echotrac; NMEA DBT; NMEA DBS

- Input Power: 11-30 volts d.c. (1.5 amps @ 12v. 0.5 amps @ 30v.)

- Dimensions: Height (including handle) 19 inches; width 17.5 inches; depth 9 inches

- Weight: $35 \mathrm{lbs}$ (recorder with transducer)

- Operating Temperature: $-10{ }^{\circ} \mathrm{C}$ to $+50{ }^{\circ} \mathrm{C} /$ Humidity $95 \%$ non-circulating

Bathy-500MF Transducer (P/N P01540)

- Resonant Frequency: $208 \mathrm{KHz}$

- Nominal Impedance: 50 ohms

- Beamwidth (@3 dB point): 8 degrees

- Cable: 30 feet (with plug to mate with recorder)

- Housing Material: Brass (with urethane acoustic window)

- Piezo Material: Barium titanate 
Horizon DS150 Single-beam Echo Sounder

- Power Supply: 0.7 to 16.6 VDC 15 mA nominal, $35 \mathrm{~mA}$ with backlight on

- Operating temperature: $32^{\circ}$ to $114^{\circ} \mathrm{F}\left(0^{\circ}\right.$ to $\left.45^{\circ} \mathrm{C}\right)$

- Accuracy rating: \pm 2 percent

- Size of display: $4.4 \times 4.4 \times 1$ inches $(112 \times 112 \times 20 \mathrm{~mm})$

- Overall depth: 1.4 inches $(35 \mathrm{~mm})$ behind panel

- Display type: Twisted Nematic (TN), gray background)

- Illumination: Red LED

- RF Interference: Less than $6 \mathrm{~dB}$ maximum quieting on any marine radio channel with $3 \mathrm{~dB}$ gain antenna within 1 meter of instrument head

- Depth: 3 to $400 \mathrm{ft}, 1$ to 120 meters, or -.5 to 67 fathoms

- Alarms: Shallow and deep water, Audio and LCD flag

- Display unit selection: Feet, meters or fathoms, keypad selectable

- Display damping: Three levels keypad selectable

- Keel Offset: Keel/propeller or waterline, $\pm 9.9 \mathrm{ft}, \pm 1.6$ fathoms or \pm 3.0 meters, user selectable trend indication

- NMEA outputs: DPT, DBT

- Proprietary Outputs: Alarm and Trend arrows

- Transducer: $201 \mathrm{kHz}, 600$ ohm, 1500pF parallel capacitance

Infinities USA Model 220 ultrasonic water level loggers

- Number of measurements in memory: 3906

- User programmable interval: 1-reading/second to 1-reading/6 months

- User interface to Logger: PC or opt. HP 48GX or 48G+ calculator w/ software

- Data logger power: Four AA alkaline batteries

- Data logger battery life, typical: 4 years

- Data logger range: 18 feet

- Minimum target distance: $\sim 16$ inches

- Ranging environment: inside $11 / 4$ " to 3" PVC sch. 40 pipe

- Temperature compensation: $0 \mathrm{~F}$ to $120 \mathrm{~F}$

- Humidity: to $100 \%$

- Accuracy: $+/-1 \%$ of distance measured

- Resolution: $\sim 0.04$ inches or $1 \mathrm{~mm}$

- Ultrasonic Frequency: $49.7 \mathrm{kHz}$

- Data download rate: 150 measurements per second

- Download medium: serial cable

- Hewlett-Packard 48GX storage: multiple data loggers, 40,000 measurements

Trimble Pro XR Receiver

- Fully sealed, dustproof, waterproof, shock resistant

- $1 \mathrm{~Hz}$ update rate

- Time to first fix $<30$ seconds, typical

- Size: $11.1 \mathrm{~cm}$ x $5.1 \mathrm{~cm}$ x $19.5 \mathrm{~cm}$ (4.4" x 2" x 7.7")

- Weight: $0.76 \mathrm{~kg}(1.68 \mathrm{lbs})$

- Power: 5 watts (maximum) 
- Temperature: $-30^{\circ} \mathrm{C}$ to $65^{\circ} \mathrm{C}\left(-22^{\circ} \mathrm{F}\right.$ to $\left.149^{\circ} \mathrm{F}\right)$ Operating $-40^{\circ} \mathrm{C}$ to $85^{\circ} \mathrm{C}\left(-40^{\circ} \mathrm{F}\right.$ to $\left.185^{\circ} \mathrm{F}\right)$ Storage

- Humidity: $100 \%$ non-condensing

Integrated GPS/BEACON Antenna

- Right-hand, circular polarized; omnidirectional; hemispherical coverage

- Size: $15.5 \mathrm{~cm}$ diameter x $10.8 \mathrm{~cm}$ high (6.1" x 4.2")

- Weight: $0 / 49 \mathrm{~kg}(1.08 \mathrm{lbs})$

- Temperature: $-30^{\circ} \mathrm{C}$ to $65^{\circ} \mathrm{C}\left(-22^{\circ} \mathrm{F}\right.$ to $\left.149^{\circ} \mathrm{F}\right)$ Operating $-40^{\circ} \mathrm{C}$ to $85^{\circ} \mathrm{C}\left(-40^{\circ} \mathrm{F}\right.$ to $\left.185^{\circ} \mathrm{F}\right)$ Storage

- Humidity: $100 \%$ fully sealed

- Case: dustproof, waterproof, shock resistant

Trimble DSM212H Integrated GPS/MSK Receiver Standard Features

- 12-channel GPS receiver

- Integrated GPS and dual channel MSK beacon receiver

- Outputs positioning reports at 1,5 , or $10 \mathrm{~Hz}$

- Isolated power supply

- Positioning based on carrier-phase filtered L1 pseudo-ranges

- Two programmable RS-232 serial ports:

- NMEA-0183 output or RTCM SC-104 output

- RTCM SC-104 input

- TSIP input and output

- 1PPS output

- Windows configuration software

- DSM212 operation manual

- Compact L1 GPS and MSK H-field loop antenna

- 15 meter RG58 antenna cable

- Power/data cable

- 12Pin to data cable

Performance Characteristics

- 12-channel, parallel tracking, L1 C/A code with carrier phase filtered measurements and multi-bit digitizer

- Differential speed accuracy: $0.1 \mathrm{knt}(0.1 \mathrm{mph}, 0.16 \mathrm{~km} / \mathrm{h}, 5.6 \mathrm{~cm} / \mathrm{s})$

- Differential position accuracy: Less than 1 meter horizontal RMS (at least 5 satellites, PDOP < 4 and RTCM SC-104 standard format broadcast from a Trimble DSM12RS or equivalent reference station

- Time to first fix: <30 seconds, typical

- NMEA messages: ALM, GGA, GLL, GSA, GSV VTG, ZDA, RMC, MSS

Physical Characteristics

- Size: $14.5 \mathrm{~cm} \mathrm{~W} \times 5.1 \mathrm{~cm} \mathrm{H} \times 19.5 \mathrm{~cm} \mathrm{D}$

- Weight: $0.76 \mathrm{~kg}(1.68 \mathrm{lb})$

- Power: 5W (max), 10 to 32 VDC 
- Operating temperature: $-30^{\circ} \mathrm{C}$ to $+65^{\circ} \mathrm{C}$

- Storage temperature: $-40^{\circ} \mathrm{C}$ to $+85^{\circ} \mathrm{C}$

- Humidity: $100 \%$ condensing, unit fully sealed

MSK Beacon Dual-Channel Receiver

- Frequency Range: $283.5 \mathrm{KHz}$ to $325.0 \mathrm{KHz}$

- Channel spacing: $500 \mathrm{~Hz}$

- MSK modulation: 50, 100 \& 200 bits/second

- Signal strength: $10 \mu \mathrm{V} /$ meter minimum @ 100BPS

- Dynamic range: $100 \mathrm{~dB}$

- Channel selectivity: $70 \mathrm{~dB}>500 \mathrm{~Hz}$ offset

- Frequency offset: $17 \mathrm{ppm}$ maximum

- $3^{\text {rd }}$ order intercept: $+15 \mathrm{dBm} @ \mathrm{RF}$ input (min. AGC setting)

- Beacon acquisition time: $<5 \mathrm{sec}$, typical

AMREL Rocky II Plus

- CPU: Intel Pentium, $366 \mathrm{MHz}$ Pentium II

- Ram Memory: 64MB SDRAM standard

- Storage: Removable 2.5" HDD (available 6GB up to 10GB); Removable 3.5" 1.44MB FDD

- Display: 12.1" 800 x 600; AGP compliant 128-bit video engine with 256-bit bus 2.5MB embedded SDRAM

- Keyboard: 89-key KB standard keycap with dust cover and Windows 95 keys ready; PS/2 compatible touchpad

- Power System: Removable 10.8V 4500mAH Lithium ion primary battery; secondary $10.8 \mathrm{~V} 4500 \mathrm{mAH}$ Lithium ion battery pack (DR202 compatible) swappable with FDD; smart battery and smart charger

- I/O Ports: 2S, 1P, CRT, external kb, eternal FDD, Fax/Modem (RJ-11), LAN (RJ-45), Audio, PS/2 mouse, USB, port replicator; 2 PCMCIA type II slots or 1 type III slot; LAN, radio modem etc, Cardbus and ZV port support; IrDAcompliant infrared transceiver (fast IR $4 \mathrm{MB} / \mathrm{sec}$ transfer rate)

- Dimension: $312 \mathrm{~mm}$ x $246 \mathrm{~mm} \times 62.5 \mathrm{~mm}$; Weight approximately $4.7 \mathrm{~kg}$; rain and dust proof, shock resistant structure; magnesium case

Dell Dimension XPS T750MHz Pentium III

- 768MB DSRAM Memory with ECC

- V.905/56K PCI DataFax Modem

- $8 x / 4 x / 32 x$ CD-RW

- 32MB NVIDIA geForce Plus AGP Graphics Card

- 18GB 10K SCSI Hard Drive

- 3." Floppy Drive

- 3Com US Robotics 3C905C-TXM 10/100 Remote Wake Up Nic 
Advantage Range Finder

- Dimensions

- Weight

- Laser

- Distance Measurement

- Compass

Azimuth

Measurement

- Inclination

Measurement

- Communications

- Internal Data Recording

- Power Requirements

- Displays

- Environmental
$8.5 \mathrm{H} \times 4.5 \mathrm{~W} \times 7.5 \mathrm{~L}$ (inches) $\circ \quad(21.5 \times 11.5 \times 19$ centimeters $)$ $4.5 \mathrm{lbs} .(2.1 \mathrm{~kg}$.

Eye Safety: - Beam Divergence $3 \mathrm{mrad}$ Wavelength: $\quad 905 \mathrm{~nm}$

- Acquisition Time: $\quad 0.4$ seconds

Reflectorless: $10-2,000 . \mathrm{ft}(2-610 \mathrm{~m})$

Reflector: $\quad 10-330,000$ ft. $(2--9,188 \mathrm{~m})$ - Accuracy: $\quad \pm 0.5 \mathrm{ft}(15.3 \mathrm{~cm}) 3$ Sigma Type: $\quad$ Strapped Down Magnetometer Range: $\quad 0.0$ to $359.9^{\circ}$ Accuracy: $\quad \pm 1.0^{\circ} \mathrm{RMS}$ (when level) - $\pm 1.5^{\circ} \mathrm{RMS}$ (when tilted)

$\circ$ Repeatability: $\pm 0.3^{\circ}$

Type: Dual-Axis, Fluid

Range: $\quad \pm 50^{\circ}$

- Accuracy: $\pm 0.4^{\circ}$

- Repeatability: $\pm 0.3^{\circ}$

Type: $\quad$ RS-232 at standard baud rates

Type: $\quad$ PCMCIA Type II SRAM

Voltage: $\quad 6 \mathrm{VDC}$ Current: $\quad 400 \mathrm{~mA}$

- Battery Type:6 Volt NiCad

Rear Panel: Backlit 4 line $\times 20$ character LCD

- Head Up Display: 1 line $x 4$ character LCD, reticule

Temperature, Operating: $\quad-22^{\circ} \mathrm{F}$ to $\pm+140^{\circ} \mathrm{F}$ - Temperature, Storage: $-40^{\circ} \mathrm{F}$ to $\pm+176^{\circ} \mathrm{F}$

- Enclosure: Water Resistant, Ruggedized 


\section{Survey Tide Correction Program}

Conceptual Description

The Survey Tide Correction program developed in the University of Florida Coastal and Oceanographic Engineering Department by Bill Miller under the direction of Dr. Max Sheppard consists of three Fortran 90 programs. The basic program is survcorr.f90 which performs the linear interpolations and corrects the survey data. The other programs, baseline1.f90 and baseline2.f90, may be used to provide "SURVCORR" with its baseline files.

The basic concept is to provide a means of correcting a survey of water depth within a winding canal or river system using a limited amount of tidal data. To do this a "baseline" of correcting reference points is constructed along the survey path within the system. In an ideal case, tide gages would be located at each baseline point and the survey could be corrected using a linear interpolation to the two gages nearest to the survey point.

However, setting up so many tide gages is not practical. Therefore, a baseline tide data file is constructed using two gages at either end of the system. The data is interpolated by program "BASELINE2" based on the distance of the point from each gage. The baseline data is then used to correct the survey data. By using this "baseline method," the distance between the gages within the winding path of the system may be considered, rather than the direct distance from the survey point to the gages. This direct distance will likely cut across the system and not reflect the true distance seen by the tide as it propagates along the baseline path.

Thus, the baseline points are best located at the corners and bends in the system and the file describing the locations must list the points in sequence along the path of the system. The diagram below illustrates such a baseline. 


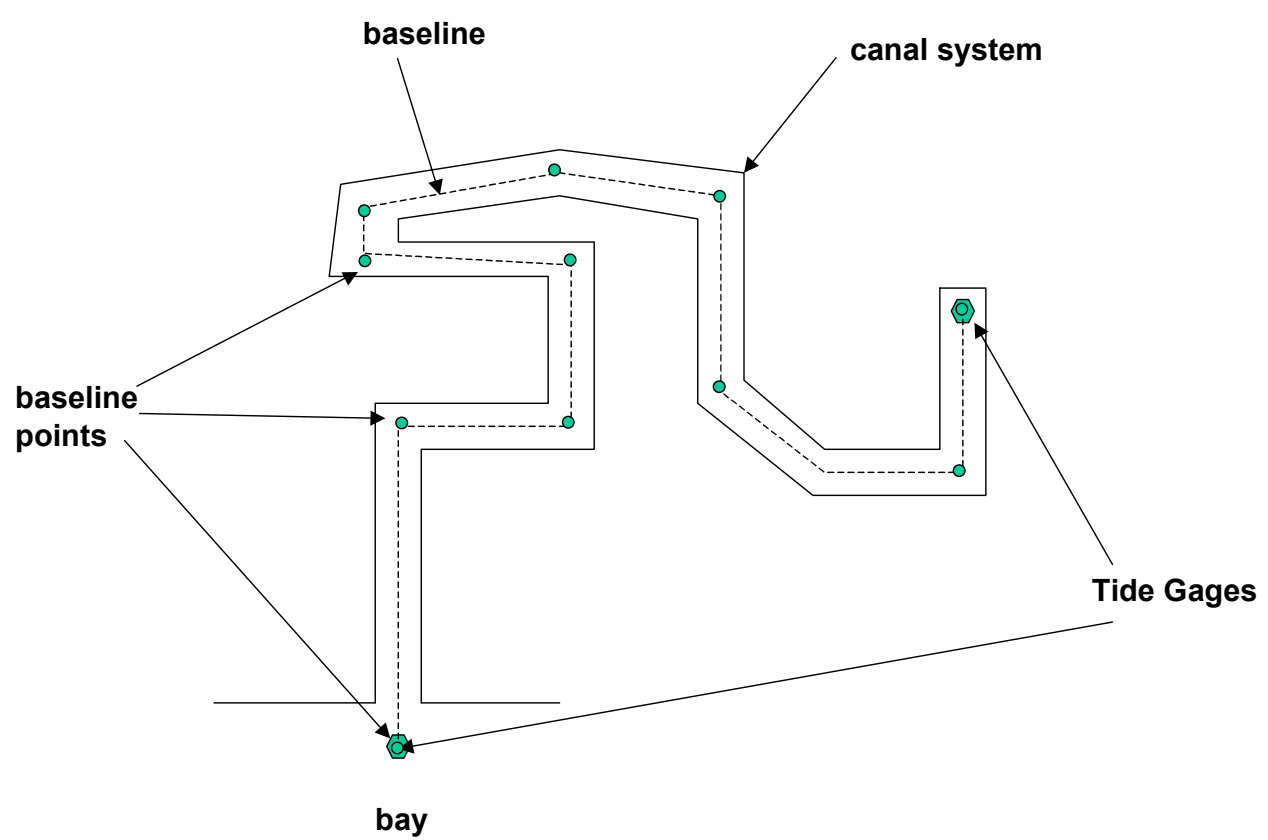

Fig. 1, Canal System and Baseline Development

If a branch to the canal system exists, a branch to the main baseline may be developed using the "BASELINE1" program. The figure below illustrates this situation.

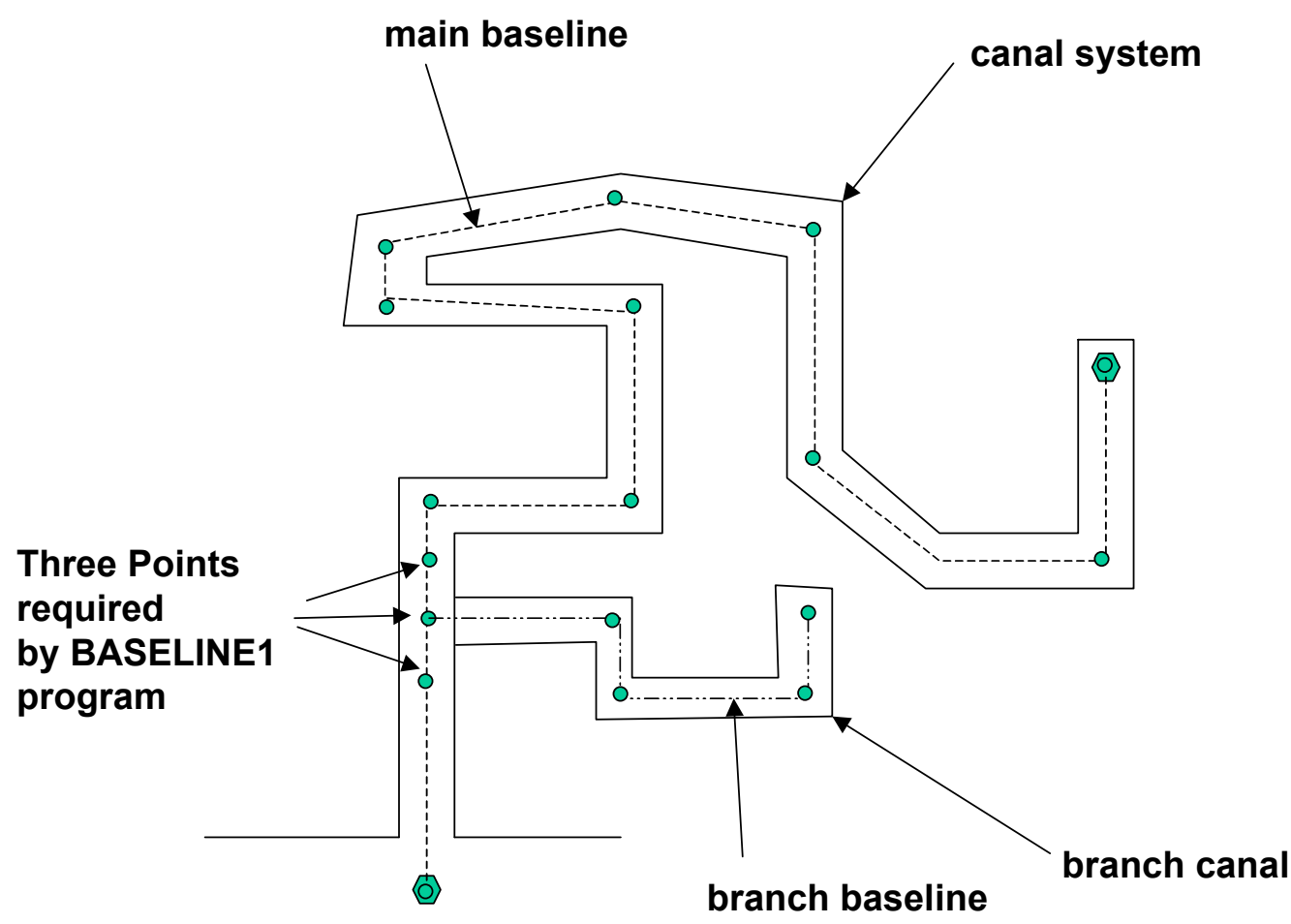

bay

Fig. 2, Branch Canal Case 
The three baseline points are used to determine a water surface slope (time dependent). This slope is then applied along the branch baseline to determine the appropriate tidal correction with distance.

If the tide is the same throughout the system, using a single baseline point in "SURVCORR" will result in a direct interpolation of the survey to this one point. In other words, only the time will be considered and interpolated and not the distance from the point.

\section{Instructions for Correcting a Survey}

\section{A. Correction between two tide gages}

1. Divide the survey data into appropriate paths and format in an ASCII file described under the "SURVCORR" Program section of these instructions.

2. Per Fig. 1, plot a baseline on a chart of the survey area and record the locations of each point. The first and final points of the baseline should be tide gages. Each bend and corner in the canal system should be marked by a baseline point. Record these points in an ASCII data file described under the "SURVCORR" Program section of these instructions.

3. Use the "BASELINE2" program to interpolate the tide data from the two tide gages and develop the "Baseline Tide Data" file used by the "SURVCORR" program.

4. Use these files as the inputs to the "SURVCORR" program described under the "SURVCORR" Program section of these instructions.

5. The output file of the "SURVCORR" program should be examined to verify reasonableness of the corrections made to the survey data.

\section{B. Corrections to a canal branch}

1. Per Fig. 2, determine the three main baseline points to be used in the "BASELINE1" program and build their location and data files. These files must have the form described under the "BASELINE1" Program section of these instructions and be saved in ASCII format.

2. Plot a branch baseline on a chart of the survey area and record the locations of each point. The first point must be the middle point of the three points chosen above. Each bend and corner in the canal system should be marked by a baseline point. Record these points in an ASCII data file described under the "BASELINE1" Program section of these instructions.

3. Use these files as inputs to the "BASELINE1" program. The output of this program will be the "Baseline Tide Data" file used by the "SURVCORR" program. 
4. Use the "Baseline Tide Data" from (3), the Baseline location file from (2) and the survey data file as the inputs to the "SURVCORR" program described under the "SURVCORR" Program section of these instructions.

5. The output file of the "SURVCORR" program should be examined to verify reasonableness of the corrections made to the survey data.

\section{Corrections to a system with one tide gage}

If only one tide gage is used, no reference exists for how the tide varies with distance. In this case, the survey cannot be corrected for distance. Use the tide gage location and tide data as the only baseline point and repeat steps 4 and 5 of section A above.

"SURVCORR" Program

Input Files. This program requires 3 input files.

1. Survey Data File. This is the actual survey data file to be corrected. The file must be in 4 columns with two column headers.

$$
\left[\begin{array}{ccccc}
\text { time1 } & \text { id1 } & x 1 & y 1 & \text { depth1 } \\
\text { time2 } & \text { id2 } & x 2 & y 2 & \text { depth2 } \\
\text { time3 } & i d 3 & x 3 & y 3 & \text { depth3 } \\
\text { time4 } & i d 4 & x 4 & y 4 & \text { depth4 } \\
\vdots & \vdots & \vdots & \vdots & \vdots
\end{array}\right]
$$

The time should be in a continuous sequential format (i.e. seconds, minutes or hours) from a common reference time. Depth must be measured from the water's surface, positive downward.

2. Baseline Location File. This file locates (in $\mathrm{x}, \mathrm{y}$ coordinates) the baseline points used to interpolate and correct the survey data. The file must be in three columns with two column headers.

$$
\left[\begin{array}{ccc}
\text { po int number } 1 & x 1 & y 1 \\
\text { point number } 2 & x 2 & y 2 \\
\text { point number } 3 & x 3 & y 3 \\
\text { point number } 4 & x 4 & y 4 \\
\vdots & \vdots & \vdots
\end{array}\right]
$$

The "point number" must be an integer value, but will not be used in the calculations. The $\mathrm{x}$ and $\mathrm{y}$ coordinates must have the same reference as the survey data. The rows of this file correspond to the 
location of the tide data in the columns of the "Tide Data File" described below.

3. Baseline Tide Data File. This file contains the tide information used in the correction calculation. Either the BASELINE1 or BASELINE2 programs described later may generate the file. If the baseline points consist only of known tide gages, the data developed from these gages may be used. Only one time column may be used, therefore actual tide gage data should be interpolated to this common time series. The file has the following format, again with two column headers.

$$
\left[\begin{array}{cccc}
\text { time1 } & \eta 11 & \eta 21 & \cdots \\
\text { time2 } & \eta 12 & \eta 22 & \cdots \\
\text { time3 } & \eta 13 & \eta 23 & \cdots \\
\text { time4 } & \eta 14 & \eta 24 & \cdots \\
\vdots & \vdots & \vdots & \ddots
\end{array}\right]
$$

The time must have the same form and reference as the time in the survey file. The time series must also precede the minimum survey time and exceed the maximum survey time. The value corresponds to the tide level at each baseline point (by column) and should be referenced to the desired vertical datum (i.e. NGVD, MTL, etc.). The interpolation will subtract the appropriate tide level from the survey. In other words, at a high tide level ( $\eta>$ datum, i.e. $\eta$ positive), the program will subtract the tide level from the survey depth. At a low tide level $(\eta<$ datum, i.e. $\eta$ negative $)$, the program will add the absolute value of the tide level to the survey depth.

Output File. The program output file will have the following form.

$$
\left[\begin{array}{cccccc}
\text { time1 } & \text { id1 } & x 1 & y 1 & \text { original-depth1 } & \text { corrected-depth1 } \\
\text { time2 } & \text { id2 } & x 2 & y 2 & \text { original-depth2 } & \text { corrected-depth2 } \\
\text { time3 } & \text { id3 } & x 3 & y 3 & \text { original-depth3 } & \text { corrected-depth3 } \\
\text { time4 } & \text { id4 } & x 4 & y 4 & \text { original-depth4 } & \text { corrected-depth4 } \\
\vdots & \vdots & \vdots & \vdots & \vdots & \vdots
\end{array}\right]
$$

The left five columns will be identical to the survey file described in (1) above. The sixth column will contain the corresponding survey depth corrected for the tide. 


\section{Single Point Baseline Construction Program ("BASELINE1")}

This program will interpolate the tide data, based on distance, for a baseline which branches off of a main baseline. If only one baseline point is used, distance will not be used in the interpolation, only time. In this case, the entire system will be assumed to have the same tide.

Input Files. This program requires 3 input files.

1. Three Point Tide Data File. The three points used here will typically be chosen from a baseline file previously constructed from the BASELINE2 program. The file has the following format with no column headers.

$$
\left[\begin{array}{cccc}
\text { time } 1 & \eta 11 & \eta 21 & \eta 31 \\
\text { time2 } & \eta 12 & \eta 22 & \eta 32 \\
\text { time3 } & \eta 13 & \eta 23 & \eta 33 \\
\text { time4 } & \eta 14 & \eta 24 & \eta 34 \\
\vdots & \vdots & \vdots & \vdots
\end{array}\right]
$$

The time must have the same form and reference as the time in the survey file. The time series must also precede the minimum survey time and exceed the maximum survey time. The $\eta$ value corresponds to the tide level at each baseline point (by column) and should be referenced to the desired vertical datum (i.e. NGVD, MTL, etc.).

2. Three Point Baseline Location File. This file locates (in $\mathrm{x}, \mathrm{y}$ coordinates) the three baseline points whose tide data was input in (1) above. The file must be in three columns without column headers.

$$
\left[\begin{array}{lll}
\text { po int number } 1 & x 1 & y 1 \\
\text { point number } 2 & x 2 & y 2 \\
\text { point number } 3 & x 3 & y 3
\end{array}\right]
$$

The "point number" must be an integer value, but will not be used in the calculations. The $\mathrm{x}$ and $\mathrm{y}$ coordinates must have the same reference as the survey data. The rows of this file correspond to the location of the tide data in the columns of the "Tide Data File" of (1) above.

3. Baseline Location File. This file locates (in $\mathrm{x}, \mathrm{y}$ coordinates) the new baseline points. These new baseline points must begin with the middle (number 2) point in the three-point list above (i.e. "point numberl" of this file is "point number2" of the above file). 


$$
\left[\begin{array}{ccc}
\text { po int number } 1 & x 1 & y 1 \\
\text { point number } 2 & x 2 & y 2 \\
\text { point number } 3 & x 3 & y 3 \\
\text { point number } 4 & x 4 & y 4 \\
\vdots & \vdots & \vdots
\end{array}\right]
$$

Output File. The program output file will have the following form.

$$
\left[\begin{array}{cccc}
\text { time } 1 & \eta 11 & \eta 21 & \ldots \\
\text { time2 } & \eta 12 & \eta 22 & \ldots \\
\text { time3 } & \eta 13 & \eta 23 & \ldots \\
\text { time4 } & \eta 14 & \eta 24 & \ldots \\
\vdots & \vdots & \vdots & \ddots
\end{array}\right]
$$

This file corresponds to the Baseline Tide Data File described in the "SURVCORR" program and may be used directly in this program.

\section{Two Tide Gage Baseline Construction Program ("BASELINE2")}

This program will interpolate the tide data for a set of baseline points located between two tide gages. The interpolation will be a weighted linear interpolation based on the distance between the two gages.

Input Files. This program requires 2 input files.

1. Tide Gage Data File. This file contains the actual tide information used in the interpolation calculation. Only one time column may be used, therefore the time for each tide gage data should be interpolated to this common time series. The file has the following format, again with two rows of column headers.

$$
\left[\begin{array}{ccc}
\text { time } 1 & \eta 11 & \eta 21 \\
\text { time2 } & \eta 12 & \eta 22 \\
\text { time3 } & \eta 13 & \eta 23 \\
\text { time4 } & \eta 14 & \eta 24 \\
\vdots & \vdots & \vdots
\end{array}\right]
$$


The time must have the same form and reference as the time in the survey file. The time series must also precede the minimum survey time and exceed the maximum survey time. The $\eta$ value corresponds to the tide level at each tide gage (by column) and should be referenced to the desired vertical datum (i.e. NGVD, MTL, etc.). The "SURVCORR" program will subtract the appropriate tide level from the survey. In other words, at a high tide level ( $\eta>$ datum, i.e. $\eta$ positive), the program will subtract the tide level from the survey depth. At a low tide level $(\eta<$ datum, i.e. $\eta$ negative), the program will add the absolute value of the tide level to the survey depth.

2. Baseline Location File. This file locates (in $\mathrm{x}, \mathrm{y}$ coordinates) the baseline points used to interpolate and correct the survey data. The file must be in three columns with two rows of column headers.

$$
\left[\begin{array}{ccc}
\text { po int number } 1 & x 1 & y 1 \\
\text { point number } 2 & x 2 & y 2 \\
\text { point number } 3 & x 3 & y 3 \\
\text { point number } 4 & x 4 & y 4 \\
\vdots & \vdots & \vdots
\end{array}\right]
$$

The "point number" must be an integer value, but will not be used in the calculations. The $\mathrm{x}$ and $\mathrm{y}$ coordinates must have the same reference as the survey data. The first and last point in this file should be the two tide gages from the Tide Gage Data File of (1). The first point corresponds to the first data column (i.e. not the time column) of the Tide Gage Data File and the last point corresponds to the second data column.

Output File. The program output file will have the following form.

$$
\left[\begin{array}{cccc}
\text { time1 } & \eta 11 & \eta 21 & \ldots \\
\text { time2 } & \eta 12 & \eta 22 & \ldots \\
\text { time3 } & \eta 13 & \eta 23 & \ldots \\
\text { time4 } & \eta 14 & \eta 24 & \ldots \\
\vdots & \vdots & \vdots & \ddots
\end{array}\right]
$$

This file corresponds to the Baseline Tide Data File described in the "SURVCORR" program and may be used directly in this program. 